


\title{
Theorie der Massenerscheinungen
}

\author{
in der
}

menschlichen Gesellschaft.

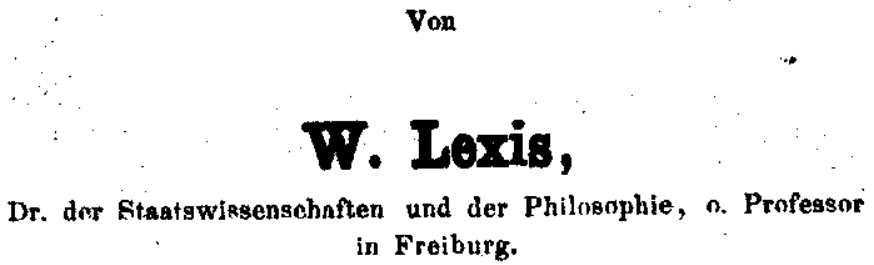

in Freiburg.

Freiburg 1. $B$.

Fr. Wagner'sche Buchhad 1 ug.

1877. 


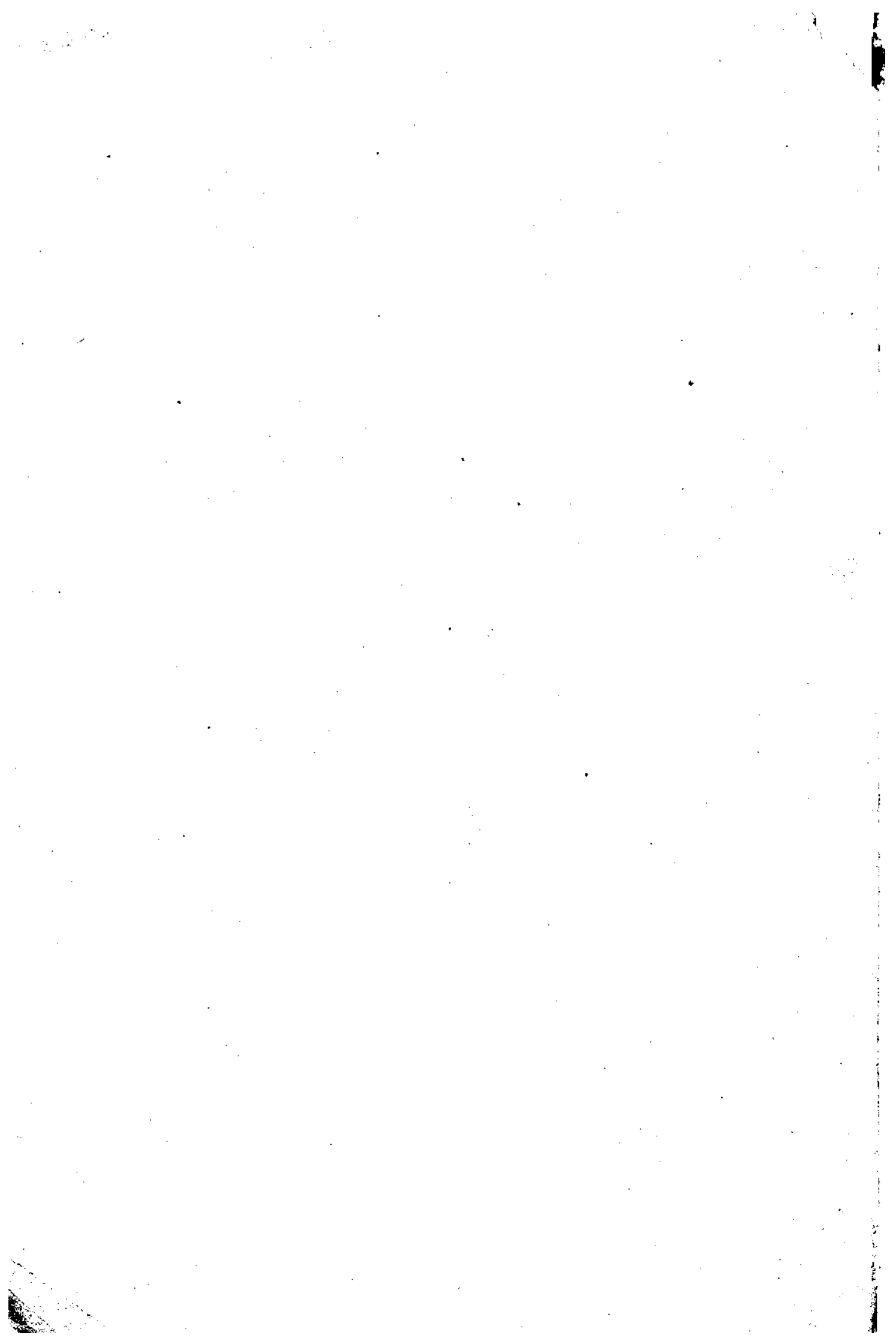




\title{
Theorie der Massenerscheinungen
}

in rler

\author{
menschlichen Gesellschaft.
}

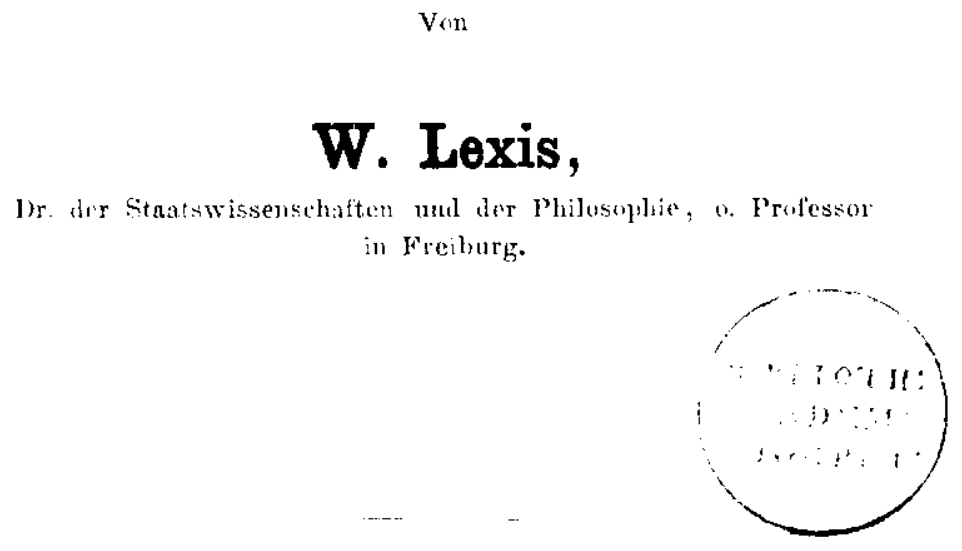

Freiburg i. B.

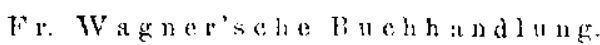

$18 \% 7$. 
. 


\section{Vorbemerkung.}

Dic vorliegende Schrift enthïlt ausser einer Fortsetzung meiner Untersuchungen über das Geschlechtsverhältniss der Geborenen den Versuch einer neuen Theorie auf dem Gebiete der Sterblichkeitserscheinungen. Zugleich aber ist die Tragweite der bei diesen Untersuchungen angewandten Methode aus allgeneineren Gesichtspunkten erörtert worden und dadurch eine Skizze der theoretischen Statistik als einer selbständigen Wissenschaft entstanden. Natiirlich konnte wegen des Zweckes der Abhandlung als akademischer Gelegenheitsschrift dieser allgemeine Theil nur andeutungsweise behandelt werden.

Freiburg, im Mai $187 \%$.

Der Verfasser. 


\section{Berichtigung.}

S. $4^{4}$ Z. $\bar{\tau}$ v. o. statt 38.8 lies 42.8 und dem entsprechend in der folgenden Zeilc. statt $19.4,21.4 "$ 


\section{Allgemeinste Eintheilung der Massen- erscheinungen.}

1. Der Zustand einer menschlichen Gemeinschaft wird einestheils bedingt durch die positiven Gestaltungen und Normen der Gesellschaft und des Staates, die historisch geworden sind und deren Aenderungen historische Ereignisse bilden; andererseits aber auch durch das gewöhnliche, relativ stetige Thun und Leiden der Individuen in jhrer mannigfaltigen Gruppirung, das in seinen einzchen Elementen nicht festgehalten werden kann, aber charakteristische, der wissenschaftlichen Beobachtung zugängliche $M$ as senerscheinungen erzeugt. Die Statistik hat die selbständige Aufgabe, diese Masscnerscheinungen des Meuschenlebens nach exacter Methode aufzufassen und zu untersuchen, und es folgt schon aus dieser Definition, dass die Grundlage ihrer Methode das Zählen der Einzelfälle einer Erscheinung bildet, da sie ja nicht, wie die Geschichte, die Individualität der Ereignisse betrachtet, sondern dieselben nur als Glieder einer Masse, als Einheiten ciner Summe registrirt. Die statistische Methode findet auch in den Naturwissenschaften fruchtbare Verwendung; aber es schcint doch aweckmässig, den Namen Statistik ausschliesslich der Wissenschaft vorzubehalten, welche jene Methode - deren Wosen im Folgenden genauer hervortreten wird - auf die Untersuchung der Massenerscheinungen des gesellschaftlichen Menschenlebens anwendet.

Sehr verfehlt jedoch wäre es, wenn man alle menschlichen Massenerscheinungen lediglich vom statistischen Gesichtspunkte betrachten wollte. Denn viel wichtiger als die Aufhebung des Einzelereignisses in einer concreten Summe ist die Aufhebung desselben in einer begrifflichen Verallgemeinerung. Wenn die Einzelereignisse nur individuelle Erscheinungen derselben Gattung sind, und wir diese Gattung des Geschehens aus ciner Ursacho oder einem 
Ursachensystem begreifen können, so ist offenbar dieser abstractc Begriff des Ereignisses wissenschaftlich von grö̈serem Interesse, als die Zählung scines concreten Vorkommens.

Eine solehe begriffliche, generische Auffassung der mensehlichen Massenerscheinungen aber ist namentlich dann möglich, wenn wir, gestiit:t auf psychologische Frwägungen, Selbstbeobachtungen oder alltägrliche Erfahrungen, in jedem Einzelereignisse die gleiche überwiegend wirksame Ursache, insbesondere also in jeder zu der Masse beitragenden Einzelhandlung die gleiche durchschlagende 'Triebferler zu crkennen vermögen.

So tritt uns auf dem Gebiete des wirthschaftlichen Lebens als iiberwiegendes Motiv des individuellen menschlichen IIandelns das Sclbstinteresse entgegen. Kennen wir nun erfahrungsmïssig die allgemeinen Formen der Verhältnisse, unter denen diese 'Triebfeder zur Wirlisamkeit gelangt, so können wir auch allgemein die Gattungen oder Typen der wirthschaftlichen Ereignissc ableiten, von deners jeder in einer grossen Zabl von Fiuzclfällen, in einer Massenerscheinung des Menschenlebens auftritt. Die statistische Feststellung der Thatsachen dient in solchen Failen nur zur Präcisirung einer concreten Wirklichkeit, während die Abstraction einen Sat\% aufstellt oder doch aufzustellen sucht, der in allen Fillen sich bewalrbeiten soll, in denen bestimmte Bedingungen crfïllt sind.

Wenn an der Berliner Börse der Wechselcurs auf Paris über 81.40 hinausgeht, so darf man behaupten, dass alle deutschen Banquiers, die ïberhaupt auf Arbitrage-Operationen eingerichtet sind, Gold nach Paris senden. Diese Goldsendungen bilden eine wirthschaftlich bedeutsane Massenerscheinung, und die Ermittlung ihres Gesammbetrags ist ohne Zweifel von praktischem Interesse. Für dic theoretische Wissenschaft aber genïgt es, nach allgemeinen Erwägungen die Bedingungen fest\%ustellen, urter denen eine Goldausfular aus einem gegebenen Lande staltfinden wird, und daneben ist durch einige zahlenuässige Beispiele darzuthun, wie weit die Wirklichkeit den theoretischen Voraussagungen entspricht.

2. Für die Volkswirthschaftslehre hat also die statistische Untersuchung nur die Bedeutung eines Control- oder BerichtigungsVerfahrens. Die aus den Einzelerscheinungen abgezogenen allgemeinen Sätze stimmen nämlich mit den Massenerscheinungen der Wirklichlieit nie genau übercin; denn eincrevits haben die wirk- 
lichen Verhältnisse, unter denen ths wirthschaftliche Selbstinteresse sich bethiatigt, einen mannigfaligeren und reicheren Inhalt, als die abstracten Typen derselben; und andererseits handeln die Menschen selbst in wirthschaftlichen Dingen keineswegs ausschliesslich unter der Leitung ihres Selbstinteresses. Die Statistik gibt uns nun zahlenmässige Anhaltspunkte sowohl zur Beurtheilung des Grades, in welchem die wirlilichen wirthschaftlichen Massenerscheinungen den abstracten 'Typen derselben entsprechen, als auch zur richtigen Schätzung der Tragweite der beobachteten Abweichungen von den theoretischen Vorausschungen.

Statistische Zahlenreihen können auch dazu dienen, in exacter Wcise dic historische Entwicklnng einer specicllen wirthschaftlichen Erscheinuug darustellen, wic z. B. das Aufblühen der englischen Baumwollfabrikation, der Kohlen- oder Eisenindustrie in diesem Jahrhundert.

Man kaun ferner durch statistische "Reactionen" - um einen Ausdruck Engels zu gebrauchen - vermuthete Beziehnngen zwischen verschiedenen Reihen wirthschaftlicher Erscheinungen bestïtigen; aber die Vollswirthphaftslelire sieht in solchen Nachweisen nur insofern einen Gewinn, als sic den statistiseh beobachteten Tusammenhang aus allgemeinen Gründen zi erklären vermag.

Aus dem volkswirthsehaftlich-statistischen Material für sich allein lässt sich also kcine besondere Wissenschaft aufbauen; es wird nur dadurch fruchthar, dass wir es nit unsern sonstigen Erfahrungen über dic Natur des gescllschaftlichen und wirthschaftenden Mensehen verbinden.

Noch weniger natiirlich kann in den eigentlich socialen und politischen Wissenschaften die Statistik eine selbständige Rolle spielen. Uebcrhaupt tritt sie auch als Hülfswissenschaft um so melir zurïck, je mehr sich die betrachteten Massenerscheinungen historisch individualisiren, und je vollkommener wir das Princip, das in der Masse jeder Einzelcrscheinung zu Grunde liegt, die Ideen und Zweeke, die der menschliche Geist in der Geschichte zu verwirklichen strebt, zu erkennen im Stande sind.

3. Gleichwohl kann die Statistik als Wissenschaft von den menschlichen Massenersehcinungen auf cinem bestimmten, wenn auch engen Gebiete selbständig auftreten. Denn es gibt Massenerscheinungen, deren wissenschaftliches Interesse zunächst nur in ilıren numerischen Verhältnissen liegt. Eine blosse Abstraction aus 
den Einzelereignissen würde in diesen Fällen einen zu geringen Inhalt haben, da das Gemeinsame der Einzelerscheinungen lediglich in dem gleichen Endresultate liegen würde, während z. B. dic Einzelvorgänge einer wirthschaftlichen Massenerscheinung nicht nur in ihrem Resultate, sondern auch in ihrer Verursachung und in ihrem Verlauf eine wissensehaftlich fassbare Gemeinsamkeit zeigen. In dem oben angefïhrten Beispiele handeln alle Banquiers nach demselben Motive, nach derselben Berechnung und mit demselben Resultat, und ein älnliches IIanteln wird sich unter gleichen Bedingungen immer wiederholen. Und eben desswegen kann man hier von einem typischen Geschehen, von einer Gattungserscheinung sprechen, die auch ohne numerische Präcisirung cin wissenschaftliches Interesse besitzt.

Wenn man aber \%. B. sagt: "Von den Geborenen einer gewissen Zeitstrecke sterben viele in ersten Lebensjahre", so ist dies ein wissenschaftlich bedeutungsloser Satz. Die Linzelereignisse, die Sterbefälle, kommen, sogar wenn sie durch dieselbe Krankheit verursacht sind, auf so mannigfaltige Art zu Stande, dass wir dureh Abstraction nur zu der leeren Thatsache der Häufigkeit der Sterbefälle gelangen. Um eine neue Linsicht zu erlangen, müssen wir die beobachteten Massen numerisch bestimmen. Und da zeigt sich dem, dass das Verhältniss der Zahl der Gestorbenen zu der Zahl der Geborenen für verschiedene Generationen ziemlich constant bleibt. So finden wir trotz unserer Unwissenheit über die Entstehung der Einzelfälle einen bedeutsamen, verhältnissmässig allgerneinen Satz ïber die Massenerscheinung, während in dem volkswirtlischaftlichen Beispiele der allgemeine Satz aus unserer Kenntniss des typischen Verlaufs des Einzelvorganges entsprang.

4. Somit zcrfallen alle menschlichen Massenerscheinungen zunächst in zwei Classen: die cinen, die man als "generische" bezeichnen kann, bestehen aus Einzelfällen eines generisch gleichartigen Geschehens, das für sich wissenschaftlich erheblich und erklärlich ist; der Ausdruck und die Erklärung diescs generischen Geschehens ist bier das wesentliche Resultat der Wissenschaft; die Statistik aber dient als Hülfswissenschaft, um dasselbe zahlenmässig zu controliren und zu präcisiren. Die Massenerscheinungen der anderen Classe aber, welche wir die "conereten" nennen wollen, bestehen aus Einzelfällen, deren Gleichartigkcit wir nur in dem gleichen Endergelniss finden. Jedes Einzelereigniss steht zwar in 
ciner streng geschlossenen Kette der Causalität, dic man auch in jedem gegebenen Falle nachweisen könnte; aber die vorhandenen Ursachensysteme sind so zahlreich und mannigfaltig, dass uns das Zusammentreffen der Einzelfïlle nur als Zufall crscheint. Hier werden die Einzolfaille tür uns blosse Einheiten ,einer Gesammtzahl, das Zählen der Massen wird Iauptzweck, die Statistik tritt in ilure selbständigen Rechte ein und hat zu zeigen, wie sich die grossen Zahlen zur Erweiterung unserer wissenschaftichen Einsicht in die Erscheinungen verwerthen lassen. Sie fiuhrt ihre Lutersuchung nittelst ciner besonderen Methorle, die hauptsächlich durch die Wahrseheinliehleitsrechmung gegeben wirl. Diese Art der Untersuchung kann ührigens auch auf die gencrischen Massenerscheinumgen angewandt werden, jedoch werden solche Versuche mehr ein methodologisches, als sachliches Interesse bicten.

Häufg lassen sich übrigens dic gegebeneu Massenerschcinungen in mehrere Partialmassen zerlegen, von denen jede einzelne aus Elementen von einer gewissen Gleichartiglieit besteht; aber trotzdem bleibt in jeder I'artialmasse dic Mannigfaltigkeit der Entstehungsbedingungen der Einzelfälle so gross, dass wir sie nicht nit Gewinn auf ein generisches Geschehen zurückführen könnten. So mögen in gewissen Schichten der Bevölkerung 40 , in anderen nur 20 Procent der Geborenen im ersten Lebensjahre sterben; aber das Zustandekommen des einen wie des anderen Procentsatzes ist für uns cine rein empirische Thatsache, wenn wir auch im Allgemeinen wohl erkennen lö̈nen, warum in der einen Gruppe die Sterblichkeit grösser ist, als in der anderen. Diese letztere Erkenntniss wäre ülrigens schon als ein Resultat der statistischen Untersuchung anzuschen, da sie ohnc exacte numerische Begründung nur als vage Vermuthung auftreten könnte.

5. Die selbständigen Ergebnisse der Statistik bestehen vorzugsweise darin, dass sie dic angenäherte Constan\% gewisser numerischer Verhältnisse der Massenerscheinungen feststellt. Dadurch entsteht der Schein, als wern das menschliche Thun und Leiden Zahlengesetzen von mechanisch-naturwissenschaftlichem Charaliter unterworfen sci. IIandelt es sich um generische Massencrscheinungen, deren Einzelprocesse wir also nach ihrem allgemeinen Typus genügend übersehen können, so fallen uns solche Regelmässigkeiten gar nicht auf; es ist $z$. B. selbstverständlich, dass, wenn nicht ein ungewöhnlicher Aufschwung der Geschüfte oder anderseits eine 


\section{$-6-$}

Krisis eintritt, in einem Jahre ungefaihr ebenso viel von einer bestimmten Waare auf den Markt kommt, als in den nächstvorhergehenden oder nächstfolgenden, da die Zahl der Fabriken oder Arbeiter, welche diese Waare produciren, sich in normalen Zeiten sicht plötzlich ändern wird. Erscheint uns aber die Masse als ein zufälliges Aggregat von Einzelfällen mit sehr verschiedenen Verursachungen, so werden uns alle numerischen Regelmässigkeiten in derselben in hohem Grade auffullen.

Ist man nun wirklich berechtigt, dic Regelmässigkeit der menschlichen Massenerscheinungen als Gesetze im naturwissenschaftlichen Sinne aufzufassen?

Ein Gesetz im naturwissenschaftlichen Sinne ist eine Abstraction aus einem glcichartigen Geschehen. Das Geset»mïssige des Geschehens muss allen beobachteten Linzelvorgiinge gemeinsam sein, und wir müssen au dem Inductionsschluss berechtigt sein, dass es überhaupt in allen Vorgängen dieser Art in gleicher Weise hervortreten wird. Dic Wissenschaft fordert aber weiter, dass wir uns diesen generisch aufgefassten Process möglichst verständlich und begreiflich machen, und das geschieht, indem wir versuchen, denselben in einfachere Vorin̈inge $/ u$ zcrlegen, bis wir endlich zu Elementaranschauungen gelangen, über die wir schlechthin nicht mehr hinaus können. Für die Naturwissenscbaft ist dieser höchste und einfachste Typus cines Gesetzes durch die allgemeinen Differenzialgleichungen der Dynamik gegeben. Ein Naturgesetz in seiner höchsten Ausbildung gibt daher nur die allgemeine Formel für die Bewegung eines unendlich kleinen Elementes der Materie in einer unendlich kleinen Zeit. $A$ ber auch die integrale, cier wissenschaftlichen Beobachtung ztugängliche Erscheinung (die ais Massenerscheinung aufgefasst werden kann) wird vermögc der begrifflichen Einheit des Elementarprocesses durch eine F'urnei dargestellt, die ebenfalls als Gesetz betrachtet werden darf, da sie einfach die logische Folge aus dem Elementargesetz als $1 \mathrm{~cm}$ Grunde bildet und das letztere wieder aus ihr abgeleitet werden liann. Insofern kann man auch sagen, dass die Gesammterscheinung durch diese Integralformel beherrscht werde.

So wird beispielsweise das Gravitationsgesetz durch eine Differenzialformel ausgedrückt, welche allgemein für jeden Zeitmoment die Bewegung eines Planeten bestimmt; dic Integration dieser Formel aber gibt das Kepler'sche "Gesetz" der elliptischen Bewegung des Planeten. 
6. Das Element der mensehlichen Massenerseheinungen ist nun eben der Mensch. So oft man also sich berechtigt glaubt, zu behaupten, dass alle Menschen oder alle Menschen einer gewissen Kategorie unter bestimmten lomständen immer auf eine bestimmte Art handeln werden, stellt man in der That im naturwissenschaftlichen Sinue ein Gesct\% für cine menschliche Elementarerscheinung auf. Aber sind wir erfahrungsnüssig jemals wirklich berechtigt, mit derselben Bestimmtheit in clieser Weise das menschliche Handeln vorausmsaren, wie wir $\%$. B. behaupten dürfon, dass so oft ein electrischer Strom ein Stiick Fisen umkreist, das letytere magnetisch wird? Offentar niclit, denn unser abstractes Schema des menschlichen Handehs ist nothwendigr immer ein unvollständiges, indem nur die in der Regel überwiegenden Ursachen und Wirkungen ane gesonioyt sind. Der Induetionsscluluss von den beobachteten Erscheimungen auf die nichtbcobachteten, der anf naturwissenschaftlichem Gebiete eine empirische Gewissheit erlangt, fülnt daher in dem unerschöpflichen Reichthum des Nensehonlebens nur zu einem grösscren oder geringeren (iracle von Wahrscheinlichkeit. 1) Auch die iusseren Unstände werden in der Wirklichkeit grössere Verschicdenheit darbicten, als es in dera allomeinen Formulirung des "Gesetyes" vorgesehen ist. Und so kam die Masse der Erschejnungen doch crhebliche Abweichungen von der "gesetzlichen" Schablone aufweisen.

Fs findet also nur cine formale Analogie zwischen den Naturgesetzen und den generischen P'rocessen in den menschlichen Massenerscheinungen statt. Die ersteren boruhen auf einem Inductionsschluss von praktisch absoluter Gültigkeit; die letzteren aber wiederholen sich, mögen wir ihre Bedingungen auch noch so speziell feststellen, irnmer nur nit einer gewissen Wahrscheinlichkeit. Mit anderen Worten, wir können auf dem Gebiete des Menschenlebens keinen Complex von Bedingungen angeben, der nothwendig und

1) Allgrmejn künnte man wit $R$ ümelin frngen: "Solite das Incinandergreifen aller pşchischen Kräfte sich vielleicht immer und überall ciner wissentschaftlichen Feststellung antziehen, sollten sich die pgychischen Krüfte gerade darin von den plyssikalisehen und fhysiologisclien unterscheiden, dass diesen ein ewig unwandelbares hanss der Idistungstïhiglirit zukomml, jue alor bei aller Beharrlichkeit ihrer Grundform litusiehtlich ihres St:̈rhegrales einer allmüllichen inneren Umbildung unterworfen sind ?t6 
hinreichend wäre, um mit Sicherheit ein bestimmtes menschliches Handeln nach sich zu ziehen.

So scheint es auf den ersten Blick ein allgemein gültiges "Gesetz", dass das flüssige Capital aus einem Lande mit niedrigem Zinsfuss überströmen werde nach cinem Lande mit hohem Zinsfuss, dass also insbesondere 7. B. die Bank von Frankreich, wenn sie ihren Baarvorrath nicht geführden will, nicmals auf längere Zeit einen erheblich niedrigeren Discontosat; bestehen lassen darf, als die Bank von England. Und doch finden wir in dem Zeitraum von October 1865 bis September 1866 in Paris als Disconto-Minimum $3 \%$, als Maximum $5 \%$, während in London in diesen elf Monaten das Minimum $6 \%$, das Maximum aber $10 \%$ betrug, und awar mit so scharfem Gegensatze, dass 1866 von Mai bis August das Londoner Maximum mit einem Discontofusse von $4 \%$ und $3 \frac{1}{2} \%$ in Paris zusammenfält. Und trotzdem trat der crwartete Baarabfluss von Paris nach London nicht ein, vielmehr stand der Wechselcurs meistens so, dass Gold aus England nach Frankreich geschickt werden musste. Die damalige Handelslage beider Lünder, die Krisis in England und der Einfluss der Peel'schen Bankakte machen bei genauerer Untersuchung jene merkwürdige Divergenz vollkommen begreiflich. Aber mit der Gesetzeskraft des obigen allgemeinen Satzes ist es schlecht bestellt, wenn die concreten Umstände mächtig genug sind, gerade das Gegentheil der erwarteten Erscheinung hervorzurufen. Man kann dann nur noch von einer Regel sprechen, die in unberechenbarer Weise eclatante Ausnahmen gestattet.

7. Es gibt aber auch in der Natur concrete Massenerscheinungen, nämlich solche, deren Elementarvorgänge nicht gleichartig sind oder nicht unter einem durch das Ganze herrschenden Gesetze stehen. In solchen Fällen wäre es wohl möglich, dic Aussenseite der Erscheinung durch eine empirische ${ }_{i}$ Formel darrustellen, aber diese Formel würde nicht der Ausdruck eines Naturgesetzes sein, sondern nur dem Endresultat des Zusammentreffens vieler verschiedenartiger, einzeln nicht zu verfolgender Elementarprocesse entsprechen.

So könnte man z. B. die Obcrfläche eines aufgeschütteten Sandhaufens durch eine empirische Formel wenigstens näherungsweise ausdrücken, aber Niemand würde dieselbe als das Geset\% betrachten, das die Gleichgewichtslage der einzelnen, verschieden geformten Sandkörner geregelt hätte. Jedes Korn ist vielmehr der Einwirkung 
eines besonderen Complexes von Stössen und Reibungen ausgesetzt gewesen und, zwar streng naturgesetzlich, aber auf einem für uns unberechenbaren Wege in seine Ruhelage geführt worden. Wenn wir uns dagegen die Körner sänmtlich glcichartig und zwar unendlich klein und absolut glatt denken, so sind wir im Stande, die (hydrostatischen und hydrodynamischen) Gleichungen aufzustellen, die allgemein für jedes Element eincr solchen Masse die Normen des Gleichgewichts und der Bewegung ausdrïcken, und dann haben wir diese Erscheinungen unter ein einheitliches Naturgeset\% gebracht.

Die concreten Massenerscheinungen des Menschenlebens sind nun offenbar analog jenen unauflislichen Massenerscheinurigen der Natur. Die Einzelvorgiinge derselben sind so verschiedenartig, dass sich leine allgemeine Regel über die Verursachung und den VerJituf derselben abstrahiren lïsst. Es lässt sich also gleichsam nur die Aussenseite der Massencrscheinung untersuchen und zahlenmässig feststellen. Aber was in Betreff des eben angefiihrten physikalischen Beispieles Niemandem einfallen wïrde, nehmen Manche hinsichtlich der statistischen Massenerscheinungen ohne Weiteres an, dass nïmlich die expirische Formel für die Aussenseite einer Aufhäufung von Einzelfillen ein die Gesammterscheinung beherrschendes Gesetz darstelle.

Freilich wird man z:1 dicscr Auffassung leicht verführt durch die numerischen Regelmässigkeiten der Massencrscheinungen. Die Beobachtung, dass von eitrer Million Geborener in einem gegebenen Lande $250,000 \mathrm{im}$ ersten Lebensjahre sterben, gibt allerdings nur dem äusseren Umriss dieser Massencrscheinung; aber wenn dieses Verhältniss für cine ganze Reihe von Generationen näherungsweise constant bleibt, so gelangt man zur Abstraction einer numerischen Sterblichkeitsregel, die jedenfalls eine äusscre Analogie mit einem Naturgeset\% besitzt.

Indess pflegt man doch die That ache, dass die mittlere Jahrestemperatur eines Ortes z. 13. ziemlich constant 9 Grad C. beträgt, nicht als cin Naturgeset\% $\%$ bezeichnen. 1)iese Mitteltemperatur ist nur die Folge sehr ntannigfaltiger, im Einzelnen naturgesetzlich bestimmter meteorologischer Processe, die sich awar von Jahr zu Jahr in Grossen und Ganzen in ähnlicher Weise wiederholen, aber doch auch zuweilen bedeutend divergirende Durchschnitteresultate ergeben. Der Schiuss von dem Beobachteten auf das nicht Beob- 
achtete ist also weit unsicherer, als in dem Fallo eines wirklichen, isolirten Naturgesetzes.

Noch unsicherer ist nun aber dieser Schluss bei concreten Massenerscheinungen der menschlichen Gesellschaft. 1)ie allgemeinen Vorbedingungen der meteorologischen Processe bleiben jedenfalls in höherem Grade constant, als dic verwicliciten Ursachensysteme der menschlichen Frscheinungen. Unter den auf kürzere Zeitstrecken ziemlich unverändert bleibenden statistischen Verhältnisszahlen wüsste ich lieine, von der es nicht wahrscheinlich wäre, dass sic mit der Veränderung und Entwicklung der allgcmeinen Culturverlältnisse, mit den Fortschritten der Gesundlicitspflege, des Wohlstandes u. s. w. im Laufe eines längeren Zeitraumes in positivem oder negativem Sinne langsam veränderlich sein werde. Die statistischen Zahlen folgen ja selbstverständlich der Entwicklung der menschlichen Zustände, die sie numerisch präcisiren sollen.

8. Die äussere Regelmässigkeit der concreten Massenerscheinungen könnte nur dann als Gesetz im naturwissenschaftlichen Sinne anerkannt werden, wenn sie unmittelbar das Zusammentreffen der Einzelfälle regelte. Die Elementarvorgänge besässen dann trotz der grossen Mannigfaltigkeit ihrer Verursachung nur scheinbar dic Unabhängigkeit von einander, die sich ausserlich zeigt; in Wirklichkeit bestände eine innere Beziehung zwischen ihnen, die unmittelbar das Zustandekommen der beobachteten numerischen Regelmässigkeit in der Massenerscheinung bedingen müsste. Dann hätten wir eine allgemeine, durch alle Einzelfälle gehenden Norm des Geschehens, die wohl den Auspruch auf den Titel Geset:z besässe, auch wenn sie langsamen Veränderungen in der Zeit unterworfen wäre.

Sind aber Gesetze dieser Art in den menschlichen Massenerscheinungen, zumal den aus bewusstem Handeln der Individuen hervorgehenden, wirklich nacliweisbar?

Von einer vollständigen Unabhängigkeit der im Schoosse der Gesellschaft vorkommenden Einzel-Vorgänge und -Handlungen kann allerdings keine Rede scin. Insbesondere besteht ein gewisser "socialethischer" Zusaminenhang zwischen dem Ganzen der Gesellschaft und ihren Gliedern; dic Gesinnungen, welche den Fandlungen der Indivtluen zu Grunde liegen, wirken anch wieder in ihrer Gesammtheit als Gemeingeist, Zeitgeist, sittliche Stimmung der Gesellschaft zurück auf den Einzelnen. $\Lambda$ ber wenn auch der Complex 
von Motiven, aus dem die Ilandlung eines Individuums hervorgeht, durch psychologische, sittliche oder unsittliche Linflüsse aus seiner näheren oder entfernteren Lmgebung mit bestimmt wird, so folgt doch daraus keineswegs, dass diese Einflusse nach einer in ihnen selbst licgenden Norm zusammenwirlen, um ein bestimmtes numerisches Ergebuiss in der T'otalerschcinung $z, 1$ Stande $z / 1$ bringen. Eine Vorstellung dieser Art, und zwar in überwiegend mechanischer Auffassung, liegt offenbar dem Standpunkte Quételets zu Grunde. Man denke nur an scine oft wiederholte l'hrase von dem Budget des Schaffots und der Gefïngnisse. Buckle hat diese Anschaung in dilettantenhafter Weise bis \%u den äussersten Grenzen erweitert, während in Deutschland A. Wagner Anfaniss zwar Quételet sehr nahe stand, später aber von dessen Einseitigkeit zurïckgekommen ist. An die Stelle der mechanischen Auffassung der moralstatistischen Erscheinungen, die namentlich schon von Drobisch mit Erfolg bekämpft worden war, ${ }^{1}$ ) machte $\Lambda \mathrm{l}$. v. Oettingen die "socialethische" geltend, die ohne Zweifel berechtigt ist, wenn sie in den oben angedeuteten Grenzen bleibt. Wollte man aler so weit gehen, dass man den Zahlenverhältnissen in der sittlichen Welt eine geheimnissvolle, wirksame Rolle beilegte, anstatt sie lediglich als Resultate der Wirklichkeit anzuschen, so nühme man statt des unbegreiflichen mechanischen ein ebenso unbegreifliches mystisches Gesetz an.

9. Vom Standpunkt des Mechanismus aber wie der Mystik müsste man zur Frklïrunır der statistischen Gesetzmässigkeiten voraussetzen, dass neben den bewussten Motiven der menschlichen Individuen noch ein Unbewusstes lanfe, das als durch das Ganze herrschende Macht bestimmte numerische Verhältnisse in der Totalerscheinung erstrebe und er\%winge.

Nun stehen allerdings auf dem Gebicte des vollbew ussten, selbstbestimmten Handelns sehr häufig dic Einzelvorgänge einer Massenerscheinung trotz ihrer Mannigfaltigleit in cinem Zusammenhange, der auf ein constantes numerisches Endresultat hinwirkt und dasselbe näherungsweise auch wirklich hervorruft. Solche Erschei-

5) Auch Knap und Schmoller sind len statistischen Naturgesctren entgegen getreten. Vgl. u. a. auch Wi ndelband, die Lehren rom /ufalle, S. $26 \mathrm{ff}$. und die sehr scharte Litik Quetelets von Rehniseh in der Zcitschrilt für Philos. unà phs. lírit. B., 68 u. 6 J. 
nungen gehören namentlich im volkswirthschaftlichen Leben zu den trivialen Dingen. Angenommen ein in einem gewissen Lande in grösserem Umfange betriebener Industriezweig bedürfe zweier $\Lambda$ rten von Rohstoffen, die aus verschiedenen Ländern eingeführt werden müssen, und rwar soll das fertige Product von dem Stoffe A immer doppelt so viel enthalten, als von dem Stofie 13. Dann ist einleuchtend, dass dieses Verhältniss 2:1 die relativ unabhängigen, weil von vielen Importcuren selbständig betriebenen einzelnen Einfuhren beider Rohstoffe in der Weise beherrscht, dass es bei jeder Operation im Auge behalten werden muss. Wäre in den ersten Monaten des Jahrcs die Zufuhr des Stoffes B ungewöhnlieh stark gewesen, so würde die Rücksicht auf die massgebende I'roportion entweder die Importeure dieses Stoffes zur Mibssigung ihrer Unternehmungen oder, bei einem grossen Aufschwunge der Geschüfte, die Importeure des Stoffes A zu einer entsprechenden Mehreinfuhr veranlassen. Und so würde Jahr aus Jahr cin immer nahezu das richtige Verhältniss der T'otaleinfuhr beider Stoffe zu Tage treten.

Auf dieses schematische Beispiel sind die numerischen "Gesetze" zurückzuführen, welche die Befahrung eines Weltmarlites regeln. Es gibt eben viele Waarengruppen, die in quantitativ bestimmten Verhältnissen zusammengehören, und diese Verhältnisse müssen durch das Zusammenwirken zahlreicher, äusserlich von einander unabhängiger Einzelsendungen in der Gesammtzufuhr einer gewissen Zeitstrecke zum Ausdruck gebracht werden.

Freilich gehören diese und ähnliche Massenerscheinungen, in denen die Herrschaft eines Zahlenverhältnisses unmittelbar erkennbar ist, zu den generischen, da die wesentlichen Bedingungen ihrer Elementarvorgänge in abstracto ïbersehen werden können. Auch hat der numerische Nachweis der Constanz solcher Verhältnisse im Allgemeinen kein wissenschaftliches Interesse, es sei denn, dass man einzelne Beispicle zu methodologischen Zwecken behandelt.

Denkt man sich aber statt des bewussten ,zielstrebigen" $\mathrm{Zu}$ sammenhanges der Einzelerscheinungen einen unbewussten, so hätte man eben das kabbalistische Phänomen eines herrschenden Zahlengesetzes in einer concreten Massenerscheinung.

10. Diese Betrachtungen fïhren uns zu einer zweiten Eintheilung der Massenerscheinungen: die einen, dic man als unverbu ndene bezeichnen kann, sind solche, deren Einzelfälle von einander unabhängig sind oder doch nicht in einem solchen Zusammen- 
hange stehen, der auf die Erzcugung eines bestimmten numerischen Verhältnisses in der Gesammterscheinung hinwirkt; die andern aber sind dann als verbundene zu bezeichnen und dadurch charakterisirt, dass ihre Einzelfälle in cinem Zusammenhange mit cinander stehen, der ein bestimmtes numerisches Verhältniss in der Totalerscheinung bedingt. Insbesondere müsste also, wenn durch eine Anzahl von Einzelfällen Abweichungen von diesem Verhältnisse zu entstehen drohen, durch andere Fälle $A$ usgleichung oder Ersat $z$ eintreten.

Die unverbundenen Massenerscheinungen können sowohl $\mathrm{zu}$ den generischen wie zu den concreten gehören; verbundene dagegen kommen unzweifelhaft nur unter den generischen vor; dass sie auch unter den concreten Massenerscheinungen zu finden seien, wird man jedenfalls in Abrede stellen dürfen, bis der positive Beweis dafür geliefert ist. Jedoch ist von der Theorie $z u$ fordern, dass sie allgeneine Kriterien aufstelle, um Massenerscheinungen dieser problematisehen Art z.u erkennen, wenn sie vorkommen sollten. Diesen Kriterien würcle man natürlich auch schon dann einen Gewinn verdanken, wenn sich mit ihrer Hülfe zeigen liesse, dass alle genauer untersuchten Massenerseheinungen zu jener Kategorie nicht gehören. Weiter unten wird man, wie jch glaube, diese Aufgabe wenigstens theilweise gelöst finden.

\section{Die Theorie der Massenerseheinungen und die Wahrscheinlichkeitsrechnung.}

11. Die Theorie der' Massenerscheinungen hat zunächst eine formale Aufgabe zu erfüllen: sie soll die richtige Abgrenzung der Massen lehren und namentlich die Methode festellen, wie eine Masse, deren Elemente zu verschiedenen Zeiten eine Reihe von Veründerungen erfabren, in ihrem gesammten Zustandswechsel correct verfolgt werden kann. Diese formale, besonders für die Bevölkerungsstatistik wichtige Theorie ist in neuerer Zeit, nachdem Knapp's Arbeiten den Anstoss gegeben, zur Genüge ausgebildet worden. ${ }^{1}$ )

1) Ueber das Nähcre und die Litteratur s. meine „Einleitung in die Theoric der Bevölkerungsstatistik". Strassh. 1875. 
Aber die Theoric soll anch dic Möglichkeit gewïhren, wenigstens in gewissem Simne eine vermehrte Einsicht in das Materielle der Massenerscheinungen zu gewimlen. Bei dieser Untersuchung, mit der wir uns im Folgenden näler beschäftigen wollon, wird dic Thatsache ausgenutyt, dass wir eben nit Massen, mit grossen Zahlen zu thun haben, und sio beruht daher wescntlich auf der Wahrscheinlichleitsrechnung.

Einige allgeneine Bemerkungen über die Anwendbarkcit der Walırscheislichkeitsrechnung auf die objective Aussenwclt mögen vorausgeschickt werden.

Als mathematische Walrscheinlichkeit eines Ereignisses bezeichnet man bekanntlich das Verhältniss der diesem Lireignisse günstigen, gleich möglichen Fille zu der gesammten Zahl der gleich möglichen Fälle überhaupt. Als Zweig der reinen Mathematik braucht die Wabrscheinlichkeitsrechnung auf die Bedeutung oder Bedeutungslosigkeit dieses Verhältnisses für die objective Welt keine Rücksicht zu nehmen; sie stellt dasselbe als Definition auf, rechnet auf dieser Grundlage weiter und gelangt zu interessanten analytischen Entwicklungen, dic mathematischen Solbstzw eck besitzen.

Nun folgt schon aus der Voraussetzung gleich möglicher Fälle, dass diese Rechnung nur auf dem Gebiete der subjectiven Wahrscheinlichkeit eine apriori'sche Anwendbarkeit besityt.

Wenn wir in Folge unseres ungenügenden Wissens keinen Grund absehen, wesshalb wir einen Fall für leichter möglich halten sollen, als einen anderen, so nehmen wir für unser subjectives Ermessen alle Fälle als gleich möglich an, und Jedermann der nicht mehr über die objective Entstehungsart der Ereignisse weiss, wird diesc gleiche Möglichkeit ebenfalls zugeben. So dient dic Wahrscheinlichkeitsrechnung zur Beantwortung von Fragen über Combinationen von Chancen, die als gleich angenommen werden und ihre unmittelbare praktische Verwendung wïrde sie daher lediglich in dex Regelung von Glückspielen und Wetten finden, dic denn ja auch den ersten Anstoss zu ihrer Ausbildung gegeben haben. Denn die Gerechtigkeit und Billigkeit der Bedingungen eines Würfelspiels z. B. lässt sich auf Grundlage der gleichmässigen Unwissenheit der Betheiligten über die complicirten Bewegungen des Würfels vollkommen befriedigend herstellen.

12. Aber mit der so dargestellten subjectiven Wahrscheinlich- 
keit eines Ereignisses darf die objective, physjsche Möglichleit desselben nicht verwechselt oder vermengt werden, - ein Satz, den besonders Cournot nachdrücklich hervorgehoben hat.

Die Anwendbarkeit der Wahrscheinlichkeitsrechnung auf' die Beurtheilung der objectiven Möglichkeit eines Ereignisses ergibt sich keineswegs aus ihr selbst oder aus ibrem Grundprincip, sondern lediglich aus der Erfahrung. Denn es gibt in der Wirklichkeit keine gleich $m o ̈ g l i c h e n$ Fälle, jedes Ercigniss ist cin absolut individueller Process, das Endglied einer Causalitätskette, die ins Unendliche zurücklïuft. Auch gibt es streng genommen keine gegeneinander absolut indifferente Lreignisse, wie es doch dic Grundvorstellung der Wabrscheinlichkeitsrechnung ebenfalls verlangt.

Wenn die Kugel bereits in der Roulette rollt, ist für die Spieler die suljective Wahrscheinlichleit des Herauskommens irgend einer Nummer noeh cben so gross wie die jeder anderen, und die weitcren Einsätze regeln sich mit Recht noch nach dieser Voraussetzung. Und doch steht der Verlauf des mechanischen Processes und somit auch die Endlage der Kugel dann schon naturgesetzlich fest und von einer gleichen Möglichkeit aller Endergebnisse liann oljectiv gar keine Rede mehr sein.

Nun aber vergleiche man die Resultate, welche die Wahrscheinlichkeitsrechnung, indem sie von der Vorstellung gleich möglicher Fälle ausgeht, für eine Massencrscheinung ableitet, mit der beohachteten Wirklichkeit: dann wird man finden, dass selhr viele Massenerscheinungen sich so verhalten, als wenn es gleich mögliche, von cinınder völlig unahhängrige Ein»elereignisse gäbe. So gewinnt also die Wahrscheinlichkeit auf Grund der Erfallrung eine objective Bedeutung und dadurch eine ausgedelinte Anwendbarkeit. Wir können namentlich die beobachteten Massenerseheinungen mit den nach der Wahrscheinlichleitsrechnung zu crwartenden Ergebnissen vergleichen: findet ein Widerspruch statt, so sind wir wahrscheinlich von falschen Voraussetzungen ausgegangen und es gelingt dann oft, durch genauere Untersuchungen unser Wissen zu berichtigen.

13. Wie aber erklärt sich die Uebereinstinmung von Wahrscheinlichkeitsrechnung und Wirklichkeit, wenn es in der Wirklichkcit weder gleich mögliche noch absolut von einander unabhängige Ereignisse gibt?

Man kann sich hicr weder auf den $13 \mathrm{ernou} 1 \mathrm{li}$ 'schen 
Satz, noch auf Poisson's Formulirung des Gesetzes der grossen Zahlen berufen.

Nach diesen Sützen wird, wenn ein Ereigniss cine bestimmte mathematische Wahrscheinlichkeit besitzt, bei einer grossen Zahl von Beobachtungen sehr wahrscheinlich die Zahl des Vorkommens des Ereignisses dividirt durch die Beobachtungs- oder Versuchs\%ahl nahezu jener Wahrscheinlichkeit gleichkomnen. In dem Bedingungssatz wird aber die objective Bedeutung der auf der Vorstellung gleich möglicher Fälle beruhenden mathematischen Wahrscheinlichleit schon vorausgesetzt. Es handelt sich für uns vielmehr um die Umkehrung dieses Satzes. Wenn bei ciner gegebenen Zahl z von Bcobachtungen oder Versuchen ein gewisses Ereigniss $e$ mal eintritt, darf man daun den Bruch $\frac{e}{z}$ als Näherungswerth einer mathematischen Wahrscheinlichkeit behandeln, die zugrleich die physische Möglichkeit des Ereigrnisses ausdrückt? Darf man mit diesem Werthe weiter rechnen, wie mit einer mathematischen Wahrseheinlichkeit, und entsprechen die weiteren Rechnungsresultate ebenfalls der Wirklichkeit? Zur Beantwortung dieser Frage kann auch der Satz über die Walnscheinlichkeit a posteriori nichts helfen, da dieser nur eine vorausgesetzte Wahrscheinlichkeit a priori nälherungsweise bestimmt; jene Frage kann vielmehr in jedem Falle nur erfahrungsmässig entschieden werden. Vor allem ist zu untersuchen, ob sich der Werth von $\frac{e}{z}$ mit zunehmendem $z$ in bestimmter Richtung dauernd verändert. Das Ereigniss kann ja nach ciner uns unbekannten Entwicklung nach und nach relativ häufiger oder seltener eintreten. In solchen Fällen kann jener Quotient offenbar nicht die Bedeutung eincr mathematischen Wahrscheinlichkeit besitzen.

Nun zeigt aber die Erfahrung, dass bei vielen Massenerscheinungen der Natur und des Menschenlebens jener, die relative Häufigkeit des betrachteten Ereignisses darstellende Quotient $\frac{c}{x}$ in vielen neben einander oder nach einander angestellten Beobachtungs- oder Versuchsreihen nahezu constant bleibt, besonders wenn diese Reihen sehr gross sind.

Diese Thatsache deutet zunächst nur darauf hin, dass der Quotient $\frac{\mathfrak{c}}{\mathrm{z}}$ ein zweckmässiges empirisches Kriterium der physischen Möglichkeit des Ereignisses sei. Auch erscheint ja von vornherein trotz seines vagen Charakters der Satz plausibel, dass ein Ereigniss um so leichter mörrlich ist, je lüufiger 
$$
-17-
$$

es in einer gegebenen grossen Zahl von Versuchen vorkommt.
\end{abstract}

Die ungefähre Constanz eines solchen Möglichkeitscoëfficienten, wie wir jenen Ausdruck der Kürze wegen nennen wollen, ist also nur ein Symptom, welches auf das ungefähre Gleichbleiben der allgeneinen Entsteliungsbedingungen des Ereignisses hindeutet.

14. Aber selbst wenn der Möglichkeitscoëfficient in mehreren Reihen eine angenäherte Constanz aufweist, darf man ihm doch noch nicht ohne weiteres den präcisen Charakter einer näherungsweise ausgedrückten nathematischen Wahrscheinlichkeit beilegen. Dazu bedarf es noch des Nachweises, dass die empirischen Werthe dез Möglichkeitscoüfficienten bei zunehmender Beobachtungszahl in solcher Weise gegen einen festen Grenzwerth convergiren, wie es die mathematische Wahrscheinlichlieitstheorie verlangt. Wie dieser Nachweis indirelst geliefert werden kann, wird unten näher erörtert. Er lässt sich in der That in manchen Fällen mit genügender Sicherheit führen, und wenige Beispicle dieser Art reichen schon aus, um der mathematischen Wahrscheinlichkeit eine objective Bedeutung als Mass der realen Möglichkeit zu sichern. Man ist dann berechtigt, auf Grund der Wahrscheinlichkeitstheorie für die Massenerscheinungen cin ideales Schema aufzustellen und sie zu classificiren, je nachdem sie diesem Schema nüherungsweise entsprechen oder in dem einen oder dem andern Sinne wesentlich von demselben abweichen.

Was bedeutet aber der Satz, dass eine Massenerscheinung auf das Schema der Wahrscheinlichkeitsrechnung zurückgefïhrt sei? Die Möglichkeitscoëfficienten der einzelnen Versuchsweisen haben in diesem Falle einen festen Grenzwerth $\frac{t}{Z}$, und das Ereigniss tritt in solcher Frequenz auf, wie sie nach der Theorie zu erwarten wäre, wenn bei jedem Versuche einer von $Z$ gleich möglichen und von einander unabhängigen Umständen die Entscheidung gäbe, und zwar $E$ von diesen Umständen das Ereigniss hervorriefen, die übrigen aber dasselle verhinderten.

Man kann natürlich die Zahl der günstigen und ungünstigen Umstände ausserordentlich, selbst unendlich gross annehmen, ohne dass dadurch das Verhältniss $\frac{E}{Z}$ verändert wird.

Nun sind in der wirklichen Welt sowohl für das Eintreten als für die Verhinderung eines Ereignisses unziihlig vicle Umstände entscheidend, aber diese Umstände sind selbstverständlich weder 
gleich möglich noch absolut unabhängig von einander. Wären sie in strengem Sinne gleich möglich, so wäre ja das wirkliche Auftreten eines dieser Umstände ein absoluter $Z$ ufall, der in der objectiven Welt undenkbar ist.

Folglich ist das Zusammenfallen des Grenzwerthes des Möglichkeitscoëfficienten mit einer mathematischen Wahrscheinlichkeit, soweit es näherungsweise durch die Erfahrung constatirt wird, nur durch die Annahme zu erklären, dass die unberechenbare Mannigfaltigkeit der Umstände, welche das Ereigniss hervorufen oder verlindern eine genügende A nialogie des alsoluten Zufallsspiels mit $E$ guinstigen gegen $Z-E$ ungünstige Chancen darbiete.

15. Kehren wir nun zur Botrachtung der Massenerscheinungen der menschlichen Gesellscliaft zurïek, und zwar insbesondere derjenigen, deren Einzelvorgänge auf bewusstem Handeln beruhen. Gebören dieselben in die Classe der "concreten", so ist damit schon gesagrt, dass die Finzelfälle hinsichtlich ihrer Entstehungsbedingungen und ihrer Motivirung sehr verschiedenartig wird. Gehören die betreffenden Massenerscheinungen ausserdem zu den "unverbundenen" - und die Verbundenheit ist ja unter den concreten Massenerscheinungen ganz unerwiesen - so sind die Linzelfälle wenigstens in Bezug auf das Zustandekommen des empirisehen Möglichkeitscoëfficienten von einander unałhängig.

Verhalten sich die einzelnen Möglichkeitscoëfficienten in einer Anzahl von Versuchsreilien 1) nachweislich wie Nïherungswerthe einer constanten mathematischen Wahrscheinlichkeit, so ist dadurch dargethan, dass die allgemeinen Bedingungen der Möglichkeit des Ereignisses trotz der Schwankungen der einzeinen Quotienten in den verschicdenen Beobachtungsreihen unverändert geblieben sind.

Was aber ist mit diesem Nachweise gewonnen?

"Allgeneine Bedingungen der Möglichkeit" eines Ereignisses das nach der Voraussetzung unter höchst mannizfaltigen, im Ein»elnen unbekamnten, subjectiven und objectiven Linflüssen zu Stande kommt - das ist ein von vornherein sehr unklarer und problematischer Begriff. Durch den eben erwähnten Nachweis aber wisd gezeigt, dass er wirklich objective Bedeutungr besitzen und auf einen bestimmten mathematischen Ausdruck gebracht werden kann, der

1) Unter ..Versuch" ist jeder mitgezïhlte Fall zu verstehen, in dem das besontere Eroigniss eingetreten oder nioht eingelreten is?. 
seinerseits auf der Vorstellung eines Zufallsspiels mit einer bestimmten Zahl günstiger und ungünstiger Chancen beruht.

Es gibt also dann doch etwas allgemeines und bleibendes in den concreten Massenerscheinungen, deren Einzelfälle für unsere Betrachtung nur den Endausgang gemeinschaftlich haben. Aber es handelt sich in diesen Fälen nur um allgemeine und bleibende Möglichkeiten, die für uns nicht unmittelbar fassbar sind.

16. Durch dieses Gleichbleiben der Möglichkeitsbedingungen einer Massenerscheinung wird aber, auch wenn die Einzelfälle aus bewussten (aber sehr mannigfaltigen) Motiven cntstehen, die individuelle Willensfreiheit, die doch nicht als bestimmungslose Willkür aufunfassen ist, durchaus nicht in Frage gestellt, Jeder Einzelfall bleibt in seiner besonderen Causalitätsliette; er wird nur registrirt als Wirkung eines der unzähligen möglichen Ursachensysteme, die das Ereigniss zu Stande bringen können.

Die Beziehungen der Finzelfälle unter sich können nähere und entferntere sein, aber ausdriicklich zugestanden ist ja, was im Interesse der Willensfreiheit anch zu fordern wäre, dass sie im Bezug auf das Zustandekommen des Möglichleitscö̈ficienten von einander unabhängig seien. Dies heisst, lass cine etwaige starke Abweichung von dem normalen Möglichkeitscoëfficienten, die sich in einen Theile der Versuche herausstellte, in kciner Weise eine entsprechende Ausgleichung in einem andcren Theile bedingen darf, ebensowenig, wie bein Roulettespiel cine Reihenfolsce von awanzigmal "Roth" irgend welchen Einfluss auf die folgenden Spielresultate haben kann und darf. Niemand ist also z. 13. genïthigt sich aufzubängen, um das Budget der Selbstmorde vollständig zu machen.

Ein sogenannter gesetzlicher Einfluss des nur als Resultat und nicht als herrschende Formel auftretenden Möglichkeitscoüfficienten ist ja ausdrücklich ausgeschlossen, da wir nur unverbundene concrete Massenerscheinungen vor uns haben; ganze Versuchsreihen körnen sehr weit von der Wahrscheinlichlieit abweichen, wie beim Roulettespiel zwanzigmal diesclbe Farbe nach einander folgen kann; es ist dann eben etwas geschehen, was a priori selr unwahrscheinlich, aber doch nicht, unmöglich war.

Aber trotz der mehr oder minder grossen Abweichungen der Einzelreihen lelirt uns die Wabrscheinlichkeitsrechnung in den hier angenommenen Fällen, dass die objective M̈̈glichkeit des Ereignisses in allen Reihen dieselbe war; ne lehrt uns verstehen, wie die grösste 
Mannigfaltigkeit des einzelnen Geschehens mit geringer Veränderlichkeit der numerischen Verhältnisse der Massenerscheinungen verbunden sein kann.

17. Dass es wirklich nur auf die den Zufall nachahmende grosse Munnigfaltigkeit der physischen oder geistigen Verursachung unter gewissen allgemeinen Bedingungen ankommt, dürfte aus folgendem Beispiel klar werden.

Man zähle nach, wie oft in einem Bande von Göthe's Werken der Iuchstabe $e$ vorkommt und wic viele Buchstaben der Band iiberhaupt enthält. Das Verhältniss der ersteren Zahl zu der letzeren stellt dann einen empirischen Ausdruck (ler Möglichkeit des Vorkommens von $e$ in der deutschen Sprache dar. In jedem anderen Bande von Göthe wird man sehr wahrscheinlich einen nahezu gleichen Näherungswerth dieses Möglichkeitscö̈fficienten finden; ${ }^{1}$ ) und wenn man den Satz eines Bandes aufbräche und aus dem fortwährend blindlings aufgewühlten Haufen der rettern so oftmal cine derselben herausnälıme, als der Band Buclistaben nählte (mit jedesmaligem Zuriickwerfen des gezogenen Buchstabens) so wïrden diese Ziehungen wiederum nahe\%u denselben Möglichkeitscoëfficienten des $e$ ergeben.

Aber hat diese, durch den phonetischen Charakter der deutschen Spraclie bedingte Stabilität des Möglichkeitscoëfficienten von $e$ oder irgend einem anderen Buchstaben die Freiheit von Göthe's Gedanken und Stil beschränkt? Gewiss nicht; er hat deutsche Worte in grosser Zahl und Mannigfaltigkeit aneinander gereiht ohne sich um die relative lläufigkeit des $e$ in seinen Worten $z u$ kümmern; welche Ideen ihn bei diesen Wortverbindungen leiteten, kommt gar nicht in Betracht, die blosse Mannigfaltigkeit und grosse Zahl der Worte genügt um die Frequenzverbältnisse der einzelnen Buchstaben nach den allgemeinen Bedingungen ihrer Möglichkeit, wie sie durch die Besonderheit der Sprache gegeben sind, hervortreten zu lassen.

Ver "phonetische Charakter" einer Sprache ist ebensowenig etwas scharf' Fassbares, wie "die allgemeinen Bedingungen der Mög-

1) Man kann dies schon aus dem intelessanten Experimente schilessen, welches Hagen schon in der ersten Auflage seiner "Wahrscheinlichkeitgrechnung" (Berlin 1837) in Betreff des Vorkommens des a in der Vorrede von Fytrlweins Mechanik angestellt hat. 
lichkeit" des Einzelereignisses ciner concreten Massenerscheinung; aber der eine wie der andere Begriff besityt gleichwohl seine bestimmte objective Bedentung, welche in vielen Fïllen in der mathematischen Wahrscheinlichkeit einen adäquaten Ausdruck findet.

Handelt es sich um generische Massenerscheinungen, so vermögen wir die wesentliehen Enstehungsbedingungen der Einzelcreignisse als gleichartig wu erkennen, und die Regelmässigkeiten der Gesammterscheinung werden uns im Allgemeinen ebenso begreiflich sein wie die etwaigen starken Schwankungen. Wir finden es ganz natürlich, dass auf den Kopf der Bevölkerung eines Landes, das weder durch eine Krisis gestört, noch in einem ungewöhnlichen wirthschaftlichen $\Lambda$ ufschwung begriffen ist, von Jahr zu Jahr eine ungeführ gleiche Getreideconsumtion kommt; und ebenso natürlich ist es, dass dieses I and, wenn es nur in normalen Jahren seinen Getreidebedarf selbst $\%$ produciren vermag, je nach den Erntecrgebnissen in den verschiedenen Jahren einen sehr stark veränderlichen Bruchtheil seiner Consumtion aus dem Auslande cinführt.

Der Uebergang von den generischen zu den concreten Massencrscheinungen ist übrigens ein allmähliger; wir sind häufig noch im Stande, Bedingungen zu erkennen, welche von grossem Einfluss auf das Zustandekommen des Ereignisses sind, aber nicht allgeme in mit zu Grunde liegen; je zahlreicher solche Bedingungen von beschränkter Tragweite auftreten, um so deutlicher erhält die Massenerseheinung den Clarakter einer coucreten, bei der cben ein gar nicht zu entwirrender Bedingungscomplex der Totalerscheinung zu Grunde liegt.

17. Also weder die generischen noch die unverbundenen concreten Massenerscheinungen stellen uns durch die ungefähre Constanz ihrer numerischen Verhältnisse vor eine Unbegreiflichkeit oder eine mechanische Gesetzmässigkeit. Denn diese Regelmässigkeiten entstehen in den unverbundenen Massenerscheinungen, ohne dass unter den Einzelfällen eine Beziehung bestände, welche auf die $\mathrm{Com}-$ pensation der Abweichungen hinwirkt; in den concreten entstehen sie dadurch, dass die Einzelfälle jeder Versuchsreilıe einen wenig veränderlichen allgemeinen Bedingungscomplex gewissermassen nach allen Richtungen hin ausprobiren und daher einen nahezu gleichbleibenden äusseren Umriss desselben ergeben; in den generischen unverbundenen Massenerscheinungen aber ergibt sich die äussere Regelmässigkeit einfach dadurch, dass jeder bcobachtetc 
Einzelfall anf dasselbe Resultat hinzielt und es mehr oder weniger genau verwirklicht; bei den verbundenen generischen Massenerscheinungen endlich waltet in den Finzelhandlungen eine für uns orkennbare und erklärliche Rücksicht auf die Erzielung cines gewissen Verhältnisses in der Totalerscheinung ob.

Unbegreiflich bliebe uns also, wie schon frither bemerkt wurde, nur die verbundene concrete Massenerscheinung - wenn sic wirklich vorkommen sollte. Denn in dieser bestände zwischen den Einzelfällen eine geheimnissvolle, unserer Erkenntniss nicht zugängliche Compensationstenden\%.

$E_{S}$ ist also wïnschenswerth zu zeigen. dass die uns bisher bekannten Regelmässigkeiten eoncreter Massenerscheinungen in diese problematische Kategorie nicht gehören.

Das Kriterium zur Unterscheidung dieser Art von Massenerscheinungen kann nur gcsueht werden in dem Grade der Divergen\% oder der "Dispersion" der Ergebnisse mehrerer Versuchsreihen.

Wenn das Vorkommen eines Ereignisses in eirer grösseren Zabl von Versuchsreihen sich so gestaltet, als ob es von einem reinen Gliicksspiel mit $E$ Chancen gegen $Z-E$ abhinge, so liegt uns olne Zweifel eine unverbundene Massenerscheinung vor. Denn im reinen Zufallsspiel, das wenigstens näherungsweise durch Roulette, Würfel u. s. w. verwirklicht werden lsann, findet ein compensatorischer $\mathrm{Zu-}$ sammenhang der Einzelfälle nicht statt.

Ist die Dispersion der Reihenergebnisse noch grösser, als sie unter der Voraussetzung eines Zufallsspiels mit constanter Wahrscheinlichkeit des Ereignisses zu erwarten wäre, so tritt die "Unverbundenheit" der Massenerscheinung noch entschiedener zu Tage. Dieser Fall ist zu vergleichen mit dem zufälligen Ziehen von schwarzen und weissen Kugeln aus verschiedenen Urnen, die von Reihe zu Reihe zufällig gowählt werden und die nicht sämmtlich schwarze und weisse Kugeln in gleichem Verhältnisse enthalten, sondern ungenau und zwar mit zufälligen Fellern gefüllt worden sind.

Zeigte sich dagegen in einer grossen Zahl von Versuchsreihen eine entschieden geringere Dispersion der einzelnen Resultate, als dem Schema eines Glüclistpiels entipricht, so würde es mit der steigernden Zahl der Versuchsreihen immer walusclieinlicher, dass eine Bezielung zwischen den Einzelfällen besteht, welche auf das Zustandekommen eines festen Endverhältnisses direlst hinwirkt.

Wenn die mathematische Theoric zeigt, dass bei einem reinen 
Glitekspiel die Ceberschreitung einer gewissen Alwcichung von dem wahrsehcinlichsten Resultate ${ }^{1}$ ) die Wahrseheinlichkoit $1 / 2$ hat, so ist mit grosser Wahrscheinlichkeit on erwarten, dass bei einem wirklichen Gliickssuiel, das sich dem reinen Zufallsspiel genïgend amiatiert. in 1000 Versueben jene $A$ bweichungsgrenze nabezu 500 Mal uicht erreicht und auch nahezu 500 Mal iibersdreiten werde. Sollte sich nun aber herausstellen. dass die sämmtlichen 1000 Versuchsresultate in nerhalb der bezeichneten Grenze blieben, so wäre of fant gewiss dass die Versuehe nicht den Bedingungen cines Glïcksepiels mit festen Chancen entsprachen, dass irgend eine unbekannte Ursache thititig gewesen, um grössere Abweichungen von dem wahrscheinliehsten Eudresultate \%u verhindern.

Es wäre \% B. anzunchmen, dass dem Ziehenden dic Kugeln der einen oder anteren Art in der Urne mit Riicksicht auf das Endresultat irgendwic in die Hände gespielt worden seien.

18. Die Wichtirrkeit der Wahrscheinlichkeitsrechnung für die Erlienntniss der inneren Constitution der Massenerscheinungen erscheint hiernach in einem neuen licht.

Wic aber erfihrt man aus der Theorie, ob eine concrete Massenerscheinung den Schena des Zufallsspiels mit constanten (oder auch zufällig schwankenden) Chancen entspricht, oder ob die Divergen\% der Einzelresultate so gering ist; dass man eine innere Verbundenheit derselben annehmen muss?

Diese Frage läst sich nur mathematisch beantworten, und ich kann daher hier nur eine ungefialure Vorstellung von ihrer Lösung geben. Näheres findet man in meiner Abbandlung ïber das Geschlechtsverhältniss der Geborenen. ${ }^{2}$ )

Wir betrachten nur solche aus Massenbeobachtungen abgeleitete Zahlenverbältnisee, die von vorn herein als empirische Nälıerungswerthe ciner mathematischen Wahrscheinlichkeit oder doch als Functionen von solchen Wahrscheinlichkeiten angesehen werden

1) Beim IIeransgreifen z. B. von je 1000 Fugeln aus ciner Lóne, dic unbegrentt viele schwarge und weisse liugeln in gleicher Anzahl enthiclte. wäre das wahrscheinlichste Resultat 500 schwarze und 000 weisse Kugeln. Ws beatände ungefthr die Wanrscheinlichkeit ${ }_{i}$ dafïr, dass eine der beiden Farben mit we nig gteng 20 Kugeln mehr auftrite, als dic anderc. also in dem Verhältniss von wenigstens 510 gegen 490.

2) Ilildebrand und Conrad, Jabrbücher, XXVII., S. 209. 
können. Die Zahl der Gestorbenen eines Jahres dividirt durch die Zabl der Lobenden am Anfang des Jahres ist zwar ein Bruch, aber keine Wahrscheinlichkeit, da ausser jenen Lebenden auch noch die im Laufe des Jahres geborenen Kinder dem Sterben ausgesetzt werden und einen gewissen Tribut von Sterbefällen zu der Gesammtzahl beitragen. Die Zahl der Knabengeburten dividirt durch die Gesammtzahl der Geburten eines Jahres dagegen kann als eine empirische Wabrscheinlichkeit aufgefasst werden, denn jede Geburt ist eine Erprobung, ob ein Knabe oder ein Mädchen geboren wird, und aus einer grossen Anzahl solcher Proben ergibt sich also ein empirischer Möglichkeitscoëfficient $v$ für die Knabengeburt. Das Verhältniss der Knabengeburten zu den Mädchengeburten aber ist keine Wahrscheinlichkeit, wohl aber eine Function der eben angeführten Wahrscheinlichkeit $v$; denn man lat die Bezichung: $p=\frac{i}{i-v}$

Angenommen nun, man habe in $n$ Reihen von je $z$ Versuchen die empirischen Wahrscheinlichkeiten oder Möglichkeitscoëfficienten eines Ereignisses bestimmt, die mit $\mu_{1}, \mu_{2}, \ldots \mu_{n}$ bezeichnet werden mögen. Sind dieselben wirklich als Näherungswerthe einer bestimmten, der objectiven Möglichkeit des Ereignisses entsprechenden matbematischen Wahrscheinlichkeit anzusehen, so ist der wahrscheinlichste Werth dieser unbekannten objectiven Wahrscheinlichkeit $W$ gleich dem aritlimetischen Mittel $m$ aus den Grössen $\mu_{1}, \mu_{2}$ u. S. w., und ferner müssen sich diese letzteren Werthe, wenn ihre Anzahl einigermassen gross ist, zu beiden Seiten des Mittelwerthes (den wir an die Stelle des wahren Werthes $\boldsymbol{W}$ setzen dürfen) in einer der Theorie entsprechenden Weise gruppiren.

Selbst bei mässiger Grösse von $n$ dürfte man wenigstens erwarten, dass die theoretisch bestimmte "wahrscheinliche" Abweichung (nämlich diejenige, die ebenso oft, sei es nach der positiven oder nach der negativen Seite, nicht erreicht, wie überschritten wird) durch die wirkliche Vertheilung der Werthe $\mu$ näherungsweise bestätigt werde, dass also naheza die eine Hälfte der $\mu$ innerhalb, die andere ausserhalb der theoretisch festgestellten Grenzen falle.

19. Der theoretische Ausdruck der "wahrscheinlichen" Abweichung ist nüherungsweise $\pm \frac{\rho \sqrt{2 m(1-m)}}{\sqrt{*}}$, wenn $\varrho$ die Constante 
0,4769 darstellt, und $m$ und $z$ die oben angegebene Bedeutung haben. 1)

Die wahrscheinliche Albweichung ist also umgekehrt proportional der Quadratwurzel aus der Bcobachtungszahl einer Reihe.

Je grösser diese Beobachtungszahl $z$, desto kleiner wird die wahrscheinliche Abweichung $r$, desto grösser also die Zuverlässigkeit oder Präcision dicser Näherungsbestimmung von $W$.

Die sämmtliehen $\mu$ haben, wegen des gleichbleibenden $z$, trotz ilırer verschiedenen Distanzen von $m$ dieselbe "Präcision", und zwar ist der Ausdruck dieser für dic Theorie wichtigen Charakteristik gleich $\frac{\theta}{r}$ oder $\frac{\sqrt{2}}{\sqrt{\frac{1}{2 m-m}}}$

Bezeichnen wir diese Präcision der Einzelbestimmung der " (dic nur bekannte Grössen enthält) mit $h$, ferner allgemein dic $\mathrm{Ab}$ weichung oder den Fehler des einzelnen $\mu$ mit $x$, und das Product $h x$ mit $u$, so stellt die Theorie eine besondere Function von $u$ auf, mit deren Hülfe man sofort die Wahrscheinlichkeit bestimmen kann, dass der Fehler zwischen $+x$ und $-x$ liege. Die Werthe dieser Function, die wir mit $F_{n}$ bezeichnen wollen, sind in einer nach dem Argument $u$ von 0 an fortschreitenden Tabelle zusammengestellt ${ }^{2}$ ) und der zu jedem $u$ gehörende Tabellenwerth stellt die Wahrscheinlichkeit eines Fehlers zwischen den Grenzen $+\frac{\pi}{i}$ und $-\frac{u}{h}$ dar.

So erhält man die theoretische Vertheilung der ungenauen Einzelwerthe für beliebige Strecken zu beiden Seiten (symmetrisch) des wahren Werthes, und bei hinreichend grosser Zahl der Beobachtungsreihen muss die Vertheilung der $\mu$ um den Mittelwerth $m$, der dem wahren Werthe möglichst nahe kommt, wenigstens näherungsweise der Theorie entsprechen, wenn wirklich dic beobachtete Massenerscheinung auf das Schema eines Zufallsspiels mit der Wahrscheinlichkeit $W$ für das Eintreten der Ereignisse zurückfülhrbar ist.

Es könnte aber auch vorkommen, dass die beobachtete Vertheilung der $\mu$ sich noch zur Genüge nach der Function $F_{u}$ dar-

1) Wenn $z$ eine grosse Zahl ist, kann man ohne crheblichen Fehlur statt $m$ das nus einer einzigen Versuchsreihe sich ergebende $u$ nchmen.

2) Ein Auszug aus dieser 'Tabolle ist im Anhang beigefügt. 
stellen liesse, aber nur, wenn man statt des oben angefibhrten $h$ irgend einen kleineren oder grösseren Werth annähme. Inı ersteren Falle wäre die Präcision der Einzelbestimmung kleiner, als sie theoretisch unter der Voraussetzung sein müsste, dass die Bedingungen der $A$ bweichungen vom walren Werthe denjenigen analog seien, welche beim Ziehen von Kugeln aus einer Une mit schwarzen und weissen in gleichbleibendem Verhältniss vorliegen. Ausser dieser letzteren Fehlerursache, die ich die "combinatorische" nennen will, ${ }^{1}$ ) wird also in solchen Fällon noch cine weitere vorhanden sein, wie z. B. die oben erwähnte Verschiedenhcit der Umen von Reihe zu Reihe mit zuftilligen Fehlem des Füllungsverhältnisses. Diese Fehlerquelle mag die "physisclie" genannt werclen.

Wäre daggegen die Annalime eines grösscren $h$ erforderlich, so müsste durch eine besondere Ursache die Präcision der Einzelbestimmungen der "über diejenige hinaus gesteigert sein, welehe nach Analogie der Ergebnisse eines normalen Zufallsspiels zu erwarten wäre. Diese Ursache wïrde nicht absolut sicher wirken, es blieben noch a ufällige Abweichungen von dem wahren Werthe übrig, und eben wegen dieser Zufälligkeit der Fehler behielte dic Funktion $F_{u}$ ibre Bedeutung.

Also wäre eine allgemeine Regel zur Erkennung der "verbundenen" concreten Massenerscheinungen: man untersuche, ob die wirkliche Vertheilung der beobachteten $\mu$ auf eine erheblich grössere Präcision hinweist, als die durch den Ausdruck $\frac{\sqrt{z}}{\sqrt{2 m(1-m)}}$ gegebene.

In der Praxis würde es schon genügen zu constatiren, dass die durch Abrählung gefundene wabrscheinliche Abweichung bedeutend kleiner wäre, als die theoretisch bestimmte.

20. Diese Untersuchungen setzen jedoch nicht nur vicle Beobachtungen, sondern viele Beobachtungsteilien voraus. Es ist nun jedenfalls wünschenswerth, ein Kriterium zu besitzen, welches auch bei einer kleineren Anzahl von Reihen den Charakter der Massenerscheinung einigermassen andeutet. Das folgende diurfte in vielen Fällen genïgend scin.

Die Vertheilung ungenauer Einzelbestimmungen um einen festen,

1) In der oben angeführten Abhandlung über das Geschlechtsverhältniss habe ich diese Fehlerursache die "statistische" genannt. 
wahren Werth erfolgt immer nach der Funktion $F_{n}$, wenu die Entstehung der Fehler eine zu fïlli ge ist, woru namentlich anch erforlert wird, dass statt jeter positiv wirkenden Fehlerursache ebenso leicht eine gleiche, aber negativ wirlicnde aufteten könne und dass die Gesummt\%ahl der Felilerursachen eine sehr grossc sci. Die Natur der bestinmten Grösse und die Art der Mlesung int vollkommen gleichgïltig.

Der walrscheinlichste Werlh der gemessenen (irösse ist (bei gleichen Gentuigkeitsbedingungen in allen Einzelbostimmungen) dati arithmetische Mittel der Einzelwerthe, und der wahrscheiuliche Fehler (in der oben angegebenen Bedeutung) kann direct durch die $\Lambda$ bweichungen der Einzelwerthe vom Mittel ausgedrüelit werden. Isezeichnet man nämlich die Summe der Quadrate dicser $A$ b weichungen, also in unserem Beispiele $\left(\mu_{1}-m\right)^{2}+\left(\mu_{2}-m\right)^{2}-\cdots\left(\mu_{n}-m\right)^{2}$ mit $\left[\delta^{2} /\right.$, so ist die "wahrscheinlicho Abweichung" $r$ der Jinzel-

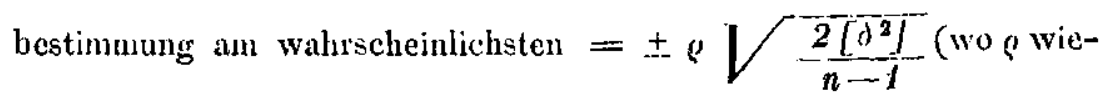
$\mathrm{der}=0,4769)$ und dennach die Prïcision $h=\frac{0}{r}=\sqrt{\frac{\bar{n}}{2\left[\overline{\partial^{2}}\right]}}$

Der wahrseheinliche fehler dieses $h$ wieder ist nalıezu gleich $\frac{\varrho h}{V}$, also umgekehrt der Quadratwurzel aus der Zahl der Versuchsreihen proportional.

Somit haben wir zwei von einander unabhängige Arten der Bestimmung des wahrscheinlichen Fehlers und der Präcision. Die muletzt betrachtete, welche die "physikalische" heissen mag, gilt allgemein für alle Grössen, deren Einzelbestimmungen oder Messungen \%ufälligen Störungen ausgesctat sind, also auch fïr die aus verbundenen Massenerecheinungen abgeleiteten Verhältnisszahlen, wenn nur die Bedingung der '/ufälligkeit der Störungen erfüllt ist. Die andere $A$ rt der Ableitung der ''räketion dagegen, die wir die "combinatorische" nennen wollen, passt nur dam, wenn die I3eobachtungen jeder Reihe der empirischen Ermittlung einer constanten Wubrecheinlichkeit durch z Versuche cines reinen Zulallsspiels entsprechen.

Durch Vergleichung ler nach beiden Arten berechneten Präcision exhalten wir also entwoler: 


$$
\text { a) } \quad \text { } \sqrt{\frac{z}{2 m(1-m)}}=\sqrt{\frac{z-1}{2 \frac{n-1}{\left[\delta^{2}\right]}}} \text {, oder }
$$

Die Kriterien a) oder b) charakterisiren die unverbundenen concreten Massenerscheinungen, und zwar ist die Gleichung $a$ ) von besonderem Inseresse, weil sie eine Beziehung zwischen der Zahl z der Versuche in jeder Reihe und den Fehlern der Resultate der $n$ Versuchsreihen darstellt.

Die Ungleichheit $c$ ) dagegen würde auf cine verbundenc concrete Massenerscheinung hindeuten, indem nur durch eine besondere innere Verbindung der Einzelereignisse zu erklären wäre, dass die nach der physikalischen Methode, also unmittelbar aus den beobachteten Abweichungen vom Mittel, bestimmte Präcision wesentlich grösser sein könnte, als die nach der combinatorischen Methode berechnete.

Statt der Präcisionen kann man natïrlich auch die nach beiden Methoden bercchneten wahrscheinlichen Fehler zur Aufstellung der gesuchten Kriterien verwenden.

21. Kann die untersuchte statistische Verhältnisszahl nicht unmittelbar als eine mathematische Wahrscheinlichkeit, jedoch wohl als Function einer solchen aufgefasst werden, so wird der wahrscheinliche Fehler der Einzelbestimmung näherungsweise ausgedrückt durch das Product des ersten Differentialquotienten der Function nach jener Wahrscheinlichkeit als Veränderlichen und des wahrscheinlichen Fchlers der Einzelbestimmung dieser Wahrscheinlichkeit, ausgedrïckt nach der combinatorischen Methode; andererseits aber kann man die unmittelbar gefundenen Verhältnisszallen wieder nach der physikalischen Methode, d. h. nach der Methode der kleinsten Quadrate behandeln und somit einen zweiten Ausdruck für den wahrscheinlichen Fehler der Linzelbestimmung gewinnen; durch Vergleichung dieser beiden Ausdrücke oder der aus ihnen durch Division in $\varrho$ abgeleiteten Präcisionen gelangt man wieder, wie oben, zur Cbarakterisirung der untersuchten Massenerscheinung. In vielen Fällen ist es der Anschaulichkeit wegen zweckmässig, 
dic von der Statistik gelieferten Möglichkeitscoëfficienten als empirische Ausdrücke einer Summe uusammengesetzter Wahrscheinlichkeiten, oder, wie wir der Kürzc wegen sagen wollen, als empirische "Totalwahrscheinlichkeiten" aufzufassen. Es entspricht der Wirklichkeit besser, wenn wir z. B. annehmen, dass die mathematische Sterbenswahrscheinlichkeit der Neugcborenen im ersten Lebensjahre für verschiedene Bevölkerungsgruppen verschieden sei und "war gleich $c_{1}, c_{2}, c_{3} \ldots c_{n}$; wenn nun ausserden die Wahrscheinlichkeiten, dass ein auf's Gerathewohl bezeichnetes ncugeborencs Kind einer dieser Gruppen angehöre, ausgredrückt werden durch $\gamma_{1}, \gamma_{2}, \gamma_{3} \ldots \gamma_{n}$, so ist die totale Sterbenswahrscheinlichkeit $k=c_{1} \gamma_{1}+c_{2} \gamma_{2}+c_{3} \gamma_{3}+\ldots c_{n} \gamma_{n}$

Dieselbe bleibt constant, wenn die einzelnen $c$ und $\gamma$ keine Aenderung erleiden. Dass die aus vielen Versuchsreihen abgeleiteten Möglichkeitscoëfficienten die Annahme einer constanten Totalwahrscheinlichkeit rechtfertige, ist ganz in derselben Weise erfahrungsmässig nachzuweisen, wie wenn man eine einfache Wahrscheinlichkeit voraussetzt, und auch die oben aufgestellten Kriterien zur Classificirung der Massenerscheinungen bleiben bei bciden Anschauungen umgeändert.

22. Diese Unterscheidung verdient namentlich Beobachturg, wenn ein Theil der $;$ absolut gleich 0 zu setzen ist, $d$. h. wenn Versuche oder beobachtete Fälle mit in Rechnung gezogen werden, in denen das besondere Ereigniss $u \mathrm{nmöglich} \mathrm{eintreten} \mathrm{kann.} \mathrm{Die}$ Zahl $G$ der Geburten eines Jahres dividirt durch die Gesammtzah! $L$ der Einwohner eines Landes zu Anfang des Jahres kann z. B. als Näherungswerth einer zusammengesetzten Wahrscheinliclikeit dieser Art betrachtet werden. Greifen wir blindlings ein Individuum aus der Bevölkerung heraus, so bestehe die Wahrscheinlichkeit $c_{1}{ }^{\mathbf{D}}$ ) dafür, dass dasselbe männlichen Geschlechts sei, in welchem Falle natïrlich die Wahrscheinlichkeit des Gebärens $\gamma_{1}$ gleich 0 ist. Ferner sei die Wahrscheinlichkeit $c_{2}$ vorhanden, dass man unter den weib-

1) Die Zahl der männlichen Inlividuen, die im Anfang des Jahres im Lande vorhanden war, dividirt durch die Gesammtzahl der Bevölkerung ist nur ein cinzelner Näherungswerth von $c_{1}$; diese Grösse selbst ist die durch die allgemeinen Verhältnisse bedingte abstracte Wahrscheinlichkeit, dem männlichen Geschlechte anzugehören, die constant bleiben kann, auch wenn das empirische Verhälniss der beiden Geschlechter von Jahr zu Jahr gewissen Schwankungen unterliegt. 
lichen Individuen anf ein solches stosse, das durch zu geringes oder " $\mathrm{u}$ hohes Alter alsolut niclut gebärfihing ist, so dass das entsprechende $\gamma_{2}$ wieder $=0$ sein muss. Dic Wahrscheinlichkeit aber, eine gebürfähige weibliche Person zu treffen, sei $c_{3}$, und $\gamma_{3}$ sei die nittlere Wahrscheinlichkeit, dass eine solche im Laufe eines Jahres wirklich gebären wird - wobei wir der Einfachleit wegen von einer weiteren Zerlegung der Gebärfühigen in Gruppen mit verschiedener Wahrscheinlichlejt des Gebärens (namentich in Verheirathete und Ledige) absehen.

Ist nun $F$ die Zahl der Gebärfühigen, so ist $\frac{\eta}{\eta}$ ein Näherungswerth fïr $c_{3}$ und $\frac{i}{F}$ ein solcher für $\gamma_{3}$, mithin stellt das Verhältniss ${ }_{L}^{\prime}$ einen Näherungswerth der zusammengesctzten Wahrscheinlichkeit $c_{3} \gamma_{3}$ dar. Dieses Product ist jedenfalls weniger interessant, als jeder der beiden Factore für sich, die freilich auch weit schwieriger festzustellen sind.

Bildet man nun die empirischen Quotienten $\frac{6}{i}$ fïr eine Reihe auf einander folgender Jahre, so wirl eine Anwendung der Formeln a), b), c) (\$20) im Allgemeinen keinen Zweck haben, sclbst wenn die einzelnen Quotienten sich als zutallige Modificationen eines festen Werthes verhalten und denmach die Anwendung der Methode der kleinsten Quadrate gestatten. Es würden nämlich die einzelnen Werthe des Quotienten $\frac{r}{\sigma}$ von einem Jahre zum anderen sich nicht so ändern, wie es der Fall scin müsste, wemn sie durch ein Glücksspiel in je $L$ Versuchen erlangten Näherungswerthe der objectiven Wahrscheinlichkeit $c_{3}$ wären. Demn jene Werthe sind nicht genïgend unabhängig von einander, da in zwei auf cinander folgenden Jahren die Hauptmasse der Lebenden sowohl wie cler Gebïrfähigen aus denselben l'ersonen besteht. Auch die Quotienten $\frac{F_{F}^{*}}{F^{\prime}}$ stehen in auf' einander folgenden Jahren nicht in der gegenscitigen Unabhängigkeit, wie sie den empirischen Einzelbestimmungen einer constauten Wahrscheinlichkeit $\gamma_{3}$ zukommen müsste.

Aber auch abgeselien von solchen speciellen IHindernissen sind Möglichkeitscö̈fficienten, die in ihrem Nenner gewissermassen einen unnöthigen Ballast mit sich führen, \%ur theoretischen Untersuchung wenig gecignet.

23. Man kann diese Schwierigkeit ungehen, indem man sich auf relative Wahrscheinlichiciten beschränkt, um den Grad der 
Regelmüssigkeiten gewisser Massenerscheinungen nach den oben angegebenen Kriterien zu untersuchen.

Einen empirischen Näherungswerth der absoluten IIeirathswahrscheinlichkeit während eines Jahres in einem gegebenen Lande liönnte man nur mit der melır oder weniger unsicheren Zahl der "Ileirathsfähigen" als Nenner ausdrüicken. Sehr zuverlässior dagegen lässt sich durch den Quotienten aus der Zahl der heirathenden Junggesellen und der Gesammtzahl der Heirathen empirisch die relative Wahrscheinlichkeit darstellen, dass eher ein Junggeselle als ein Wittwer heirathet. Diese empirischen Werthe können sich grïnden auf eine dureh die socialen, Alters- und sonstigen Verhältnisse der Bevölkerung bediugte, constante Wahrscheinlichkeit dafür, dass die heirathenden Männer Innggesellen seien; ob und wie weit dies wirklich der Fall sei, lässt sich num nach den Formeln des $§ 20$ untersuchen.

Man muss sich übrigens darauf gefasst machen, dass in vielen ja vielleicht in den meisten Fällen auch solche Verhältnisszahlen, die als Näherungswerthe von absoluten oder relativen $W$ ahrscheinlichkeiten aufgefasst werden $k$ önnen, bei genauerer Prüfung auf diesen Charakter keinen Anspruch belalten. Wenn \%. B. in einer längeren IReihe von Jahren ein solches Verhältniss auch nur geringe Schwankungen zeigt, so ist man doch nicht wohl berechtigt, diese Zahlen auf eine constante, durch die allgemeinen Umstände und Möglichkeitsbedingungen erzeugte mathematische Wahrscheinlichkeit zuriickzuführen, wenn die grösseren Abweichungen vom Mittelwerth der beobachteten Zahlen entschieden häufiger vorkommen als die Kleineren.

Wir liaben dann nur ein rein empirisches Gleichbleiben der beobachteten Verhältnisszahlen, das mit der Wahrscheinlichkeitsrechnung keinen bestimmten Zusammenhang besitzt. Insbesondere ist es dann auch ein rein empirischer Schluss, dass die Beobachtungen des nächsten Jahres wieder ein ungefälur gleiches Verhältniss ergeben werden; denn wir sind nicht berechtigt, nach den Regeln der Wahrscheinlichkeitsrechnung Fehlergrenzen für das Ergebuiss der nächstjährigen Beobachtungen anzugeben, wenn in der vorliegenden längeren Reihe von Jahren die $\Lambda$ bweichungen der Einzelresultate vom Mittel sich so ganz und gar abweichend von der Wahrscheinlichkeitstheorie vertheilen.

24. Das eben Gesagte gilt mit noch grösserer Bestimmtheit, 'wenn die beobachteten Verhältnisszahlen in einer Reihe von Jahren 
sich zwar nur wenig, aber mit anbaltendem Vorherrschen der einen oder der anderen Richtung ändern. Wenn $\%$ B. die beobachteten Verlhältnisszahlen awanzig Jahre nach einander immer zunehmen und dann vielleicht ebenso viele Jahre hindurch fortwälrend abnehmen, so kann von zufülligen Störungen eines constanten Grundwerthes gar keine Rede mehr sein. Daher ist dic Methode der kleinsten Quadrate von vorn herein auf solche Zahlenreiben nicht mehr anwendbar.

Man kann nun freilich auch bei zeitweilig andauernder bestimmter Richturg der Veränderungen formell in jedem Jahre eine mathematische Wahrscheinlichkeit als Charakteristik der physischen Möglichkeit der untersuchten Ereignisses voraussetzen; aber diese Wahrscheinlichkeit muss dann von Jahr zu Jahr veränderlich gedacht werden, und zwar nicht durch zufällige Störungen, sondern nach besonderen, uns unbekannten Bedingungel. Man kann nun zur Erforschung dieser Bedingungen und der Grösse ihres Einflusses auf die Aenderung der Wahrscheinlichkeit übergehen; aber die uns hier zunächst interessirende Frage, die Anwendbarkeit der Formeln des $\S 20$, kanu für Massenerscheinungen dieser Art nicht weiter verfolgt werden. Nur wenn es gestattet ist, aus einer langen Reihe von Jahresresultaten, die im ganzen eine vorherrschende Zunahme oder Abnahme der beobachteten Verhältnisszahlen zeigen, einzelne noch hinlänglich grosse Stüclse auszusondern, in denen die Veränderlichkeit der жu Grnnde liegenden Wahrscheinlichkeit gegenüber den zufälligen Schwankungen der Beobachtungswerthe als unbedeutend angesehen werden darf - nur dann hat es einen $Z$ weck, jene Formeln auf solche Strecken zur Charakteristik der vorliegenden Massenerscheinung au benützen.

Es wäre von geringem Nutzen, wenn man ïber die Veränderlichkeit der vorausgesetzten mathenatischen Wahrscheinlichkeit eine Hypothese aufstellen wollte, indem man sie algebraisch durch eine Curve oder auch durch eine geneigte oder gebrochene Linie darzustellen suchte. Es wäre dann nach der Methode der kleinsten Quadrate leicht, die Linie so $z \mathfrak{u}$ bestinmen, dass die beobachteten Zahlen so wenig wie möglich von ihr abweichen, aber die Annabme dieser Norm für die Veründerung der objectiven Wahrscheinlichkeit bliebe trotzdem eine willkürliche. Diese Veränderung erfolgt überhaupt nicht nach einem mathematisch-mechanischen "Gesctze"; sie ist lediglich symptomatisch für die Flüssigkeit und Veränderlichkeit 
der äusserst zahlreichen und mannigfaltigen Bedingungen, die wir im Einzelnen nicht verfolgen können, deren Gesamntwirkung wir aber in der Massenerscheinung gleichsam "aus der Vogelschau“ überblicken.

25. So werden wir zu einer weiteren wichtigen Eintheilung der zur Darstellung von Massenerscheinungen dienenden statistischen Reihen geführt. Die eine, und allem Anscheine nach weitaus zablreichste Classe derselben umfasst die symptomatischen Reiben, die einen mehr oder weniger veränderlichen menschlich-gesellschaftlichen Zustand durch gewisse numerische Symptome charakterisiren. Deutet eine solche Reihe auf eine anhaltende Entwicklung der untersuchten Momente zum Besseren oder zum Schlechteren hin, so besitzt sie einen historisch-individuellen Charakter und man kann sie als eine evolutorische Reihe bezeichnen. Bewegen sich die Zahlen der Reihe in längeren oder kürzeren Zeiträumen ohne durchschlagende Tendenz und auch nicht der Theorie der zufälligen $\mathrm{Ab}-$ weichungen gemäss, auf und nieder, so mag eine solche Reihe eine oscillatorische heissen. Dieselbe wird zu einer periodischen, wenn wenigstens die $R$ i chtung der Bewegung sich mit einer erkennbaren Regelmässigkeit in der Zeit, z. B. nach den Jahreszeiten, ändert.

Dieser Classe der symptomatischen Reihen steht nun gegenüber die Classe der typischen Reihen. Alle Glieder einer solchen Rcihe sind mehr oder weniger genaue Darstellungen eines constanten numorischen Typus, der in seinem Hervortreten zufälligen Störungen ausgesetzt ist.

Wegen dieser Zufälligkeit der Abweichungen kann auf alle typischen Zahlenbestimmungen die Methode der kleinsten Quadrate angewandt werden, d. h. man darf als wahrscheinlichsten Werth der zu Grunde liegenden festen Grösse das arithmetische Mittel aus den Einzelbestimmungen annehmen (wenigstens bei gleichem Gewicht derselben) und man kann nach jener Methode die wahrscheinliche Abweichung und die Präcision der Einzelbestimmungen sowohl wie des Mittels berechnen.

Die Glieder einer typischen Reihe sind entweder absolute oder Wahrscheinlichlejtsgrössen. Im ersten Falle betrachtet man sie einfach als Ergebnisse irgend eines, zufälligen Fehlern unterworfenen, Messungs- oder Bestimmungsverfahren, ohne auf ihre besondere Natur Rücksicht zu nehmen. Solche Grössen lassen nur die Methode der kleinsten Quadrate zu. 
Im anderen Falle aber können die Reilienglieder als Wahrscheinlichkeiten oder als Functionen von Wahrseheinlichkeiten aufgefasst werden und diese besondere Kategoric von typischen Grössen lïsst sich wieder nach den Formeln des $\$ 20$ in drei Classen verlegen, nämlich in:

1) typische Walırscheinlichkeitsgrössen mit normaler D ispersion, entsprechend der Formel a) und den Bedingungen eines reinen Glücksspiels mit schwaryen und weissen Kugeln in constant bleibendem Verbailtniss;

2) typische Wahrscheinlichkeitsgrössen mit übernormaler Dispersion, entsprechend der Formel b) und einem Glïchsspiel nit schwarzen und weissen Kugeln in Verhältnissen, die reihenweise zufällig um einen Mittelwerth herum variiren;

3) typische Wahrscheinlichkeitsgrössen mit unternormaler Dispersion, entsprechend der Formel c) und einem unregelmässigen Spiel, bei dem clurch absichtliche Einwirkung die Ergebnisse der einzelnen Versuchsreihen dem Mittelwerthe näher gerückt werden, als es bei einem Zufallsspiel nit constanten Chancen zu erwarten wäre. 'lypische Grössen dieser Art gehören in Wirklichkeit nicht mehr zu den Wahrscheinlichkeitsgrössen, sondern haben nur die Form derselben.

Nachdem wir nun die Theorie und die Classificirung der Massenerscheinungen im Allgemeinen betrachtet haben, gehen wir $z u$ einigen specielleren Erörterungen über.

\section{Absolute typische Grössen.}

26. Hat man eine grössere Anzahl von Bestimmungen gleichartiger Grössen, so sind diese Einzelwerthe als typisch, d. h. als Näherungswerthe eines festen Grössentypus anzusehen, wenn sie

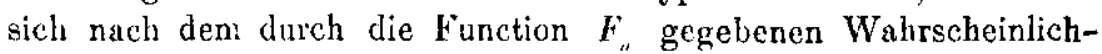
keitsgesetze des Zufalls um ihren Mittelwerth vertheilen. Der letztere stellt in diesem Falle die wahrscheinlichste Grösse des festen Grundwerthes dar und er besitzt daher als "typisches Mittel" eine weit grösscre sachliche Bedeutung als das arithmetische Mittel oder der Durchschnitt aus Grössen, welchen die obige Beziehung zu einem festen Werthe fehit.

Indess finden auch in den Fällen der letzteren Art, also wenn 
man mit gleicbnamigen Grüssen vou ganz beliebiger quantitativer Verschiedenheit $z u$ thun hat, grewisse formale Beriehungen statt, die nicht ohne Interesse sind. Es ist hier besonders auf die Untersuchungen Fechner's iiber die Potenzmittelwerthe hinzuweisen, die auch die Beachtung des Statistikers verdienen 1 ).

Das arithmetische Mittel aus einer Anzahl beliebiger Grössen ist nämlich nur ein besonderer Fall eines Potenzmittels und durch die folgenden beiden Eigenschaften charakterisirt: 1) die Summe der positiven $A b w e i c h u n g e n$ vom Mittel ist, absolut genommen, gleich der Summe der negativen Abweichungen, und 2) die Summe der Quadrate der Abweichungen ist ein Minimum.

Unter den übrigen Potenzmitteln aber gibt es namentlich noch cines von praktischem Interesse, das Fechner den "Centralwerth" nennt. Man erhält denselben einfach, indem man die gegebenen Einzelwerthe nach ihrer zunehmenden Grösse ordnet und durch $\mathbf{A b -}$ eählen den Werth bestimnit, der in der Mitte steht.

Dieser "Centralwerth", der übrigens auch früher schon beachtet worden ist, hat folgende Eigenschaften: 1) die Anzahl der von ihm abweichenden Grössen ist auf der positiven Seite eben so gross wie auf der negativen - dies folgt eben aus seiner Definition; 2) die Summe der Abweichungen auf der positiven und negativen Seite, diese sämmtlich absolut, d. h. positiv genommen, ist ein Minimum - was Fechner elementar bewiesen hat.

Der Centralwerth ist also nach seinen Kigenschaften nicht wcniger bemerkenswerth als das arithmetische Mittel, hat aber vor diesem den Vorzug, mit weit grösserer Leichtigkeit bestimmt werden zu können. Wenn man eine Masse nicht typischer Grössen durch einen Mittelwertb einigermassen charakterisiren will - eine Charakteristik, die doch immer etwas vages behält - so dürfte der Centralwerth ganz dieselben Dienste thun, wie das meist nur sehr mühsam zu berechnende arithmetische Mittel.

27. So ist z. 13. die mittlere Lebensdauer einer abgestorbenen Generation ein rein arithmetischer Begriff ohne alle typische Bedeutung; nimmt man statt derselben den Centralwerth der bei der Generation beobachteten (abgeschlossenen) Lebenslängen, also diejenige,

1) Fechner, Ueber Jen Ausgangswerth der klcinsten Abweichungssumme. (XI. B. der Abh. der math. phys. Classe ler k. Sächs. Ges. der Wissensch. Nro. 1. Leipz. 1874.) 
welche in der Reihe der nach der Grösse geordneten Lebenslängen in der Mitte steht, so erhält man die in der That ja neben der mittleren Lebensdauer längst in Aufnahme gekommene "wahrscheinliche" Lebensdauer, die für die allgemeine Charakterisirung der Vitalität und Mortalität einer Generation ebenso viel oder ebenso wenig leistet, wie jene arithmetiche Mittelzahl.

Will man eine Ziffer haben, welche im Grossen und Ganzen die Altersverhältnisse der gleichzeitigen Bevölkerung eines Landes charakterisirt und durch ihre Ab- und Zunahme Aenderungen in diesen Verhältnissen andeutet, so ist das "Centralalter" $\mathrm{d}$. b. der Centralwerth der beobachteten gleichzeitigen Altersgrössen für diese Rolle ebenso geeignet, wie das nur durch eine lange Rechnung festzustellende "Durchsehnittsalter der Lebenden". Ueberdies hat das "Centralalter" die Bedeutung, dass das Alter eines "zufällig" aus der Bevölkerung herausgegriffenen Individuum's jenen Werth ebenso walirscheinlich nicht erreichen, wie überschreiten wird. Man kann ibn daher auch als das "wahrscheinliche Alter" der gleichzeitigen Lebenden bezeichnen.

So findet man z. B. in Preussen dieses Centralalter

am 1. Decbr. 1871: männl. G. $22.38 \mathrm{Jahr}$; weibl. G. $23.27 \mathrm{Jahr}$, am 3. Decbr. 1867: $\quad 22.67 \quad$ " 23.47 "

in Frankreich:

1861: $\quad " \quad 28.70 \quad " \quad \# \quad 28.97 "$

Die preussischen Zahlen für 1867 sind etwas zu gross, weil sie durch Interpolation in eine 10jährige Altersstrecke gewonnen sind, in der alle einzelnen Jahrgänge gleich stark besetzt angenommen wurden. Für 1871 war wegen des vollständigeren Zählungsmaterials nur Interpolation in eine einjührige Strecke nöthig. Für Frankreich waren fünfjährige Altersclassen der Bevölkerung gegeben. Man sieht also aus diesen Beispielen, dass das Centralalter in jedem der beiden Länder für jedes Geschlecht xiemlich constant bleibt, dass es beim weiblichen Geschlecht etwas grösser zu sein scheint, als bei dem männlichen und dass es in Frankreich erheblich grösser ist als in Preussen. Specielleres würde man auch aus dem Durchschnittsalter der Lebenden nicht erfahren.

28. Es sei hier auch noch ein anderes Mittel erwähnt, von dem $\mathrm{Fechner}$ ebenfalls eine interessante, hier nicht weiter zu berührende mathematische Eigenschaft nachgewissen hat, nämlich der 
sogenannte "dichteste Werth", derjenige, um den sich die Einzelwerthe am dichtesten schaaren. Eine solche Anhäufung um einen besonderen Werth bildet gewissermassen den Uebergang \% den typischen Grössen und eben deswegen hat der "dichteste Werth" ") sachlich eine grössere Bedeutung, als arithmetisches Mittel und Centralwerth. Theilt man die sämmtlichen Einzelwerthe nach ihrer Grösse in Classen mit gleichen Differenzen, und zwar so, dass das Dichtigkeitsmittel in die Mitte eines Intervalls fällt, so ist a posteriori zu schliessen, dass die Einzelwerthe der untersuchten Grösse wahrscheinlicher in diese letztere Abtheilung fallen, als in irgend eine andere, und dass das Dichtigkeitsmittel überhaupt den relativ wahrscheinlichsten Werth darstellt.

Die mittlere Isebensdauer einer abgestorbenen Generation und das Durchschnittsalter einer gleichzeitigen Bevölkerung besitzen gerade deswegen eine so geringe sachliche Bedeutung, weil sich in der Nähe dieser Werthe die Einzelfülle nicht zusammendrängen, und dassclbe gilt in Bezug auf das Centralalter einer abgestorbenen Generation oder einer Bevölkerung.

Um so wichtiger aber sind diejenigen Fälle, in denen die drei hier aufgeführten Mittel genau oder nahezu zusammentreffeu.

Arithmetisches Mittel und Centralwerth fallen zusammen, wenn die Gruppirung der nach ihrer Grösse geordneten Einzelwerthe zu beiden Seiten eines Mittelwerthes symmetrisch erscheint. Dieser Mittelwerth ist dann eben zu gleicher Zeit arithmetisches Mittel und Centralwerth. Aber es ist durchaus nicht nöthig, dass auch das Dichtigkeitsmittel in denselben Punkt füllt. Denkt man sich dic Dichtigkeit der Vertheilung graphisch dargestellt, so kann z. B. die Curve gegen die Abscissenaxe, nach unten hin, convex sein, so dass der Mittel - und Centralwerth mit dem Punkte der geringsten Dichtigkeit zusammentreffen.

Ist die Curve dagegen nach unten concav ${ }^{2}$ ) und augleich symmetrisch gegen eine mittlere Ordinate, so vereinigen sich die drei Mittel in einem Punkte, und das arithmetische Mittel wird möglicher Weise zu einem typisehen, mit dem es jedenfalls nun die wichtige Eigenschaft theilt, dass verhältnissmässig die meisten Fälle sich in seiner Nähe zusammendrängen.

1) Bequemer wäre vielleicht die Bezeichnung "Dichtigkeitsmittel".

$\left.{ }^{2}\right)$ Wenigstens in der Nuhe der grössten Ordinate. 
29. Wie aber soll in ciner unverbundenen Masse einc solche symmetrische Gruppirung der Einzelwerthe nach ihrer Crösse möglich sein? Im Allgemeinen wäre dies ohne eine dircet wirksame innere Beziehung zwischen den Einzelgliedern nicht deukbar. Der Zweig der Dichtigkeitscurve auf der einen Seite des Mittels müsste massgebend sein für die Vertheilung der Dichtigkeit auf der anderen Seite, und es wäre also in solchen Fällen ein durch die ganze Masse herrschendes eigentliches Gesetz anzunehmen, das auf bestimmte numerische Ergebnissc hinwirkte - eine unbegrcifliche, kabbalistische Erscheinung.

Jene Symmetrie würde voraussetzen, dass die Einflüsse, welche den Untersuchungsgegenstand über den Mittelwerth hinaus vergrössern, ganz gleichartig wirken, wie diejenigen, welche ihn unter dem Mittel zurïckhalten.

Bei unverbundenen Massen ist dies einzig in der Weise annehmbar, dass der Mittelwerth den eigentlichen Normalwerth der Grösse darstellt, der unter der Einwirkung rein zufälliger Störungen die einzelnen Beobachtungswerthe ergibt.

Diese Bedingung der Zufälligkeit der $A$ bweichungen genügt, um eine symmetrische Vertheilung der (sehr zahlreich anzunehmenden) Finzelwerthe um das aritlmetische Mittel, das zugleich als Dichtigkeitsmittel erscheint, zu erzeugen, und diese besondere symmetrische Vertheilung, die durch eine eirtige, spe\%ielle Formel, nämlich durch die bereits erwähnte Function $F_{u}$ gegeben wird, ist diejenige, die allein mit der Unverbundenheit der Elemente einer Masse vereinbar und iiberhaupt ohne Zahlenmagie begreiflich ist.

Als typisches Mittel bezeiclinen wir num eben ein solches, das nicht nur (wenigstens näherungsweise) die drei oben betrachteten Mittel in sich vereinigt, soridern auch mit einer solchen Gruppirung der Einzelwerthe verbunden ist, die der Amnahme rein zufälliger Störungen eines Normalwertlies entspricht.

Es ist jedenfalls das IIauptverdienst Quételets auf den Gebiete der theoretischen Statistik, dass er clie Bedeutung des typischen Mittels erkannt und zugleich nachgewiesen hat, dass gewisse den Menschen betreffende Beobachtungsmassen sich annähernd der mathematischen Fehlertheorie entsprechend gruppiren. Dass er statt der Function $F_{a}$ eine elenentare Näherungsformel in Gestalt der Binomialreihe anwandte und bei der Vergleichung von Theorie und Beobachtung ein empirisches, einigermassen willkürliches Ver- 
faliren anwandte, ist von keinen Belange. Auffallend dagegen ist es, dass Quételet und seine Nachfolger in diesen Untersuchungen nicht uber die Gronzen der eigentlichen Anthropometrie, einer mehr naturwissenselsaftlichen I)isciplin, hinausgegangen sind, während die Metbode doch eine sehr allgremeine Anwendung auf Bevölkerungsund Mortalititssstatistik westattet. Die Möglichiceit einer allgemeinen Verwerthung der Methole hat Quételet ohne Zweifel nicht verkanut; aber wahrscheinlich glaubte er, dass sas rorhandene Material für solche Untersuchungen noch nicht ausreiclend sei.

30. Es wird sogar möglich sein, auch intensive Grössen, Eigenechaften, die gradweise verschieden aber nicht quantitativ nuessbar sind, auf iluren typischen Charakter yn untersuchen. Es wäre hier namentlich auf eine Abhandhng von $F$. Galton zu verweisen, die an einem für den Statistiker etwas abseits liegenden Orte erschienen ist.") Sie fühırt den Titel "Statistics by intercomparison", was man in Deutschen etwa dureh "Staffelungsmethode der Statistik" wiedergeben kann. I)as Eigenthümliche dieser Methode ist dies, diss die einzelnen Untersuchungsgegenstände nicht absolut gemessen, sondern nur nach jhrer Grösse oder dem Grade einer besonderen Eigenschaft stufenweise geordnet oder aufgestaffelt werden. Will man z. B. rasch die mittlere Grösse der Wingeborenen cines Iandes bestimmen, so genügt es, wenn man cinige Hundert Individuen nach der (xrösse geordnet nebeneinander stellt und das in der Mitte stebende herausnimmt. Dieses mittlere Individuun wird dann mit genügender Genauigkeit die typische Grösse der Rasse darstellen, und es reicht also zu deren Bestimmung eine cinzige Mcssung aus. Misst man ausserdem noch diejenigen, welche am Ende des ersten und des dritten Viertels der ganzen Reibe stehen, so erhält man die wahrscheinliche $\Lambda$ bwojchung vom Typus, die umgekehrt der Prïcision proportional ist, mit weleher der Typus yum Ausdruck grebracht wird. Diese wahrscheinliche Abweichung muss sich $/$ beiden Seiten des Mittelwerthes annähernd gleich ergeben, wenn der letatere wirklich eine typische Bedeutung haben soll. GaIton hat nun darauf hingewiesen, dass sich dieses Verfahren auf alle graduell auftretenden Eigenschaften anwenden lasse. Z. B. um die durchschnittiche Begabung eines Schulkindes darzustellen, ordine man die garze Classe

1) Philosophieal Magazine, vol. 19. Jan. 1875 S. 33. 
nach der Befähigung der Einzelnen und man kann das in der Mitte stehende Individuum als Durchschnittstypus ansehen.

Ich glaube, dass diese Methode besonders in der Ethnographio sehr fruchtbar gemacht werden könnte. Bei den Variationen von organischen Rassen und Arten werden wir im Allgemeinen das Vorbandensein cines Typus, der zufällig gestört wird, voraussetzen dürfen, wenn sich auch nicht, wie dies bei einfachen Messungen der Körperlänge der Fall ist, die Wirkung gleicher Störungscomplexe von entgegengesetztem Charakter in Abwcichungen vom Mittel zeigt, die als gleich und entgegengesetzt erkennbar sind. Ein geübter Ethnograph würde z. B. im Stande sein, aus 200 erwachsenen Individuen eines Negerstammes zunächst etwa 20 Gruppen zu bilden, deren Mitglieder nach ihrem ganzen Habitus eine möglichst grosse Aehnlichkeit unter einander besitzen; aus diesen Gruppen würden nun dic beiden auszuscheiden sein, welche am verschiedensten von cinander wären, und diese träten an die beiden Enden der zu bildenden Reihe; aus den 18 übrigen Gruppen würden abermals dic beiden verschicdensten ausgewählt und $z$ wischen die beiden vorerwähnten auseinander gestellt, und so würde man fortfahren, bis die sämmtlichen Individuen nach den Unterschieden ihres Rassenhabitus geordnet wären. Nur die mittleren Gruppen würden noch einer genaueren Vergleichung ihrer Individuen bedirfen. So erhielte man in dem die Mitte einnehmenden Individuum eine Darstellung des Stammestypus und es wäre zugleich zu erwarten, dass sich zu beiden Seiten des Mittelmannes eine grössere Anzahl von Individuen findet, die dem Typus sehr nahe kommen. Photographirt man ausser dem mittleren auch noch die am Ende des 1. und 3. Viertels der Reihe stehenden Individuen, so erhält man auch exacte Anhaltspunkte über die Veränderlichkeit des Typus. Bei einem unvermischten Naturstamme werden diese wahrscheinlichen $A b$ weichungen vermuthlich sehr mässig sein, während bei einer Mulattenbevölkerung, in cler die Rasse des Vaters (Weisser) oder der Mutter (Negerin) in einzelnen Fällen stark überwiegen kann, wohl auch schon eine auffallendere wahrscheinliche Abweichung hervortreten dürfte.

Bei kraniologischen Untersuchungen wäre zuerst festzustellen, ob die Mittel von gewissen Schädelmaassen oder Maassverhältnissen sich als Typen nachweisen liessen, was bei der eigenthümlichen Wechselwirkung organischer Formverhältnisse von vorn berein gar 
nicht gewiss ist. ${ }^{1}$ ) Lässt sich dieser Nachweis nicht liefern, so muss man den typischen Habitus eines Rassenschädels nach der obigen Methode ermitteln, wozu man freilich eine beträchtliche Anzahl von Exemplaren bedarf.

31. Diese anthropometrischen und ethnologischen Untersuchungen fallen indess mehr in das Gebiet der Naturwissenschaften, als in das der Bevölkerungsstatistik. Im Folgenden aber soll der Versuch gemacht werden, eine spexifisch statistische Frage nach der Theorie der typischen Grössen zu beleuchten: ich meinc dic Absterbeordnung einer Generation.

Es sind bekanntlich zahlreiche Versuche gemacht worden, die "Mortalitätsgesetze" durch mehr oder weniger empirische Formeln auszudrücken, so von Lambert, Babbagc, Moser. Gomperts, Edmonds, Makeham, Lazarus und Anderen, und zwar drücken die Einen die Ueberlebenden, die Anderen aber die Sterbenswahrscheinlichkeiten der einzelnen Altersjahre als Function des Alters aus welches letztes Verfahren Ph. Fischer für das allein zweckmässige hält.

Nun bestehen ohne Zweifel in einer gegebenen Bevölkcrungsschichte ziemlich constante Worthe für das Verhältniss der Zahl der Gestorbenen aus ciner bestimmten Altersclasse zu der Zahl derjenigen, welche die untere Grenze dieser Classe überschritten haben; aber es ist zunächst sehr fraglich, ob diese relative Constanz eine solche ist, wie sie unter der Voraussetzung einer festen mathematischen Sterbenswahrscheinlichkeit zu erwarten wäre; ferner würden sich für verschiedene Bevölkerungsschichten verschiedene Sterblichkeitsverhältnisse als neben einander bestehend ergeben; und endlicb ist gar lein Grund abzusehen, wesshalb irgend eine innerc Verbindung zwischen den Sterblichkeitsverhältnissen der aufeinander folgenden Altersstufen bestehen sollte, wie es doch bei der Annahme einer das Absterben der Generation beherrschenden Formel vorausgesetzt wird. Dic Sterbefälle der Generation bilden vielmehr eine unverbundene Massenerscheinung, sowohl rücksichtlich der Besetzung der einzelnen Altersclassen, als vollends in Bezug

1) Schon Cournot hat darauf aufmerksam gemacht, dasa, fills cin rcclitwinkliges Dreieck ingend wic veränderlich gedacht wird, die arithnetischen Mittel aus den Einzelwerthen jeder der drei Seiten sich nicht zu einem rechtwinkligen Dreieck vereinigen lassen. 
auf das Verhältniss der Altersclassen neben einander. Es ist hicr wieder an das bereits oben benützte Bild einer aufgehäuften Sandmasse zu erinnern; man kann durch eine empirische Formel wohl die Aussenseite der Anhäufung von Einzelfällen näherungsweise darstellen, aber diese Formel ist darum doch nicht ein die Elementar- wie die Integralerscheinung regelndes "Gesetz".

Die Sterblichkeitsverhältnisse sind also unter einem anderen Gesichtspunkte als dem der mechanischen Gesetzmässigkeit aufzufassen.

Es liegt die Annahme nahe, dass der organische Typus des Menschen, wie er eine gewisse normale Körpergrösse bedingt, so auch auf eine gewisse normale Lebenslänge eingerichtet ist. Diese Lebenslänge müsste sich als typisch nachwcisen lassen, d. h. sie müsste bei zahlreichen Beobachtungen vollendeter Lebenslängen nicht nur als ein Dichtigkeitsmittel erscheinen, sondern es müssten sich auch die Abweichungen nach der positiven und negativen Seite der Function $F_{u}$ gemäss gruppiren.

Machen wir uns zuerst ein correctes Bild von dem Absterben einer Generation.

Wir nehmen eine horizontale Grundlinie, die eine Geburtszeitstrecke, etwa ein Jahr, darstellen soll und denken uns auf derselben die Geburten einer gegebenen Bevölkerung nach ihrer Zeitfolge durch Punkte bezeichnet. In diesen Geburtspunkten errichten wir Senkrechte als "Lebenslinien", von denen jede durch einen Ster bepunk t zum $\Lambda$ bschluss kommt. Jede solche abgeschlossene Senkrechte stellt also die beobachtete Lebenslänge eines Mitgliedes der untersuchten Generation dar und kann ebenso belhandelt werden, wie eine gemessene Körperlänge. Die Lebenslängen sind jetzt gleichsam, nach der Geburtszeit geordnet, neben einander aufgestellt. Da der geringen Verschiedenheit der Geburtszeitpunlite kein wesentlicher Einfluss auf' die typische Lebenslänge beizumessen ist, so können wir auch die senkrechten Lebenslinien in eine einzige zusammenschieben, auf der sich dann die sämmtlichen Sterbepunkte vertheilt finden. Wir theilen diese Hauptlinie in Jahresstrecken ab und betrachten nun die Dichtigkeit der Sterbepunkte in den einzelnen Altersstufen. Diese Dichtigkeit ist unmittelbar nach der Geburt absolut am stärksten, nimmt dann rasch ab und erreicht im Allgemeinen irgendwo zwischen den 10. und 15. Altersjahre ein 
Minimum, von wo aus in den nächsten Jahryehnten nur ein sehr langsames, später aber ein schnclleres Anwachsen stattfindet bis in der Näle der 70er Jahre ein zweites Maxinum erscheint, dem wieder eine ziemlich schnelle Abnalume der Dichtigkeit der Sterbepunkte folgt.

32. Nun hat, wie bereits früher hervorgehoben wurde, das arithmetische Mittel aus dor Gesammtheit dieser Lebenslängen keine typische, überhaupt keine physische Bedeutung. Es handelt sich für uns um die typische Lebenslänge des Menschen bei normaler Entwicklung; alle diejenigen Fälle also, in denen der Lcbensfaden bereits abgeschnitten wurde, während das Individuum noch in der Bildung, im Heranwachsen begriffen war, können fïr die Bestimmung jener Normallänge ebensowenig in Betracht kommen, wie die Körperlänge der verstorbenen Kinder und Halbwüchsigen für die Feststellung des normalen Grössentypus.

Wir lassen also zunächst dic sämmtlichen Verstorbenen der Kindheitsperiode, die man von der Geburt bis zu dem Minimum der Dichtigkeit der Sterbcpunkte ausdehnen kann, gänzlich bei Seite. Die P'unktendichtigleit auf der übrigen Strecke würde sich nun graphisch versinnlichen lassen durch eine unsymmetrische Curve mit einem einzigen Ordinaten-Maximum in der Nähe der 70. Wenn es nun überhaupt eine typische Lebenslänge gibt, so ist diese dargestellt durch die Abscisse jenes Maximums, die das Dichtiglscitsmittel der Endpunkte der Lebenslängen bestimmt. Zur Erkïirung der Asymmetrie der Dichtigkeitscurve ist zu erwägen, dass auch vom Pubertätsalter bis etwa zum 35. vder 10. Lebensjahr der Tod im allgemeinen noch als ein vorzeitiger, abnormer, gewissernassen als ein von Aussen gekommener, nicht aber durch die typische Naturanlage des Menschen bedingter Unfall anzusehen ist. Damit stimmt denn auch, dass in dieser Periode das Alter für die Sterblichkeit am wenigsten in Betracht kommt, indem sich dic Sterbepunkte fast gleichmässig über dicse Strecke vertheilen. In fünften Jahrzehnt aber fängt in der Regel schon die typische Sterblicbkeit an einigermassen merklich $2 u$ werden, wenn auch die voryeitige noch überwiegt; im sechsten Jahrzehnt pflegt dieses Verhältniss sich umzukehren und in der ersten IJälfte der 60er Jahre kann man annchmen, dass die typische Sterblichkeit allein massgebend wird. Von dieser Altersstufe ab also muss die Dichtigkeit der Sterbepunkte näherungsweise zu beiden Seiten des Diclutigkeitsmittels der 


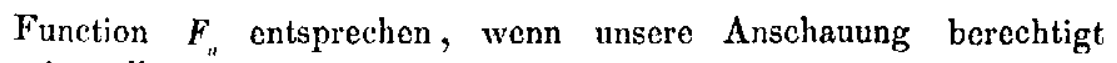
sein soll.

Unsere Auffassung wïrde folgendem Bilde entsprechen.

Man denke sich, Jemand werfe von einem festen Standpunkte aus Kugeln mit der Absicht, dieselben auf eine in einer Entfernung von etwa 70 Fuss am Boden angebrachten Marke aufschlagen yu lassen. In Wirklichkeit werden die Endpunkte der Flugbahn der Kugeln theils vor theils hinter dem Ziele liegen, aber bei einer grossen Versuchsreihe werden sich dieselben näherungsweise nach der mathematischen Fehlertheorie vertheilen, mit um so geringerer Dispersion, also um so grösserer Präcision, je grösser die Geschicklichkeit des Werfenden ist.

Ferner aber nehmen wir an, dass ein gewisser Theil der Kugeln, die der Werfende ergreift, für den Wurf ungeeignet, etwa hohl sind und zu wenig Masse besitzen. Mit diesen Hohlkugeln stellt der Schleuderer gar keinen Versuch an, sondern er wirft sie einfach vor sich hin und sie kommen weiter nicht mehr in Betracht. Endlich aber sei eine andere Person damit beschäftigt, auf einer gewissen Strecke der Bahn die geschleuderten Kugeln im Fluge a uf $\%$ u fangen, und zwar so, dass sie auf der Strecke von 15 bis 40 Fuss Entfernung vom Anfangspunkt auf jeden Fuss im ganzen fast gleich häufig eingreift oder doch mit nur geringer Zunahme der Häufigkeit bei wachsender Entfernung.

Ueber eine Distanz von 45 oder 50 Fuss hinaus soll die relative Häufigkeit dieser Eingriffe rasch abnehmen, während nach und nach immer mehr Kugeln in ungestörter Flugbahn den Boden erreichen; bald wird die Zahl der auf eine Strecke von einem Fuss von selbst niederfallenden Kugeln schon grösser, als die Zahl der aufgefangenen pro Fuss der mittleren Strecke, und in einer Entfernung von etwa 60 Fuss hören jene Eingriffe so gut wie ganz auf.

Wenn in dieser Weise viele tausend Kugeln verwendet worden wären, so würde sich also Folgendes ergeben: eine gewisse Anzahl derselben würde in der Nähe des Ausgangspunktes angehäuft sein; es wären diese die als unbrauchbar verworfenen. Ein anderer Theil würde annähernd symmetrisch vor und hinter dem Ziele liegen, in dern sich das Dichtigkeitsmittel fände, während die Gruppirung zu beiden Seiten der Function $F_{\text {u }}$ entspräche. Denkt man sich endlich die aufgefangenen Kugeln in den Entfernungen niedergelegt, wo sie eingehalten wurden, so bilden sie eine dritte Gruppe, die anfangs 
mit zunehmender Entfernung nur langsam dichter wird, schliesslich aber in ihrer Dichtigkeit schnell abnimmt und in der Nähe von 60 Fuss Distanz verschwindet, nachdem sie in der letzten Strecke mit dem einen Ausläufer der zweiten Gruppe theilweise zusammengefallen ist. Es ist leicht einzusehen, dass die der Theorie entsprechende Anordnung der «weiten Gruppe durch das vorzeitige Einhalten eines Theiles der Kugeln (eben der dritten Gruppe) nicht beeinträchtigt wird.

Die erste Gruppe in diesem Bilde entspricht nun den ,jugendlichen", die dritte den "vorzeitigen" und die zweite den "normalen" Sterbefälen.

33. Man könnte vielleicht Anstoss nehmen an dem Uebergange der "vorzeitigen" in die "normalen" Sterbefälle. Es ist indess zu bedenken, dass dieselben Ursachen, welche einen "vorzeitigen" Tod erzeugen, falls sie bei einem Individuum von 30 Jahren wirksam werden, recht wohl einen "normalen" Sterbefall liefern können, wenn sie in den Altersclassen von mehr als 50 Jahren auftreten. Eigentliche Verunglückungen freilich würden auch in den höheren Altersstufen als abnorme Sterbefälle anzusehen sein, aber deren Zahl ist verhältnissmässig so gering, dass man sie vernachlässigen kann.

Es fragt sich nun, ob sich die bier dargelegte Anschauungsweise durch die Erfahrung rechtfertigen lässt.

Hier tritt uns von vornherein der Uebelstand entgegen, dass wir correcte Daten über das Absterben wirklicher Generationen noch nicht besitzen. Zur strengen Vergleichung von Theorie und Erfahrung wären etwa dreissigjährige Erhebungen der Verstorbenen nach Elementargesammtheiten erforderlich, mit deren Hülfe man das wirkliche Absterben einer Generation während des Haupttheiles der Periode der normalen Sterbefälle verfolgen könnte.

Die vorhandenen Sterblichkeitstabellen geben besten Falles nur eine Reihe von Sterbenswahrscheinlichkeiten für die einzolnen Altersclassen, aus denen sich das Absterben, nicht einer wirklichen, sondern einer hypothetischen Generation darstellen lässt. Auch sind diese Tabellen häufig noch durch "Ausgleichungen" idealisirt, damit "das Gesetz" klarer hervortrete, während uns vor allen Dingen der wirkliche Verlauf der concreten Erscheinungen, die Vertheilung der wirklichen Sterbepunkte mit all ihren "zufälligen" Modificationen interessirt. 
Indess wird dic aus den Tabellen hervorgehende Vertheilung der Sterbefälle nach Alterselassen in den verschiedenen Iändern wenigstens im Grossen und Ganzen auch der Sterbeordnung einer wirklichen Generation entsprechen, und wir werden uns daher bis auf Weiteres mit diesen Daten behelfen.

Nehmen wir zunächst einige der Tabellen, die Quetelet in seiner Schrift "Tables de Mortalité" (Brux. 1872) S. 27 ff. zusammengestellt hat und die von den statistischen Bureaux dex betreffenden Länder als Beiträge zu diesem wenig befriedigenden Versuche einer internationalen Mortalitätsstatistik geliefert worden sinul.

Wir beginnen mit den belgischen Tabellen für beide Geschlechter. Die Zahlen sind reducirt auf eine Generation von 5(\%) Lebendgeborenen, was natürlich eine blosse Rechnungsoperation ist und keinen Bezug auí das Gewicht derselben hat.

Unter der Rubrik "Tabellenzahl" sind die tabcllarischen Kahlen der Sterbefälle in der daneben stehenden Alterstrecke angegeben, wobei die Bezeichnung 20-25 bedeutet: vom vollendeten 20sten Jahre bis zum vollendeten 25sten. Unter "Theorie" sind die normalen und in der folgenden Rubrik die "vorzeitigen" Sterbefälle angeführt, die aber, soweit sie in Klanmern stehen, einfach als die thatsächliche Differenz zwischen den tabellarischen und theoretischen Zahlen anzusehen sind.

\section{B elg i e n.}

Männer.

$\begin{array}{cccc}\text { Altersstrecke. } & \text { Tabellenzahl. } & \text { Theorie. } & \text { Vorzeitige. } \\ 15-20 & 13 & - & 13 \\ 20-25 & 14 & - & 14 \\ 25-30 & 17 & (1) & 16 \\ 30-35 & 16 & (1) & 15 \\ 35-40 & 17 & (3) & 14 \\ 40-45 & 17 & (6) & 11 \\ 45-50 & 17 & (12) & 7 \\ 50-55 & 20 & 19 & (1) \\ 55-60 & 29 & 27 & (2) \\ 60-65 & 36 & 34 & (2) \\ 65-67 & 15 & 14 & (1) \\ * & * & * & * \\ 67-70 & 20 & 21 & (-1) \\ 70-75 & 34 & 33 & (1) \\ 75-80 & 29 & 26 & (3)\end{array}$




\begin{tabular}{cccc} 
& \multicolumn{4}{c}{47} & \\
Altersstrecke. & Tabelicnzahl, & Theorie. & Vorzeitige. \\
$80-85$ & 21 & 18 & $(3)$ \\
$85-90$ & 9 & 10 & $(-1)$ \\
$90-95$ & 3 & 5 & $(-2)$ \\
Ueber 95 & 1 & 4 & $(-3)$
\end{tabular}

Normalalter: 67 Jahre. Pricision 0,0546 (aus $67-75$ ).

Wahrscheinliche Abweichung: \pm 8.73 Jahre; sollte nach der theorie je 58.5 Sterbefäle umfassen; die Tabelle ergibt nach aufwirts $62^{1}{ }_{i 4}$, nach alwwärts 6982: Fälle in diesen Gränzen.

Die Normalgruppe der Sterbefüle $=4 \times 58.5=234$ oder $46.8 \%$ der zu Grunde gelegten Generation.

\section{Frauen.}

$\begin{array}{cccc}\text { Altersstrecke. } & \text { Tabellenzah. } & \text { Theorie. } & \text { Vorzeitige. } \\ 15-20 & 13 & - & 13 \\ 20-25 & 16 & - & 16 \\ 25-30 & 15 & - & 15 \\ 30-35 & 14 & - & 14 \\ 35-40 & 15 & - & 15 \\ 40-45 & 18 & - & 18 \\ 45-50 & 19 & (2) & 17 \\ 50-55 & 23 & (4) & 19 \\ 55-60 & 23 & (12) & 11 \\ 60-65 & 25 & 24 & (1) \\ 65-70 & 33 & 351 / 2 & (-21 / 2) \\ 70-721 / 2 & 211 / 8 & 21 & (1 / 2) \\ * & * & * & * \\ 721 / 2-75 & 211 / 2 & 21 & (1 / 8) \\ 75-80 & 35 & 351 / 8 & (-1 / 2) \\ 80-85 & 23 & 24 & (-1) \\ 85-90 & 13 & 12 & (1) \\ \text { eber } 90 & 5 & 6 & (-1) \\ \end{array}$

Normalalter: 721/2. Präcision: 0,076 (aus 721/2-80).

Wabrscheinliche Abweichung: \pm 6,275 Jahr - nach der Theorie je $47^{3 / 4}$ Fälle umfassend; nach der Tabelle aufwärts und abwärts 48 Fälle.

Die Normalgruppe der Sterbefälle $=4 \times 473 \%=191$ oder $38.2 \%$ der Generation.

34. Ueber die Berechnung der theoretischen Zahlen ist Folgendes zu bemerken. ')

1) Bei den Interpolationen, die bei diesen Berechnungen nöthig waren, sind immer die tabellarischen Zablen für die Sterbefälle in einjährigen Altersclassen zu Grunde gelegt wordea. 
Da das typische Normalalter nur bis auf ein halbes, höchstens ein Vierteljabr genau bestimmt zu werden braucht, so gelangt man dazu durch eine einfache Schätzung der Lage des Dichtigkeitsmittels der normalen Sterbefälle. In der Tabelle über die Mortalität der Männer findet man für die Altersstrecke 60-65: 36; 65-70: $35 ; 70-75: 34$ Sterbefälle, während vor und nach diesen drei Perioden die Sterbedichtigkeit eine erheblich geringere ist; man wird also das Dichtigkeitsmittel etwas oberhalb der Mitte der Strecke 65-70 anzunehmen haben, also, wie oben gescheben, etwa zu Ende des 67. Jabres. In der Tabelle iiber die weibliche Sterblichleit aber hat man ober- und unterhalb der Strecke 70-75 zunäclist eine symmetrische Vertheilung der Sterbefälle, so dass man das Normalalter auf $721 / 2$ annehmen kann.

Von diesen geschätzten Normalaltern aus berechnet man nun vorläufig die theoretische Vertheilung; schliesslich aber kann man versuchen, ob sich vielleicht durch eine Verschiebung des Normalaiters um $1 / 4$ oder $1 / 2$ Jahr eine bessere Uebereinstimmung zwischen den tabellarischen und den theoretischen Zahlen erzielen lässt.

Es ist jetzt die Präcision $h$ zu bestimmen, die mit der Abweicliung $x$ multiplicirt das Argument $u$ in der Tabelle der Function $F_{u}$ gibt.

Zu diesem Zwecke nehmen wir an, dass die empirische, d. h. die tabellarische Vertheilung der Sterbefälle auf einer einigermassen grossen Altersstrecke vom Normalalter aus dem Wahrscheinlichkeitsgesetz hinlänglich genau entspricht. In der ersten der obigen Tabellen ist die Strecke 67 bis 75 , in der zweiten $721 / 2$ bis 80 gewählt. Nun fallen nach der ersten Tabelle empirisch zwischen die Altersstufen von 67 und 75 Jahren 54 Fäle, indem überhaupt über 67 Jahre linaus 117 Fälle vorkommen, welche dem einen, rein hervortretenden Zweige der Wahrscheinlichkeitscurve entsprechen, während die ganze Normalgruppe 234 Fälle enthält. Demnach können wir die Wahrscheinlichkeit, dass eine der normalen Gruppe angehörende Lebenslänge um hüchstens \pm 8 Jahre von dem typischen Mittel abweiche, gleich $\frac{54}{117}$ oder 0.463 setzen. Dieser

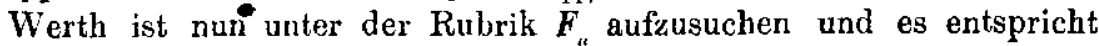
ihm in der Tabelle der Werth $u=0.437=h x$; es ist aber $x$ in diesem Falle gleich 8 , positiv oder negativ genommen, und man findet folglich $h=0,0546$. Mit Hülfe dieser Präcision lassen sich nun die theoretischen Wahrscheinlichkeiten für jede beliebige $\mathbf{A b}$ - 
weichung nach der einen und der anderen Seite hin berechnen. 7. B. für $x=3$, entsprechend der Altersgrenze 70, hat man $u=$ $3 \times 0.0546=0.161$; diesem Werthe entspricht $F_{u}=0.183$, und das würde also die Wahrscheinlichkeit sein, dass eine Lebenslänge der Normalgruppe zwischen den Grenzen $67-3$ und $67+f$ falle; bei einer Stärke der Normalgruppe von 234 wären also in dieser Strecke annähernd $0.183 \times 231$ oder 38.8 Fälle und awischen 67 und 70 demnach $0.183 \times 117$ oder 19.4 Fialle zu erwarten.

Die wahrscheinliche Abweiclung in der Normalgruppe, die also ebenso oft nicht erreicht wie überschritten wird, findet man durch Division der Präcision in die Constante $\varrho=0.1769$, also in dicsem Falle $\frac{0.4769}{0.0546}=8.73$. In dieser Strecke muss zu beiden Sciten des typischen Mittels je ein Viertel der ganzen Gruppe von 234 Fällen liegen, was mit der Vertheilung der empirischen Tabellenwerthe befriedigend übereinstimmt. ${ }^{1}$ )

35. Ueberhaupt wird nicht zu bestreiten sein, dass die tabellarischen und die theoretischen Werthe in den beiden Zusammenstellungen des Paragraphen 33 so nahe übereinstimmen, wie man in Erwägung der Unsicherheit der ersteren und des durch die Zufallstheorie gestatteten Spielraums der letzteren nur irgend erwarten kann. In der zweiten Tabelle ist die Uebereinstimmung noch vollständiger als in der ersten, und auch der theoretische wahrscheinliche Fehler wird hier empirisch sehr genau bestätigt.

Man kann demnach sagen, dass volle drei Viertel der Normalgruppe der Sterbefalle hinlänglich klar in der Vertheilung hervortreten, die durch die Zufallstheorie a priori gegeben wird; nur das erste Viertel ist gleichsam überlagert von der keilförmig auslaufenden Schicht der "vorzeitigen" Sterbefälle. Feinere Untersuchungen mit correctem Material müssen erst ergeben, $o b^{*}$ nicht eine dünne Lage dieser Schicht sich noch weiter, vielleicht sogar über das Dichtigkeitsmittel hinaus fortsetzt. In der ersten Tabelle könnte man etwas derartiges zu erkennen glauben, aber die Unsicherheit

1) Man könnte auch von dem empirischen wahrscheinlichen Fehler nusgellen, d. b. durch Interpolation die Distanz vom Normalnlter 67 bestimmen, in welcher $58 \% / 2$ Fälle vorkommen. Diese Distanz in 9 dividirt würde cine Präcision ergeben, die von der oben gefundenen nur wenig abweicht und aus der sich also auch im wesentlichen dieselbe theoretische Verthcilung der Fälle der Normulgruppe berechnen wïrde. 


$$
-\quad 50-
$$

der tabellarischen Daten ist zu gross, um cinen solchen Schluss mit Bestimmtheit zu gestatten.

Was den speciellen Inhalt der beiden obigen Tabellen betrifft, so ist besonders bemerkenswerth der ungewöhnlich grosse Unterschied des "Normalalters" der beiden Geschlechter. Dieser Unterschied wird zu Lngunsten der Männer noch verschärft durch die geringere I'rüicision der Vertheilung, d. h. durch die grössere Dispersion der Normalgruppe der Männer, deren letste $\Lambda$ usläufer bis in die Altersstrecke 25-30 reichen. Schon in dicser Altersclasse wird also nach der vorliegenden Tabelle das normale Absterben der Münner leise merklich, während es in der Strecke 35-40 bereits fuihlbarer hervortritt, als bei den Frauen in des Strecke $45-50$. Wegen dieser stärkeren Dispersion ist es für die Männer auch kein Gewinn, dass ihre Normalgruppe grösser ist als die der Frauen.

In Betreff der Normalgruppe ist im Allgemeinen zu bemerken, dass zu ihrer Bestimmung drei Elemente nothwendig und hinreichend sind: 1) das Normalalter als Mittelpunkt derselben, 2) die Präcision oder die aus derselben unnittelbar abzuleitende wahrscheinliche Abweichung, und 3) die absolute Grösse der Gruppe, die erhaltell wird durch Verdoppelung der Zahl der Sterbefälle, welche über das Normalalter hinausfallen.

Die Normalgruppe ist von der Gruppe der "jugendlichen" Sterbefälle, wic bereits hervorgehoben wurde, ganz unabhängig; doch ist der Vergleichung wegen die Frage nicht uninteressant, wie gross die letztere Gruppe sich nach den belgischen Tabellen herausstellt. Ihre Abgrenzungr hat allerdings etwas Willkiirliches; doch dürfte es am passendsten sein, sie abzuschliessen mit dem Ende desjenigen Altersjahres, welches zuerst ein Minimum der Sterbefälle aufweist. Hiemach ergäbe sich beim männlichen Geschlecht in Belgien das Ende des 10., beim weiblichen das Ende des 12. Altersjahres als Crenze für die Strecke der jugendlichen Sterblichkeit, und die Stärke der Gruppe würde auf 500 Geborene resp. 159 urd 157 oder 31.8 und 31.4 Procent betragen. Fïr die Gruppe der "vorzeitig" Gestorbenen blieben nun bei den Münnern 21.4 und bei den Frauen $30.4 \%$ übrig. Die angefiuhrten Zahlen haben natürlich keinen allgemcinen Werth, und selbst für Belgien mögen exactere Sterblichlieitstabellen andere Resultate ergeben; es sollte mur nuf dir ziemlieh zalulreichen Elemento hingewiesen wer- 
den, welche das Gesammtbild der Mortalität eines Landes zusammensetzen, und es zeigt sich dabei wieder, wie wenig man von einer einzigen "Ziffer" zur Charakterisirung dieser verwickelten Verhältnisse erwarten darf.

36. Wir betrachten nun noch einige andere Sterblichkeitstabellen aus der angeführten Zusammenstellung, jedoch mit Weglassung der leicht herzustellenden Rubrik der Vorzeitigen.

Frankreich.

\begin{tabular}{|c|c|c|}
\hline \multicolumn{3}{|c|}{ Männer. } \\
\hline Alter. Tal & ab.-Zahl. & Theorie. \\
\hline $40-45$ & 15 & - \\
\hline $45-50$ & 10 & (2) \\
\hline $50-55$ & 19 & (4) \\
\hline $55-60$ & 24 & (12) \\
\hline $60-65$ & 32 & (24) \\
\hline $65-70$ & 38 & 37 \\
\hline $70-721 / g$ & 20 & 21 \\
\hline$*$ & $*$ & * \\
\hline $721 / 2-75$ & 20 & 21 \\
\hline $75-80$ & 38 & 37 \\
\hline $80-85$ & 26 & 24 \\
\hline $85-90$ & 12 & 12 \\
\hline Ueber 90 & 4 & 6 \\
\hline \multicolumn{3}{|c|}{$\begin{array}{l}\text { Normalalter: } 72 \frac{1}{2} . \\
\text { Präcision: } 0.076\left(\mathrm{avg} 72^{1 / 2}-80\right) \text {, } \\
\text { Wahrsch. Abw.: } \pm 6.275 \text { Jahre; soll } \\
\text { umfasen je } 50 \text { Falle, was oben } \\
\text { und unten zutrifft. } \\
\text { Normalgruppe: } 200 \text { Fälle }=40.0 \% \% \\
\text { der Generation. }\end{array}$} \\
\hline
\end{tabular}

Frauen.

Alter. Tab.-Zahl. Theorie.

$40-45 \quad 14$

$45-50 \quad 15$

$55-55 \quad 18$

$55-60 \quad 23$

(2)

$60-65$

31

$65-70$

28

$70-72 \quad 17 \quad 18$

*

$72-75 \quad 27 \quad 27$

$75-80 \quad 38 \quad 38$

$80-85 \quad 26 \quad 26$

$85-90 \quad 14 \quad 14$

Leber 90

7

8

Normalalter: 72 .

Präcision: 0.071 (aus $72-80$ ).

Wahrsch. Abw.: \pm 6.72 Jahre; soll umiassen je $50 \mathrm{Fälle}$; in der'labelle: aufwärts 5j, abwärts 56 Fulle.

Normalgruppe: 224 Fülle $=44.8^{\circ}$. der Generation.

Die Uebereinstimmung der empirischen und der theoretischen Zahlen ist durchaus befriedigend, in der zweiten Tabelle sogar auffallend gross. Man darf indess nicht vergessen, dass die empirischen Zahlen selbst nur annähernd das Absterben eiıer wirklichen Generation darstellen.

Die Verhältnisse der beiden Geschlechter zeigen, im Gegensatz zu Belgien, keinen erheblichen Unterschied. Die geringe Differenz im Normalalter würde vielleicht bei der Benuitzung von correkterem 
Material ganz verscbwinden. Die Frauen weisen jedoch eine etwas stärkere Normalgruppe auf, was unter den vorliegenden Umständen, da das Normalalter und die Vertheilungspräcision bei beiden Geschlechtern nahezu gleich sind, den Männern gegenüber eine Begünstigung darstellt.

Die jugendliche Gruppe der Gestorbenen wäre nach den hier za Grunde gelegten Tabellen und der oben angegebenen Regel beim männlichen Geschlecht mit dem vollendeten 12., bei dem weiblichen mit dem vollendeten 15 . Jahre abzuschliessen; sie würde hiernach resp. 169 und 162 Fälle oder 33.8 und 32.4 Procent der Generation umfassen.

Auf die vorzeitigen Sterbefälle kämen dann noch resp. 26.2 und 22.8 Procent. In dem geringeren Procentsatz der vorzeitig gestorbenen Frauen zeigt sich der Vortheil der grösseren Normalyruppe.

Als nächstes Beispiel betrachten wir die Mortalitätstabcllen von

$$
\text { Norwegen. }
$$

Männer.

Alter. 'l'ab.-Zahl. Theorie.

$40-45 \quad 16$

$45-50 \quad 17$

$50-55 \quad 21$

$50-60 \quad 24$

$60-65 \quad 29$

$65-70 \quad 39$

$70-74 \quad 39$

* 45

$75-80 \quad 45$

$80-85 \quad 38$

$85-90 \quad 22$

$90-95 \quad 8$

Ueber $95 \quad 2$

Normalalter : 74.

Präcision: 0.068 (aus 74-80).

Wahrech. Abw.: $t 7.01$ Jahre; soll umfassen je 62 Fälle; nach der Tabelle aufwärts 64 , abwärts 63 Fìlle.

Normalgruppe 248 Fälle oder $49.6^{\circ} \%$ der Gineration.
Frauen.

Alter. 'T'ab.-'/ahl. Theorie.

$40-45 \quad 16 \quad-$

$45-50 \quad 16$

$50-55 \quad 17 \quad$ (4)

$55-60 \quad 22 \quad$ (12)

$60-65 \quad 27 \quad 25$

$65-70 \quad 40 \quad 41$

$70-75 \quad 51 \quad 51$

75-80 * * *

$80-85 \quad 44 \quad 41$

$85-90 \quad 27 \quad 25$

$90-95 \quad 11 \quad 12$

Ueber $95 \quad 5 \quad 6$

Normalalter: 75 .

Präcision : 0.0705 (aus 75-85).

Wahrsch. Abw.: \pm 6.76 Tahre; soll umfassen je $67 \overline{1 / 2}$ Falle; nach der Tabelle aufwärts $60^{3 / 4}$, abwärts $63^{1 / 4}$ Fälle.

Normalgruppe : 270 Fälle oder $54.0 \%$ ler Generation. 
Die bekannte norwogische Langlebigkeit äussert sich hier in den holien Ziffern des Normalalters und in der starken Besetzung der Normalgruppe. Durch das Zusammentreffen einer grösseren Präcision mit diesen beiden Umständen würden die Mortalitätsverhältnisse Norwegens sich noch günstiger charakterisiren, da sich alsdann die normale Sterblichkeit erst später fühlbar machen würde.

Die Periode der jugendlichen Sterblichkeit schliesst beim männlichen Geschlecht mit den 15. und beim weiblichen mit dem 16. Altersjahre, und diese Gruppe umfasst resp. 26.6 und 23.6 Proc. der Generation. Es bleiben somit als vorzeitige Sterbefälle bei den Männern 23.8 Proc., bei den Frauen 22.4 Proc.

37. Die Sterblichkeitstabelle für diç $\mathrm{S} \mathrm{chwoiz}$ ergibt Folgendes:

Männer.

Alter. Tab.-Zahl. Theoric.

$40-45 \quad 18$

$45-50 \quad 19$

$50-55 \quad 23$

$55-60 \quad 27$

$60-65 \quad 37$

$65-70 \quad 47$

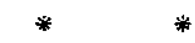

$70-75 \quad 46$

$75-80 \quad 38$

$80-85 \quad 20$

$85-90$

Ueber 90

Normalalter: 70 .

Präcision: 0.0701 (aus 70-80).

Wahrsch. Abw.: $\pm 6.03 \mathrm{Jahr}$; soll umfassen 57 Fälle; nach der Tabelle aufwärts 56 , abwärts 53 Fälle.

Normalgruppe: 228 Fälle $=45.6 \%$ der Generation.

Jugendliche Sterbefülle (bis $10 \mathrm{Jahr}$ incl.) $: 31.0 \%$.

Vorzeitige: $23.4 \%$.

Frauen.

Alter. Tab.-Zahl, Theoric.

$\begin{array}{lll}40-45 & 17 & (1) \\ 45-50 & 18 & (2) \\ 50-55 & 23 & (8) \\ 55-60 & 29 & (22) \\ 60-65 & 39 & 37 \\ 65-691 / 2 & 46^{1 / 2} & 43 \\ * & * & * \\ 69^{1 / 2}-75 & 49^{1 / 2} & 49^{1 / 2} \\ 75-80 & 39 & 36 \\ 80-85 & 17 & 19 \\ 85-90 & 9 & 8 \\ \text { eber } 90 & 1 & 3\end{array}$

Normalalter: $691 / 2$.

Präcision : 0.0758 (aus 691/2-75).

Wahrsch. Abw.: $\pm 6.29 \mathrm{Jahr}$; soll umfassen $57^{3} / 4$ Fälle; nach der Tabelle aufwärts $621 / 2$, abwärts 55 Fälle.

Normalgruppe: 231 Fülle $=46.2 \%$ der Generation.

Jugendliche Sterbefälle (bis $12 \mathrm{~J}$. incl.) $28.4^{\circ} \%$.

Vorzeitige: $25.4 \%$. 


\section{B a y e r n.}

\begin{tabular}{|c|c|c|}
\hline \multicolumn{3}{|c|}{ Männer. } \\
\hline Alter. & Tab.-Zahl. & Theorie. \\
\hline $40--45$ & 13 & - \\
\hline $45-50$ & 16 & (2) \\
\hline $50-55$ & 10 & (6) \\
\hline $55-60$ & 22 & (14) \\
\hline $60-65$ & 28 & 24 \\
\hline $65-70$ & 29 & 32 \\
\hline * & $*$ & * \\
\hline $70-75$ & 30 & 32 \\
\hline $75-80$ & 26 & 24 \\
\hline $80-85$ & 14 & 14 \\
\hline $85-90$ & 6 & 6 \\
\hline Ueber 90 & 3 & 2 \\
\hline- & - & - \\
\hline \multirow{2}{*}{\multicolumn{3}{|c|}{$\begin{array}{l}\text { Normalaiter: } 70 \text {. } \\
\text { Prücision: } 0.0761 \text { (aus } 70-80 \text { ). } \\
\text { Wahrsch. Abw.: } \pm 6.27 \text {.Jahr; soll } \\
\text { umfassen } 39 \text { Fälle; nach der Ta- } \\
\text { belle aufwärts } 38, \text { abwärts } 39 \\
\text { Fälle. }\end{array}$}} \\
\hline & & \\
\hline \multicolumn{3}{|c|}{$\begin{array}{l}\text { Normalgruppe: } 156 \text { Fälle }=31.2 \% \\
\text { der Generation. } \\
\text { Jugendliche Sterbefalle } \quad \text { (bis } 12 \quad \mathrm{~J} \text {. } \\
\text { incl.) } 46.4 \% \% \text {. } \\
\text { Vorzeitige: } 22.4 \% \text {. }\end{array}$} \\
\hline
\end{tabular}

Frauen.

Alter. Tab,-Zahl. Theorie.

$40-45 \quad 16 \quad$ (1)

$4 \mathfrak{1}-50 \quad 18 \quad(3)$

$50-55 \quad 21 \quad(8)$

$55-60 \quad 26 \quad(18)$

$60-65 \quad 29 \quad 29$

$65-69 \quad 27 \quad 29$

* * *

$69-70 \quad 8 \quad 7$

$70-75 \quad 34 \quad 35$

$75-80 \quad 24 \quad 25$

$80-85 \quad 13 \quad 13$

$85-90 \quad 6 \quad 6$

Ueber $90 \quad 3 \quad 2$

Normalalter: 60.

Präcision: 0.0753 (ans 60)-75).

Wahrsch. Abw.: +6.33 Jahr; soll umfaseen 44 Falle; nach der Tabesle aufwärts $42 \frac{1}{3}$, abwärts $44 \frac{1}{3}$ Falle.

Normalgruppe: 176 Fälle $=35.2 \%$ der Generation.

Jugendliche Sterbefälle (bis $10 \mathrm{~J}$. incl.) $40.6 \%$.

Vorzeitige : $24.2 \%$.

38. - Die bayerischen Tabellen in der Quételet'schen Sammlung sind von Hermann geliefert, aber es ist nichts dariber gesagt, ob sie nach der sogenannten "Hermann'schen" Methode berechnet seien. $\mathrm{Zu}$ der vollständigen Anwendung dieser Methode ist noch nicht genügendes Material vorhanden. Will man indess nur die Vertheilung der Normalgruppe untersuchen, unabhängig von der Generation, aus der sie hervorgegangen, so gibt die bayerische Statistik das beste Material, um dic Theorie mit Zablen zu vergleichen, welche der concreten Darstellung des Absterbens einer wirklichen Generation wenigstens möglichst nahe kommen, indem die einzelnen Altersclassen "dritte Hauptgesammtheiten von Verstorbenen" darstellen, welche von den eigentlich erforderlichen "ersten Haupt- 
gesanmtheiten" im Ganzen nur wenig abweichen und je cine Elementargesammtheit mit den letateren gemein haben.

Zur Anstellung einer Probe geniigt schon die Zusammenstellung des bayerischen Materials in der von Quételet und Heuschling herausgegebenen Statistique internationale. Beginnen wir mit den im Verwaltungsjahre 1835/36 und in der 66. Alterselasse (also in Alter von 65 bis 66 Jahren) Gestorbenen und stellen darunter die Verstorbenen der $67 ., 68$. u. s. w. Altersclasse aus dem ersten, zweiten u. s. w. folgenden Lrhebungsjahre, so erhält man eine Rejlic von Gesammthciten von Vorstorbenen, welche sehr ähnliche Verhältnisse aufweisen werden, wie weln sic aus einer einzigen Generation hervorgegangen wären.

Fasst man die absoluten Zahlen für je fünf Jahresclassen ausammen, so erhïlt man: ${ }^{1}$ )

\begin{tabular}{ccc|cc}
\multicolumn{3}{c|}{ Männer. } & \multicolumn{2}{c}{ Frauen. } \\
Nitcr. & T'ah.-Zahl. & Thooric. & Tab.-Zhahl. & Theoric. \\
fi5-70 & 3134 & 3289 & 3448 & 3578 \\
$*$ & $*$ & $*$ & $*$ & $*$ \\
$70-75$ & 3193 & 3289 & 3418 & 3578 \\
$75-80$ & 2603 & 2507 & 2841 & 2681 \\
$80--85$ & 1639 & 1461 & 1580 & 1502 \\
$85-90$ & 618 & 650 & 622 & 629 \\
Ueber 90 & 145 & 291 & 182 & 253
\end{tabular}

Um den Grad der Uebereinstimunung zwischen Theorie und Beobachtung im Vergleich mit den bisher betrachteten Tabellen richtig zu beurtheilen, darf man in den obigen Zahlen nur die beiden ersten Stellen, und zwar abgerundet, berücksichtigen, da man dann Grössen von ungefähr gleicher Ordnung mit den entsprechenden der ïbrigen Tabellen erhält. So findet man für die Männer folgende Reihen:

$$
\begin{array}{ll}
\text { Beobachtung: } & 31-32-26-16-6-1 \\
\text { Theorie: } & 33-33-25-15-7-3 \\
\text { he Frauen: } & \\
\text { Beobachtung: } & 3 t-3 t-25-16-6-2 \\
\text { Theorie: } & 36-36-27-15-6-3
\end{array}
$$

fiir die Frauen: $1850 / 60$.

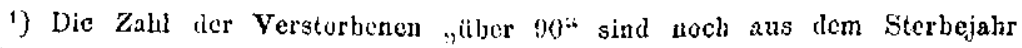


Die Uebereinstimmung der beobachteten und der theoretischen Werthen ist hiernach mit Rücksicht auf die Unsicherheit der ersteren und den Spielraum der letzteren als befriedigond anzusehen.

Das Normalalter ergibt sich jetzt bei beiden Geschlechtern zu 70 Jahren, was mit den beiden vorhergehenden bayerischen $\mathrm{Ta}-$ bellen unter den obwaltenden Umständen genügend stimmt.

Beim männlichen Geschlecht hat man ferner: Präcision 0.0743 (aus $70-80$ ); wahrsch. Abw. $\pm 6.42 \mathrm{Jahr}$; soll umfassen 4099 Fälle; in Wirklichkeit findet man in diesen Grenzen: aufwärts 4001, abwärts 3991 Fälle; die absolute Anzahl der Normalgruppe beträgt 16,396 ;

beim weiblichen Geschlecht: Präcision: 0.0771 (aus 70-80); wahrsch. Abw.: $\pm 6.19 \mathrm{Jahr}$; soll umfassen 4322 Fälle; beobachtet: aufwärts 4209 , abwärts 4155 Fälle; Normalgruppe 17,286 .

Die Präcisionen weichen von den aus den beiden vorhergehenden bayerischen Tabellen abgeleiteten so wenig ab, als man bei Berücksichtigung der Verschiedenheit der empirischen Grundlagen exwarten darf.

39. Untersuchen wir nun auch noch einige aus anderen Quellen stammende Sterblichkeitstabellen. Zunächst die ältere englische von Farr, ${ }^{1}$ ) berechnet auf eine Generation von 512.7 Männern und 487.3 Frauen.

\begin{tabular}{ccc||ccc} 
& Männer. & & \multicolumn{3}{c}{ Frauen. } \\
Alter. & Tab.-Zahl. & Theorie. & Alter. & Tab.-Zahl. & Theorie. \\
$40-45$ & 18.3 & $(0.7)$ & $40-45$ & 16.9 & $(0.6)$ \\
$45-50$ & 19.4 & $(2.1)$ & $45-50$ & 17.5 & $(1.8)$ \\
$50-55$ & 20.2 & $(6.2)$ & $50-55$ & 18.0 & $(5.4)$ \\
$55-60$ & 25.5 & $(14.4)$ & $55-60$ & 22.5 & $(12.8)$ \\
$60-63$ & 18.6 & $(14.1)$ & $60-63$ & 16.8 & $(13.2)$ \\
$63-65$ & 13.6 & 119 & $63-65$ & 12.5 & 11.0 \\
$65-70$ & 37.7 & 36.8 & $65-70$ & 35.6 & 35.0 \\
$70-72$ & 15.9 & 16.3 & $70-73$ & 23.3 & 24.2 \\
$*$ & $*$ & $*$ & $*$ & $*$ & $*$ \\
$72-75$ & 23.7 & 24.2 & $73-75$ & 15.8 & 16.3 \\
$75-80$ & 35.5 & 35.0 & $75-80$ & 37.2 & 36.7
\end{tabular}

1) Fifth report of the registrar general, Londun 1843, p. XVII. 


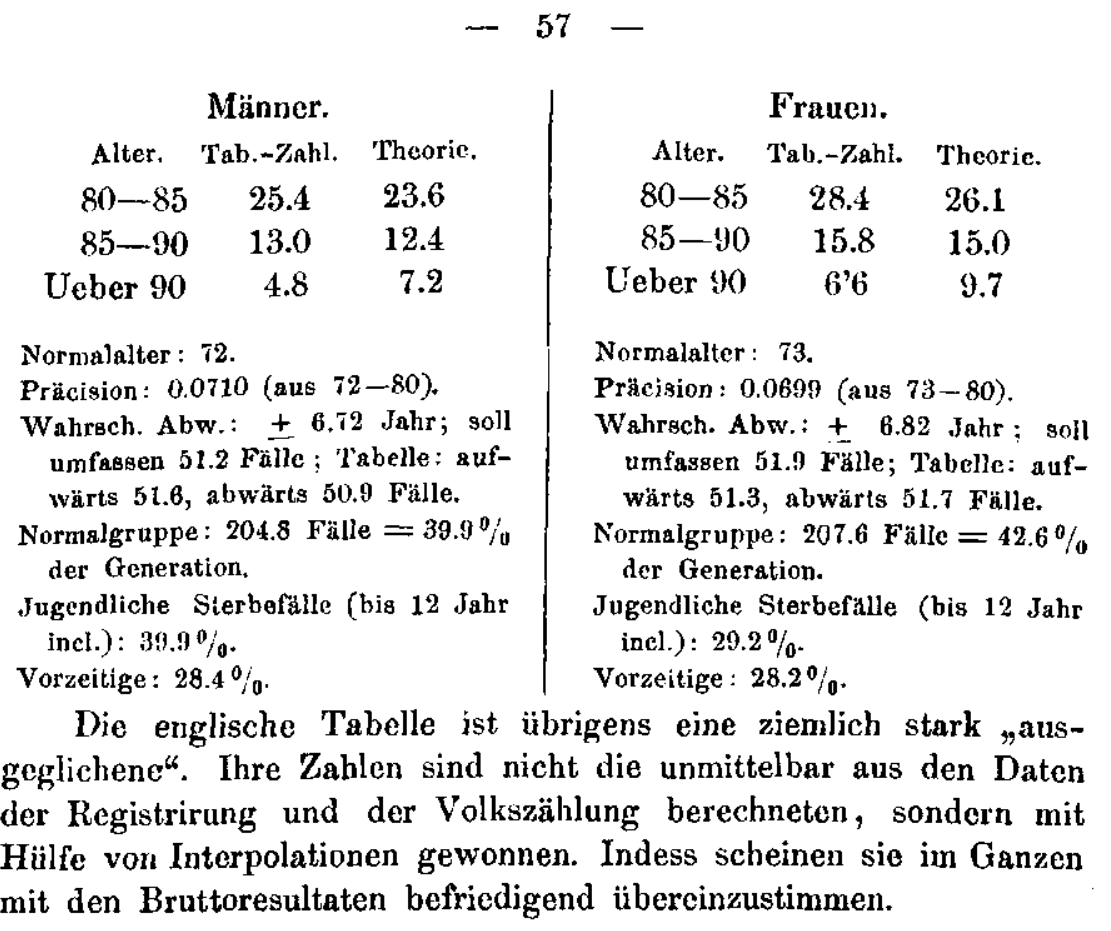

S c b w e d e n. ${ }^{1}$ )

\begin{tabular}{rcc|ccc}
\multicolumn{2}{c|}{ Männer (Gen.: 1000$).$} & \multicolumn{3}{c}{ Frauen (Gen.: 1000). } \\
Alter. & Tab.-Zahl. & Theoric. & Alter. & Tab.-Zahl. & Theoric. \\
$40-45$ & 34.2 & $(0.7)$ & $45-50$ & 32.3 & $(0.1)$ \\
$45-50$ & 40.1 & $(2.9)$ & $50-55$ & 39.4 & $(3.6)$ \\
$50-55$ & 48.5 & $(10.5)$ & $55-60$ & 51.2 & $(11.9)$ \\
$55-60$ & 58.5 & $(27.1)$ & $60-65$ & 67.5 & $(34.6)$ \\
$60-64$ & 56.2 & $(41.5)$ & $65-68$ & 49.0 & $(38.9)$ \\
$64-65$ & 15.4 & 13.1 & $68-70$ & 35.5 & 32.9 \\
$65-70$ & 81.5 & 81.5 & $70-73$ & 57.5 & 57.4 \\
$70-72$ & 34.9 & 36.8 & $73-75$ & 38.9 & 39.4 \\
$*$ & $*$ & $*$ & $*$ & $*$ & $*$ \\
$72-75$ & 52.4 & 54.7 & $75-77$ & 39.4 & 39.4 \\
$75-80$ & 79.1 & 76.8 & $77-80$ & 57.4 & 57.4 \\
$80-85$ & 53.3 & 48.7 & $80-85$ & 73.8 & 71.8
\end{tabular}

1) Nach der neuesten schwedischen Sterblichkeitstafel in "Bidrag till Sveriges off. stat.; Befolknings-stat., ny f. XII., 3. Stockholm 1874, p. 122. 


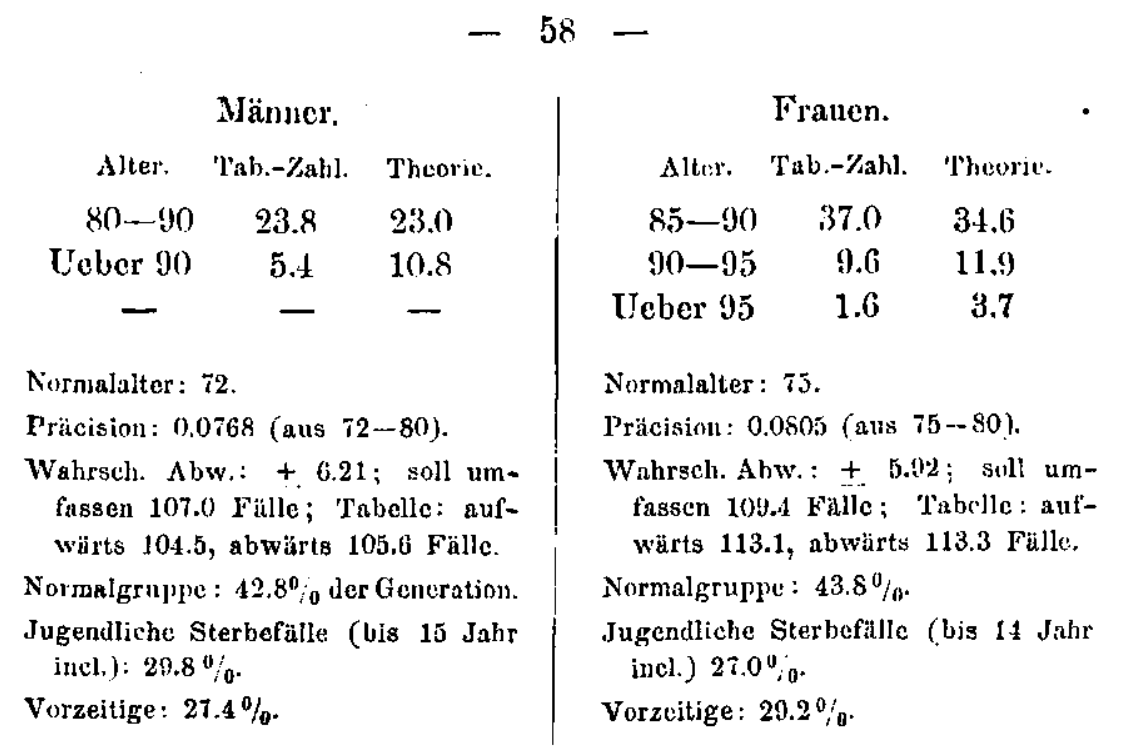

Die schwedische Tabelle ist mit Hülfe der mittleren Bevölkerungszahlen für die zehn .Jahre $1861-70$ berechnet; cine auf etwas verschiedener Grundlage berechnete Tabelle findet sich in demselben Hefte der amtlichen Statistik pag. LXII. Beide Tabellen, deren Unterschiede im Ganzen nicht sehr bedeutend sind, stellen natürlich, wie alle ijbrigen, nur näherungswejse das Absterben ciner wirklichen Generation dar.

Eine andere Sterblichkeitstabelle neuesten Datums ist dic von R. Böckh für Preussen mitgetheilte. ${ }^{1}$ )

Die Vergleichung derselben mit der Theorie ergibt Folgendes (auf je 1000 Lebendgeborene):

Männer.

Alter. Tab.-Zahl. Theoric.

$\begin{array}{llr}40-45 & 32.0 & (1.2) \\ 45-50 & 37.8 & (4.6) \\ 50-55 & 44.7 & (13.4) \\ 55-60 & 54.6 & (30.3) \\ 60-63 & 35.6 & (28.4)\end{array}$

Frauen.

Alter. Tab.-Zalsl. Theoric.

$\begin{array}{lll}40--45 & 30.9 & (0.6)\end{array}$

$45-50 \quad 32.0 \quad$ (2.6)

$\begin{array}{lll}50-55 & 38.8 & (\text { b.6) }\end{array}$

$55-60 \quad 52.2 \quad(25.8)$

$60-63 \quad 37.5 \quad(27.4)$

1) Hildebrand und Conrad, Jahcb. für Nat. u. Stat. 1875, XXV. B. S. $201 \mathrm{ff}$. 


\begin{tabular}{|c|c|c|c|c|c|}
\hline \multicolumn{3}{|c|}{ Männer. } & \multicolumn{3}{|c|}{ Frauen. } \\
\hline Alter. & 'lab.-Zahl. & 'Theorie. & Miter. & Tab.-Zahl. & 'Theoris. \\
\hline $63-65$ & 24.7 & 23.2 & $63-65$ & 25.5 & 23.8 \\
\hline $65-70$ & 65.1 & 67.6 & $65-70$ & 73.0 & 74.2 \\
\hline * & $*$ & * & $70-71$ & 16.2 & 16.2 \\
\hline $70-75$ & 65.0 & 67.6 & * & * & * \\
\hline $75-80$ & 54.2 & 51.6 & $71-75$ & 60.9 & 62.9 \\
\hline $80-85$ & 33.2 & 30.3 & $75-80$ & 63.5 & 61.5 \\
\hline $85-90$ & 12.5 & 13.4 & $80-85$ & 36.7 & 35.3 \\
\hline Ueber 90 & 4.1 & 6.1 & $85-90$ & 14.1 & 14.7 \\
\hline - & - & - & Ueber 90 & 5.0 & 5.8 \\
\hline \multicolumn{3}{|c|}{ Normalalter: 70.} & \multicolumn{3}{|c|}{ Normalalter : $\boldsymbol{i}$. } \\
\hline \multicolumn{3}{|c|}{ Präcision: 0.0741 (aus $70--80$ ). } & \multicolumn{3}{|c|}{ Präcision: 0.0708 (aus $71-80$ ). } \\
\hline \multicolumn{3}{|c|}{$\begin{array}{l}\text { Wahrsch. Abw.: } \pm 6.44 \text { Jahr: soll } \\
\text { umfassen } 84.5 \text { Fälle; Tabelle : auf- } \\
\text { wärts } 83.0 \text {, abwärts } 82.1 \text { Fälle. }\end{array}$} & \multicolumn{3}{|c|}{$\begin{array}{l}\text { Walırsch. Abw.: + 5.98 Jahr; sull } \\
\text { umfassen } 90.1 \text { Fülle; Tabelle: auf- } \\
\text { wärts } 8 ! .2 \text {, abwärls } 88.0 \text { Fälle. }\end{array}$} \\
\hline \multicolumn{3}{|c|}{$\begin{array}{l}\text { Jugendliche Sterbefälle (bis } 15 \mathrm{Jahr} \\
\text { incl.) } 41.7 \% \text {. }\end{array}$} & \multicolumn{3}{|c|}{$\begin{array}{l}\text { Jagendliche Sterbefälle (bis } 14 \mathrm{Jah} \\
\text { incl.) } 35.7 \% \text { \% }\end{array}$} \\
\hline \multicolumn{3}{|c|}{ Vorzeitige: $24.5 \%$. } & \multicolumn{3}{|c|}{ Vorzeitige: $28.3^{\circ}{ }^{\circ}$} \\
\hline
\end{tabular}

40. Wie die Sterblichkeitsverhältnisse sich in verschiedenen Ländern verscbieden gestalten, so wird man auch in demselben Lande nach geographischen Beyirken oder auch nach socialen und wirthschaftlichen Verhältnissen einigermassen verschiedene Tabellen aufstellen können.

Beispielsweise wollen wir zwei Sterblichkeitstafeln untersuchen, die von der niederländischen amtlichen Statistik einestheils für die hinsichtlich der Mortalität am ungünstigsten gestellten vier Provinzen Nord- und Siid-Holland, Seeland und Utrecht und anderntheils für die übrigen 7 Provinzen aufgestellt worden sind. ${ }^{1}$ ) Die Zahlen sind bezogen auf je 1000 Lebendgeborene.

1) Stat. Jaarboek voor het koningr. (ler Nederlanden. 14. u. 15. Jahrg. S. $390 \mathrm{ff}$. 


\begin{tabular}{|c|c|c|c|c|c|}
\hline \multicolumn{6}{|c|}{ Vier Provinzen. } \\
\hline Alter. & Tab.-Zahl. & Theorie. & Alter. & Tab.Zahl. & Theorie. \\
\hline $40 \cdots 45$ & 35.5 & $(1,6)$ & $40-45$ & 33.9 & $(2.6)$ \\
\hline $45-50$ & 38.1 & $(10.0)$ & $45-50$ & 31.2 & $(6.9)$ \\
\hline $50-55$ & 48.0 & $(24.4)$ & $50--55$ & 38.8 & $(17.2)$ \\
\hline $55-58$ & 29.5 & $(20.9)$ & $55-58$ & 27.3 & $(18.1)$ \\
\hline $58-60$ & 20.9 & 17.2 & $58-60$ & 17.7 & 15.8 \\
\hline $60-65$ & 52.9 & 52.0 & $60-65$ & 52.8 & 53.4 \\
\hline $65-68$ & 37.5 & 35.1 & $65-70$ & 67.0 & 66.9 \\
\hline * & * & * & $*$ & $*$ & $*$ \\
\hline $68-70$ & 22.8 & 23.5 & $70-75$ & 66.8 & 66.9 \\
\hline $70-75$ & 54.9 & 54.2 & $75-80$ & 55.7 & 53.4 \\
\hline $75-80$ & 43.6 & 40.8 & $80-82$ & 18.6 & 15.8 \\
\hline $80-85$ & 28.8 & 25.3 & $82-85$ & 20.0 & 18.1 \\
\hline $85-90$ & 11.1 & 12.8 & $85-90$ & 14.5 & 17.2 \\
\hline Ueber 90 & 3.1 & 7.7 & Ueber 90 & 5.4 & 9.8 \\
\hline \multicolumn{6}{|c|}{ Sieben Provinzen. } \\
\hline $40-45$ & 35.7 & (1.3) & $40-45$ & 37.9 & $(0.8)$ \\
\hline $45-50$ & 40.5 & $(4.8)$ & $45-50$ & 33.4 & (3.1) \\
\hline $50-55$ & 50.6 & $(14.5)$ & $50-55$ & 41.9 & $(10.6)$ \\
\hline $55-60$ & 57.4 & $(32.6)$ & $55-80$ & 49.0 & $(27.2)$ \\
\hline $60-63$ & 36.8 & (31.8) & $60-63$ & 35.7 & $(29.6)$ \\
\hline $63-65$ & 28.8 & 26.3 & $63-65$ & 28.1 & 25.0 \\
\hline $65-70$ & 78.1 & 78.2 & $65-70$ & 79.4 & 79.1 \\
\hline $70-71$ & 16.6 & 17.5 & $70-72$ & 33.8 & 35.7 \\
\hline * & * & $*$ & $*$ & $*$ & * \\
\hline $71-75$ & 63.5 & 66.1 & $72-75$ & 51.3 & 53.1 \\
\hline $75-80$ & 70.1 & 67.5 & $75-80$ & 76.6 & 74.8 \\
\hline $80-82$ & 24.6 & 20.2 & $80-82$ & 25.6 & 22.6 \\
\hline $82-85$ & 24.3 & 22.2 & $82-85$ & 27.4 & 25.2 \\
\hline $85-90$ & 18.5 & 20.7 & $85 \rightarrow 90$ & 22.0 & 23.1 \\
\hline Ueber 90 & 6.3 & 10.6 & Ueber 90 & 7.2 & 11.3 \\
\hline
\end{tabular}

Die Präcisionen in den beiden ersten Tabellen sind aus den Zablen fiir die Jabre $68-75$ und $65-75$, die der beiden anderen aus den Altersclassen $71-80$ und $72-80$ berechnet. Man hat nun zur Vergleichung: 


$$
-61-
$$

Männer: 4 Provinzen: Normalalter 68 - Präcision: 0.0639 Normalgruppe: $32.8 \%$.

7 Provinzen: Normalalter: 71 - Präcision: $0.0726-$ Normalgruppe: $41.5 \%$.

Frauen: 4 Provinzen: Normalalter: 70 - Präcision: $0.0680-$ Normalgruppe: $36.2 \%$.

7 Provinzen: Normalalter: 72 - Präcision: $0.0758-$ Normalgruppe: $42.0 \%$.

Die drei Elemente sind also in der zweiten Gruppe günstiger als in der ersten und überdies in jeder Gruppe wieder günstiger für das weibliche als für das männliche Geschlecht.

Im Ganzen harmoniren in diesen Tabellen die theoretischen und die empirischen Daten weniger gut, als es bisher der Fall $\% 4$ sein pflegte. Doch zeigt sich in den theoretischen und empirischen Werthen der wahrsch. Abweichungen wieder eine befriedigendere Uebereinstimmung. Man findet:

Vier Prov. Männer: w. Abw.: 7.46 J. entspr. 82.2 Fällen; 'Tab.: aufw. 85, abw. 82 Fälle.

Frauen: w. Abw.: $7.01 \mathrm{~J}$. entspr. 90.5 Fällen; Tab.: aufw. 89.3 , abw. 89.3 Fälle.

Sieben Prov. Männer: w. Abw.: 6.57 J. entspr. 103.7 Fällen; Tab.: aufw. 103.1, abwärts 102.0 Fälle.

Frauen: w. Abw.: 6.29 J. entspr. 105.5 Fällen; Tab.: aufw. 102.9, abw. 105.7 Fälle.

Die Verschiedenheit der Verbältnisse in den einzelnen Provinzen ist indess nicht so gross, dass nicht auch bei der Aufstellung einer Tabelle für das ganze Land noch eine der Theorie ungefähr entsprechende Vertheilung der Fälle um ein mittleres Normalalter hervortreten könnte.

Man findet demnach für das ganze Königreich :

\begin{tabular}{rcc|rcc}
\multicolumn{3}{c|}{ Männer. } & \multicolumn{3}{c}{ Frauen. } \\
Alter. & Tab.-Zahl. & Theorie. & Alter. & Tab.-Zahl. & Theorie. \\
$40-45$ & 35.6 & $(1.8)$ & $40-45$ & 39.5 & $(1.0)$ \\
$45-50$ & 39.3 & $(6.2)$ & $45-50$ & 32.3 & $(3.6)$ \\
$50-55$ & 49.3 & $(16.2)$ & $50-55$ & 40.4 & $(11.2)$ \\
$55-60$ & 53.9 & $(33.7)$ & $55-60$ & 46.6 & $(27.3)$ \\
$60-62$ & 23.3 & $(19.5)$ & $60-63$ & 32.7 & $(27.3)$
\end{tabular}




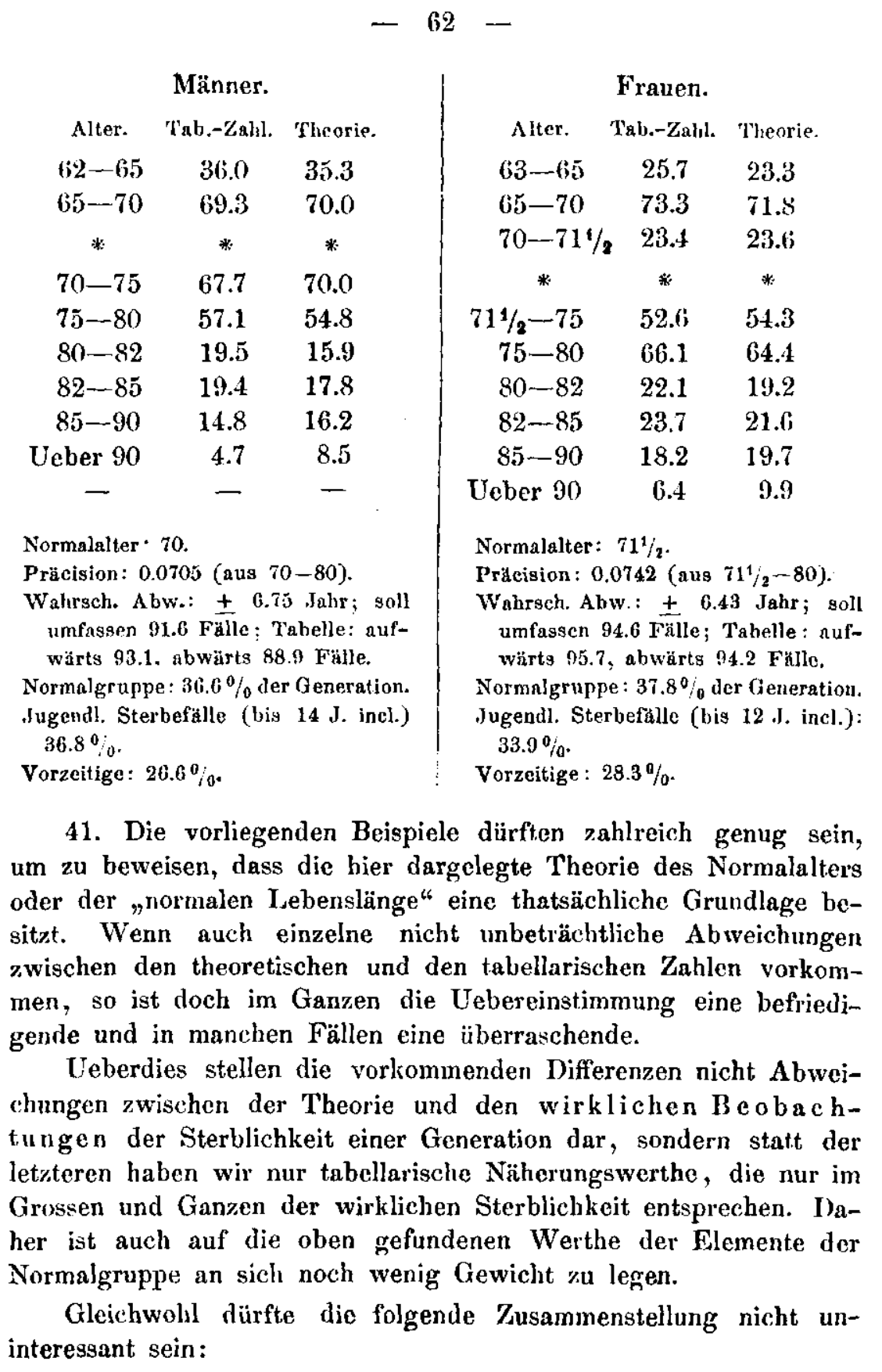




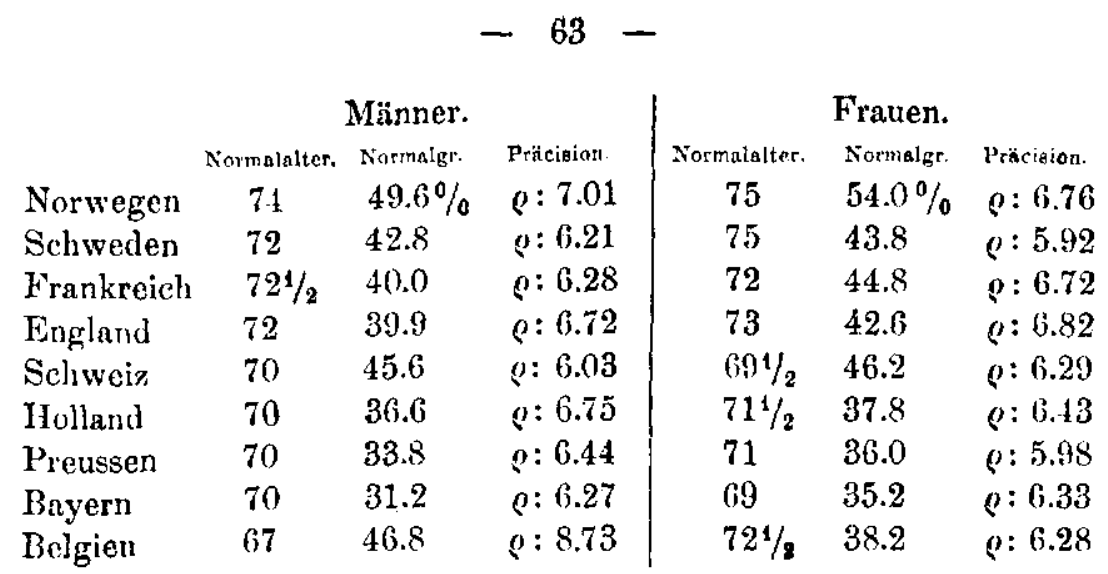

Der grösseren Anschaulichkeit wegen ist die Präcision durch die Constante $\rho(=0.4769)$, dividirt durch die wahrscheinliche $\mathrm{Ab}-$ weichung, ausgedrückt.

Es ist leicht, Rechenschaft davon zu geben, wie sich durch die Acnderung eines der drei Elemente der Charakter der Sterblichkeitsverhältnisse verbessert oder verschlimmert. Hier genüge die Bemerkung, dass die Lage um so günstiger ist, je grösser die drei Elemente sind, und so ungünstiger, je kleiner dieselben werden. Wird das eine kleiner und das andere grösser, so kam eine Ausgleichung eintreten. So wird \%. B. Belgien für das auffallend niedrige Normalalter der Männer einigermassen ontschädigt durch die beträchtliche Grösse der Normalgruppe; freilich wird diese Entschädigung wieder beeinträchtigt durch die kleine Präcision. 1)

Mit der Normalgruppe ist natürlich anch die Summe der "jugendlichen" und der "vorzeitigen" Gruppe der Gestorbenen gegeben. Die immer etwas willkürliche Zerlegung dieser Summe ist hier nicht wiederholt, weil die obigen Elemente für die Beurtheilung der normalen Lebensverhältnisse ausreichen.

Numerische Untersuchungen dieser Art von gesichertem Werth künnen nur mit Hülfe von unmittelbarem, exact abgegränztem Beobachtungsmaterial durchgeführt werden, nicht aber aus tabellarischen Zahlen, die das Product eines Verarbeitungsprozesses sind. Unsere theoretische Formel ist nicht mit einer empirischen «u verwechseln; sie stellt den Lauf der Dinge nach dem abstracten Wahrscheinlichkeitsgesetz dar und sie gibt die einzig mögliche

1) Der k leinen Präcision entspricht natürlich eine grosse walırscheinliche Abweiclung im Nempr des Ausdrucks. 
rationelle Erklärung der Symmetrie der Sterbefälle, die wenigstens auf einer gewissen Strecke ober - und unterhalb des Dichtigkeitsmittels unverkennbar nachzuweisen ist, eine Symmetrie, die durch eine empirische Formel nur als räthselhaftes Phänonen hingestellt, nicht aber erklärt werden könnte.

\section{Typische Wahrscheinlichkeitsgrössen.}

42. Wenn man in der gewöhnlichen statistischen Technik aus gewissen speciellen Massenbeobachtungen Procentzablen berechnet und diesen eine allgemeine Bedeutung beilegt für die die gleichartigen Massenerscheinungen überhaupt, so wird diese Annahme bei vielen Classen von Erscheinungen erfahrungsmässig zwar mehr oder weniger zutreffen, aber das ganze Verfahren ist gleichwohl ein rein empirisches, da jenes Procentverhältniss, als Bruch ausgedrückt, keineswegs ohne weiteres wegen seiner ungefähren Constanz auch schon den Charakter eines Näherungswerthes einer festen oder auch nur einer zufällig veränderlichen mathematischen Wahrscheinlichkeit besitzt. Um mit einiger Siqherheit den empirischen Verbältnisszahlen diesen bestimmten Charakter beilegen zu können, muss man mittelst einer grösseren Anzahl von Einzelwerthen zeigen, dass eine der Bedingungen $a$ ) oder $b$ ) des $\S 20$ erfültt ist, und überdies, namentlich im letzten Falle, dass die Einzelwerthe, absolut betrachtet, als typische Grössen erkennbar sind. Im ersten Falle hat man (§ 25) eine typische Wahrscheinlichkeitsgrösse mit normaler, im zweiten eine solche mit übernormaler Dispersion. Beide Arten von Wahrscheinlichkeiten sind nun aber in den menschlichen Massenerscheinungen, trotz der scheinbar oft grossen Constanz derselben, nur selten nachzuweisen, ja, es ist mir bisher eigentlich nur in. einem einzigen $\mathrm{Falle}$ gelungen, eine unzweifelhafte typische Wahrscheinlichkeitsgrösse mit normaler Dispersion aufzufinden, und zwar ist dies die Wahrscheinlichkeit einer Knaben- oder Mädchengeburt, also eines in das physiologisch-naturwissenschaftliche Gebiet fallenden Vorganges. ${ }^{1)}$

Dieser Gegenstand verdient daher schon dieser seiner theoreti-

1) \$. die S. 23 citirte Abhandlung in den Jahrb. von Hildebrand und Conrad. 
schen Eigenartigkeit wegen einc weitere Untersuchung, und ich lasse zunïchst im Anschluss an meine frühere Arbeit eine weitere Reihe von Vergleichungen zwischen Beobachtung und Theorie hicr folgen, deren Berechnung ich theilweise meinen Dorpater Zuhörern verdanke. Die Beobachtungsgrösse ist wieder die Zahl $z$ der Knabengeburten (incl. Todtgeborenen) auf 1000 Mädchengeburten, also eine einfache Function der Wahrscheinlichkeit $v$ einer Knabengeburt, indem $z=\frac{11000}{1-v}$

Wir untersuchen nun wieder die monatlichen Werthe von z in den 34 preussischen Beyirken (Osuabrück und Aurich sind alsammengefasst, Hohenzollern und Militïr im Auslande weggelassen) - und ywar in den 3 Jahren 1870-72.

In jedem Bexirke haben wir also 36 Einzelwerthe aus ebenso vielen Beobachtungsreihen, denen wir unbedenklich glejches Gewicht beileges dürfen, da die monatlichen Geburtenzahlen in einem und demselben Bexirke verhältnissmüssig nur wenig schwanken. Demnach ist $(\S 20) n$ gleich 36 , und wenn $\left[d^{2}\right]$ wieder dic Summe der Quadrate der Abweichungen der 36 Einzelwerthe $z$ von ihrem arithmetischen Mittel bereichnet, so ist nach der Methode der kleinsten Quadrate die Präcision $h$ der Einzelbestimmung von $z$ in dem betrachteten Bezirke $=\sqrt{\frac{35}{2\left[\delta^{2}\right]}}$

Andererseits aber ist dieselbe Präcision, ausgedrückt nach der combinatorischen Methode, $=\frac{(1-v)^{2}}{1000 \sqrt{2} v(1-v)} \sqrt{g}$, wenn $g$ die mittlere monatliche Geburtenzahl des betreffenden Bezirkes in den drei Jahren und $v$ die richtige Wahrscheinlichkeit einer Knabengeburt darstellt. Der let»teren werden wir möglichst nahe kommen, wenn wir die Zahl sänmtlicher Knabengeburten in Preussen von 1870-72 dividiren durch die Zabl sänmtlicher Geburten iiberhaupt in dem gleichen Zeitraum. Wir finden wieder wie in den Jahren $1868 / 69 v=0.515$, entsprechend $z=1063$. Der Bruch, nit dem $\sqrt{g}$ multiplicirt wird, bleibt also für alle Bezirke gleich 0.0003328 .

43. Die beiden ihrer Ableitung nach so verschiedenen Präcisionsbestimmungen müssen nun wenigstens einigermassen übereinstimmen, weun $v$ die Bedeutung einer typischen Wahrscheinlichkeit mit constanter Dispersion besitzen soll. Die folgenden Tabellen zeigen, wiefern dieses stattfindet. Die erste entbält die 17 grösseren, die zweite dic 17 kleineren Be\%irke, geordnet nach der mittleren 
monatlichen Geburtenzahl. Unter $C$ findet man die nach der combinatorischen (oder "statistischen") Methode berechneten Präcisionen, unter $Q$ dagegen diejenigen, welche die Methode der kleinsten Quadrate ("physikalische" Methode) ergibt. Zur Vergleichung sind auch die früher aus den monatlichen Beobachtungen der Jahre 1868-69 berechneten Präcisionen nochmals beigefügt, unter Verbesserung eines wonig erheblichen Rechenfehlors bei Magdeburg.

Grosse Bezirke.

\begin{tabular}{|c|c|c|c|c|c|}
\hline & \multicolumn{2}{|c|}{$1870-72$} & \multicolumn{2}{|c|}{$1868-69$} & \multirow[b]{2}{*}{$M Q$} \\
\hline & $c$ & $Q$ & $Q$ & $C$ & \\
\hline Oppeln & 0.0231 & 0.0227 & 0.0214 & 0.0232 & 0.0221 \\
\hline Breslau & 0230 & 0222 & 0205 & 0230 & 0214 \\
\hline Düsseldorf' & 0225 & 0225 & 0247 & 0218 & 0236 \\
\hline Posen & 0204 & 0208 & 0205 & 0203 & 0207 \\
\hline Königsherg & 0198 & 0234 & 0208 & 0195 & 0221 \\
\hline Frankfurt & 0191 & 0164 & 0185 & 0189 & 0175 \\
\hline Arnsberg & 0186 & 0208 & 0177 & 0180 & 0193 \\
\hline Potsdam & 0184 & 0150 & 0176 & 0183 & 0163 \\
\hline Liegnitz. & 0181 & 0202 & 0163 & 0182 & 0183 \\
\hline Marienwerder & 0180 & 0153 & 0249 & 0180 & 0201 \\
\hline Merseburg & 0180 & 0187 & 0146 & 0179 & 0167 \\
\hline Schleswig & 0174 & 0152 & 0118 & 0173 & 0135 \\
\hline Magdeburg & 0173 & 0138 & 0174 & 0171 & 0156 \\
\hline Berlin & 0172 & 0144 & 0158 & 0165 & 0151 \\
\hline Gumbinnen & 0164 & 0173 & 0144 & 0159 & 0159 \\
\hline Cassel & 0162 & 0158 & 0189 & 0164 & 0174 \\
\hline Stettin & 0156 & 0165 & 0166 & 0155 & 0165 \\
\hline \multicolumn{6}{|c|}{ Kleine Bezirke. } \\
\hline Bromberg & 0.0154 & 0.0129 & 0.0145 & 0.0154 & 0.0137 \\
\hline Cöln & 0148 & 0159 & 0149 & 0146 & 0154 \\
\hline Trier & 0145 & 0176 & 0148 & 0145 & 0162 \\
\hline Wiesbaden & 0144 & 0108 & 0108 & 0143 & 0108 \\
\hline Cöslin & 0143 & 0139 & 0119 & 0143 & 0129 \\
\hline Danzig & 0142 & 0163 & 0151 & 0142 & 0157 \\
\hline Coblenz & 0136 & 0114 & 0131 & 0137 & 0123 \\
\hline Aachen & 0129 & 0118 & 0151 & 0128 & 0135 \\
\hline
\end{tabular}




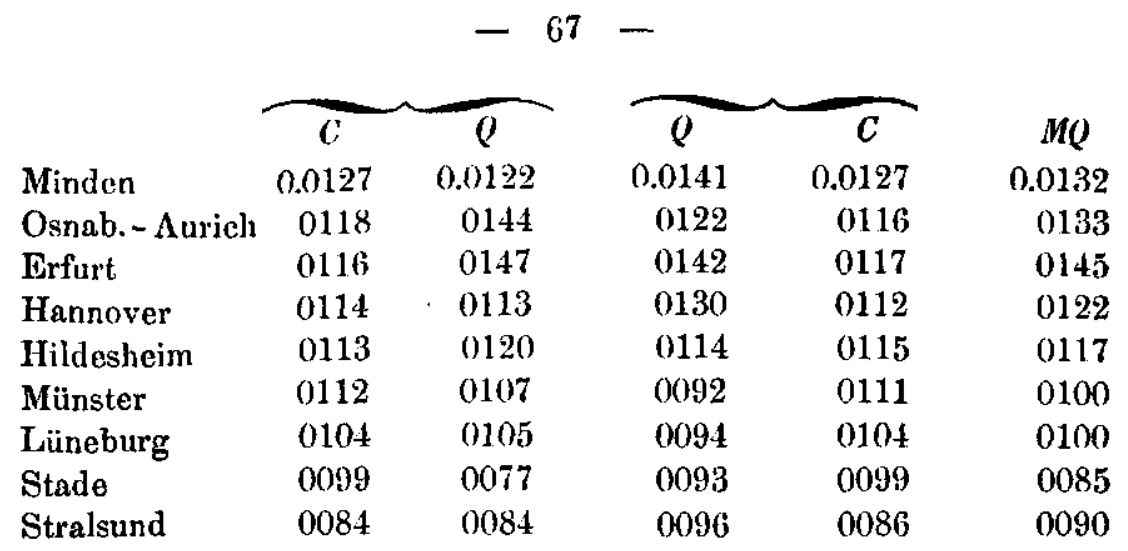

Die beiden Colonnen unter $C$ sind nahezu identisch, weil die Werthe den mittleren Geburtenzahlen der einzelnen Bezirke proportional sind und diese in dem fünfjährigen Zeitraume nur eine geringe Verïnderung erfahren haben. Auch die Präcisionen in den beiden Colonnen $g$ können daher als Näherungswerthe derselben Grösse für jeden Bexirk angesehen werden, und daher wurde zur besseren Vergleichung der Ergebnisse der beiden Methoden unter $M Q$ die Mittelwerthe aus den »usammengehörenden Zahlen der beiden Colonnen $Q$ beigefügt, obwobl diese Mittelwerthe, wegen des grösseren Gewichtes der Zahlen aus dem dreijährigen Zeitraum (grösser in Verhältniss von $\sqrt{3}: \sqrt{2}$ ) nicht eigentlich die wahrscheinlichsten Werthe der nach der physikalischen Methode bestimmten Präcisionen darstellen.

Bedenkt man nun, dass die Zahlen unter $Q$ nur Wahrscheinlichkeitsbestimmungen und wegen der keineswegs sehr grossen Zahl der Versuchsreihen in jedem Berirk (36 und 24) einem verhältnissmässig bedeutenden wahrscheinlichen Fehler ausgeset»t sind, so wird man die Uebereinstimmung der beiden Arten der Präcisionsberechwung für befriedigend halten dürfen. Wir finden demnach hier das Kriterium einer typischen Wahrscheinlichkeitsgrösse mit normaler Dispersion zutreffend. Die Mittelwerthe der vicr Zahlenreihen unter $C$ und $Q$ sind in der ersten Tabelle resp. 0.0188; $0.0183 ; 0.0184 ; 0.0186$, also sehr nahe gleich; in der zweiten aber sind sie sämmtlich $=0.0125$.

Wenn in der ersten Tabelle die conbinatorischen Präcisionen im Durchschnitt um eine Kleinigkeit grösser sind als die plysikalischen, so ist dies durch zufällige Störungen zu erklären. Bemerkenswerth aber ist, dass nur awei oder drei Mal die physikalische 
Prïcision erheblich grösser wird, als die combinatorische, nümlich bei Marienwerder 1868 - 69, bei Erfurt und allenfalls bei Trier 1870-72. Fiir den ersten und letzen Fall aber findet sich schon in dem anderen Theile des fünfjährigen Zeitraumes eine genügende Compensation, und auch die Differen\%en bei Erfurt sind nach der Analogie aller übrigen Fïlle wieder durch zufällige Störung, nicht aber durch die unbegreifliche Annahme einer verbundenen Massenerscheinung mit unternormaler Dispersion $\%$ crklären.

44. Wenn nun wirklich die Zahl der Knabengeburten auf je 1000 Mädchengeburten eine typische Wahrscheinlichkeitsgrösse nit normaler Dispersion darstellt, so nuss sich eine hinlänglich grosse Anzahl von Einzelwerthen dieser Ziffer auch der Function $F$ entsprechend um den typischen Mittelwerth grruppiren. Für die Beobachtungen der Jahre 1868-69 habe ich dies in dor mehrerwähnten Abhandlung wezeigt; aber auch die Ziffern aus der folgenden dreijährigen Periode bestätigen die Theoric.

Zur Aufstellung der theoretischen Gruppirung nehmen wir als gemeinschafthiche Präcision der Eitrelbestimmungen von $z$ in den grossen Bezirken den Mittelwerth der combinatorischen Präcisionen für 1870-72, also 0.0188, und in den kleinen Provinzen den Mittelwerth 0.0125 an. Dieses anch fïr die Prïhere Periode angewandte Näherungsverfahren ist für unsere Zwecke genau genug, da sich die einzelnen Präcisionen in den beiden Gruppen von Beairker iun Ganzen nicht sehr weit von dem betreffenden Mittel entfernen.

Als wahrseheinlichsten Werth des typischen Mittels nehmen wir die aus der Gesanmtlseit aller Geburten im Staate von $1870-72$ abgeleitete $/$ iffer 1063 an, dieselbe, die auch für die Jahre 1868 - 69 getunden wurde. Alsdann ergilst sich für die grossen Berirke:

\begin{tabular}{ccccc} 
Abweiching. & \multicolumn{3}{c}{ Reoliaclitec Füle. } & Theoris. \\
\pm & - & - & \pm & \pm \\
$0-191 / 2$ & $1101 / 2$ & $1131 / 2$ & 22.4 & 212 \\
$191 / 2-391 / 2$ & 91 & 104 & 195 & 190 \\
$391 / 2-591 / 2$ & 60 & 48 & 114 & 110 \\
$591 / 2-791 / 2$ & 30 & 20 & 50 & 48 \\
$791 / 2-991 / 2$ & 10 & 6 & 16 & 16 \\
Ueber $991 / 2$ & 4 & 9 & 13 & 5
\end{tabular}

Die letyten Colonnen stehen in genïgendem Einklange, zumal die theoretische Zahl der älswerstrn Alweichungen wegen der An- 
nahme ciner gemeinschaftlichen Mittel-Präcision nothwendig zu klein ausfallen muss. Auch die Symmetrie der positiven und negativen Abweichungen gestaltet sich recht befriedigend, wenn man dic \%weite und dritte $\Lambda$ bweichungsstrecke zu einer einzigen zusammenfasst. Dic Gesammtzahl der positiven Abweichungen beträgt 3001/2, dic der negativen $311 \frac{1}{2}$.

\begin{tabular}{ccccc}
\multicolumn{5}{c}{ Kleine Be\%irke. } \\
Ahweichung. & \multicolumn{3}{c}{ Benbachtete Fülle. } & Theorie. \\
+ & - & $-!$ & + & \pm \\
$0-191 / 2$ & 92 & 71 & 163 & 155 \\
$191 / 2-391 / 2$ & 90 & 69 & 159 & 150 \\
$391 / 2-591 / 2$ & 60 & 46 & 106 & 118 \\
$591 / 2--791 / 2$ & 41 & 42 & 83 & 81 \\
$791 / 2-991 / 2$ & 19 & 25 & 44 & 50 \\
Ueber $991 / 2$ & 20 & 31 & 57 & 49
\end{tabular}

Vie bejden letgten Colomen stimmen wieder leidlich befriedigend \%usanmen. Weniger gut tritt die Symmetric der positiven und der negativen Seite hervor, da dic erstere nur 28t, die letztere aber 328 Fälle aufweist.

45. Bei genauerer Cntersuchung wïrden sich ohne Zweifel in den versehiedenen Landestheilen verschiedene typjsche Mittelwerthe nachweisen lassen, die aber im Ganzen nicht woit von einander abweichen würden, so dass man doch wieder ein Nittel aus diesen Mittel als Grundwerth für das ganze Land behandeln kann. Wir wollen wenigstens eines jener lokalen Mittel näher betrachten, nämlich das der Stałt Berlin, und \%war legen wir die 108 MonatsWerthe ron $z$ in dem Zeitraume $1865-73$ an Grunde.

In diesen Zeitraume wurden im Garen 140,037 Knaben und 132.433 Mädchen, yusammen also 272,47 ) Kinder geboren. Hieraus wïrde sich der wahrscheinliche Werth von $z$ für Berlin $\%$ a 1057 crgeben. Das arithmetische Mittel aus den 108 monatlichen Werthen jedoch beträgt nur 1055 , and diese Zahl kann man, indem man von der Verschiedenheit des Gewichts der Einzelbestimmungen absieht. olne Bedenken als Ausgangspunkt nehmen.

Berechnet man mit dicsem Mitelwerthe nach der Methode der kleinsten Quadrate die Präcision der Einzelbestinmung - allerdings cine umständliche Reclnung, da man 108 Fehlerquadrate $z u$ bilden hat - so findet man als Werth derselben 0.0157. Auf dieser 
Grundlage findet man dann eine sehr gute Uebereinstimmung zwischen der beobachteten und der theoretischen Vertheilung der $\mathrm{Ab}$ weichungen. Dieselbe ist allerdings nicht erkennbar, wenn man sehr kleine Fehlerstrecken betrachtet. So ergibt $\%$ B. die Beobachtung:

\begin{tabular}{cccc} 
Abweichung. & \multicolumn{3}{c}{ Beobachtete Fällc. } \\
\pm & - & \pm & \pm \\
$0-91 / 2$ & $91 / 2$ & $81 / 2$ & 18 \\
$91 / 2-191 / 2$ & 10 & 6 & 16 \\
$191 / 2-291 / 2$ & 8 & 10 & 18 \\
$291 / 2-391 / 2$ & 7 & 8 & 15 \\
$391 / 2-491 / 2$ & 2 & 8 & 10 \\
$491 / 2-591 / 2$ & 5 & 5 & 10 \\
$591 / 2-691 / 2$ & 5 & 1 & 6 \\
$691 / 2-791 / 2$ & 3 & 4 & 7 \\
$791 / 2-891 / 2$ & 1 & 0 & 1 \\
$891 / 2-991 / 2$ & 2 & 4 & 6 \\
Ueber $991 / 2$ & 1 & 0 & 1
\end{tabular}

Die positiven und negativen Abwcichungen scheinen hicr gall regellos aufzutreten, was bei der geringen Grösse der einzelnen Zahlen nicht auffallen kann. Dagegen ergibt die Addition aller Fälle auf jeder Seite nahezu dieselbe Zahl, nämlich $54 \frac{1}{2}$ positive und $53 \%$ negative Abweichungen. Und wenn man grössere Gruppen bildet, so crhält man:

\begin{tabular}{ccccc} 
Abweichung. & \multicolumn{3}{c}{ Beobachtete Fälle. } & Theoric. \\
\pm & - & + & \pm & \pm \\
$0-391 / 2$ & $34^{1 / 2}$ & $32^{1 / 2}$ & 67 & 67 \\
$391 / 2-791 / 2$ & 15 & 18 & 33 & 33 \\
Ueber $791 / 2$ & 4 & 4 & 8 & 8
\end{tabular}

Also hat man bei der Annahme des Mittelwerthes 1055 und der davon abgeleiteten Präcision 0.0157 eine fast vollstïndige Uebereinstimmung awischen Theorie und Erfahrung. Uebrigens ergeben sich nahezu dieselben Resultate, wenu nan von dem Mittelwerthe 1057 ausgeht; es kommen dann auf die positive Seite 55 und auf die negative 53 Abweichungen.

Für die combinatorische Präcision bestimmen wir ebenfalls nur einen näherungsweise richtigen Mittelwerth, 1 ) indem wir für $g$ die

2) Bei Rechnungen dicser Art, dic in grosser Zahi anzustellen sind und viemals ge 4 a e lebereinstimmung mit den thcoretisch crwarteten Rcsultaten er- 
durchschnittliche monatliche Geburtenzahl in dem ganzen Zeitraume einsetzen, nämlich 2523; nehmen wir ferner als möglichst genauen Werth von $v 0.514$ an, so erhalten wir die Präcision 0.0168. Die Abweichung derselben von der nach der andern Methode berechneten ist an sjeh eine müssige, besonders da beide nur Näherungswerthe sind. Wenn man aber bemerkt, das die Uebcreinstimmung \%wischen Theoric und Beobachtung mit dieser letzteren Präcision weniger vollständig ist (die theoretischen Zahlen unter \pm werden nun: $70 \frac{1}{2}-31-6 \frac{1}{2}$ ), so liegt die Vermuthung nahe, dasss die nach der ersten Methode bercchnete Präcision die richtigere sei, und dass die combinatorische Priteision desswegen grösser erscheine, weil wir vielleicht mit einer typischenalWahrscheinlichkeitsgrösse mit etwas i bernormaler Dispersion za thun haben.

46. L'm die schr umständliche Berechnung der Präcision (oder auch des walırseheinlichen Fehlers) aus der Summe der Fehlerquadrate $z u$ vermeiden, empfiehlt Fechner die allerdings nicht gan\% ebenso sichere Berechnung derselben aus der Summe der absoluten Abweichungen (indem also alle $A$ bweichungen positiv genommen werden). Sie wird dann ausgedrückt dureh die Formel $\frac{1}{\varepsilon_{1} \frac{1}{\sqrt{n}}}$ wenn $\varepsilon_{1}$ das Mittel aus den absoluten $A b$ weichungen bedeutet und das arithmetische Hittel einfach als der wahre Werth angesehen wird.

Auf diesem bequemen Wege würden wir die Präcision 0.0156 finden, kaum abweichend von der zuerst berechneten. Fechner hat auch eine allgemeine Formel angegeben, um möglichst den Fehler zu corrigiren, der dadurch begangen wird, dass man die Abweichungen vom arithmetischen Mittel als die wahren behandelt. Diese Correctur gewährt indess nur bei der Anwendung auf viele Fälle im Ganzen eine Verbesserung, im einzelnen Falle dagegen kann sie auch den Fehler vergrössern. So bringt sic in vorliegenden Beispiele die'Präcision auf 0.0155 .

geben, ist es withtiger, rasch zu Naherungsresultaten, als langsam zu einer fic unoere Zwecke nutzlnsen Genauigkeit zu gelingen. Lebrigens könnte man ohnc Schwierigkeit die Grenzen der Fehler feststelles, die dadureh begangen werden, dass man, wie es in diesem Paragraphen und auch später noch geschieht, dio Verschiedenlteit der Gewichte der Einzelbestimmungen nicht streng in Rechnung bringt. 
Dic grosse Uebereinstimmung der Präcisionsbestimmungen aus dem mittleren Fehlerquadrat und dem mittleren absoluten Fehler, wie wir sie eben gefunden haben, ist num cin neuer Beweis daftir, dass die gegebenen 108 Einzelwerthe von $z$ wirklich als zufällige Modificationen einer festen typischen Grösse anzusehen sind. Denn nur unter dieser Voraussetzung ist die Beziehung zwischen Fìhlerquadraten und absoluten Feblern vorhanden, welche die Gleichheit der Resultate der beiden Berechnungen erzeugt.

Eben diese Bexiehung lässt sich nun noch frappanter ausdrücken durch die Formel $\pi=\frac{2 n\left[\delta^{2}\right]}{[\delta]^{3}}$, wo $n$ die Zahl der Einzelwerthe und $[\delta]^{2}$ das Quadrat der absoluten Fehlersumme bezeichnet. Man erhält also hier die Zahl $\pi$ dargestellt durch dic $\mathrm{Ab}-$ weichungen des Verbältnisses der Knaben- und Mädchengeburten von dem typischen Mittelwerthe.

In dem vorliegenden Beispiele finden wir in der That $208\left[\delta^{2}\right]-3.1307$, also fast genau 3.14 , was übrigens unuittelbar aus der nahen Uebereinstimmung der Präcisionsbestimmungen aus der Quadratsumme und der absoluten Summe folgt. Fiir die Fechner'sche Correction ist dies abermals ein nicht günstiger Einzelfall, da sie zu dem Resultate 3.147 führt.

Der typische Charakter der behandelten Wahrscheinlichkeitsgrösse ist somit ganz zweifellos; doch ist es nicht unmöglich, dass die zu Grunde liegende Wahrscheinlichkeit einer Knabengeburt nicht ganz fest, sondern im Laufe der Zeit kleinen, aber zufälligen Schwankungen unterworfen ist, so dass die eigentliche typische Wahrscheinlichkeit vielmehr das Mittel aus diesen veränderlichen Wahrscheinlichkeiten wäre. Jedenfalls aber ist die Ueberschreitung der Grenzen der nornialen Dispersion so wenig bedeutend, dass nuan sic bei allgemeinen, den ganzen Staat betreffenden Untersuchungen eben so ausser $A$ cht lassen kann, wie die Thatsache, dass der wirkliche Werth von $z$ für Berlin wohl jedenfalls um einige Einheiten kleiner ist, als die oben für den ganzen Staat angenommene Zahl 1063.

47. Da der Charakter einer Wahrscheinlichkeitsgrösse mit normaler Dispersion bei dem Geschlechtsverhältniss der Geborenen ${ }^{1}$ )

1) Statt dieges Verhältnisses kann man natïrlich auch unmittelbar dio Wahrscheinlichkeit einer Knabengeburt als tntersuchungsobject nehmen. Es ist 
sich weit schärfer ausdrückt, als bei irgend einer anderen statistischen Verbältnisszahl, die ich bisher untersucht habe, so ist \%u vermuthen, dass die natürlichen Bedingungen der Geschlechtsbestimmung eine besonders nahe Analogie mit einem Glücksspiel mit constanten Chancen besitzen. Sind die Entstehungsbedingungen der Einzelfalle äusserst verschiedenartig und verwickelt, so ist es allerdings noch immer denkbar, dass die für unsere Analyse nicht auflösliche Totalität der Bedingungen des Ereignisses dennoch auf längere oder kürzere Zeitstrecken in einem Beharrungszustande bleibt und ihre Wirkungen solche sind, als wenn fïr die Frequenz des Ereignisses eine constant bleibencle mathematische Wahrscheinlichkeit massgebend wäre. Aber Massenerscheinungen dieser Art sind wohl nur selten ausfindig zu machen, da von vornherein alle dicjenigen nicht in diese Classe gehören können, welche durch irgend einen nachweisbaren, nicht rein zufällig (also \%. B. periodisch) auftretenden Einfluss erheblich alterirt werden. Weit leichter aber kann jene Analogie mit einem Glücksspiel hervortreten, wenn ein enger umschriebener Bedingungscomplex angenommen werden darf, der jedem Einzelfalle in annähernd gleicher Weise zu Grunde liegt. Die Massenerscheinung erbält dann bis 7.0 cinem gewissen Grade den Charakter einer generischen, da ja eine Gleichartigkeit der Verursachung der Einzelfälle angenommen wird, doch bleibt der wichtige Unterschied von den eigentlichen generischen Massenerscheinungen, dass der wirksame Bedingungscomplex doch wieder ein für uns unauflöslicher und unïbersehbarer bleibt. Am einfachsten ist es nun, wenn sich derselbe direct auf die Form eines Chancenspiels zurückführen lässt, und eben desswegen halte ich die in meiner früheren Abhandlung erörterte Hypothese über die Ursache der relativen Constanz des Geschlechtsverhältnisses der Geborenen für die vorläufig empft'hlenswertheste: es würden hiernach in jedem weiblichen Individuum für das männliche oder für

(lies sogar eigentlich zweckmässiger, da in unserer Rechnung die Ableitung der Präcision des Geschleshtsverhältnisses aus derjenigen des Verhältnisses der Knabengeburten zur Gesammtheit der Geburten nur durch ein Nähorungsverfinhen erfolgt, also nicht ganz genau ist. Ich habe bisher das Geschle'htsverhäitniss zu Gruade gelegt, weil es die berkömmliche /iffer ist: bei weiteren Untersuchungen dürfte es sich jedoch empfehlen, von den empirischen Werthen der erwähnten Wahrschejnlichkeit auszugehen. 
das weibliche Geschlecht an geleg to Keime in näherungsweisc demselben Verhältnisse der Befruchtung ausgesetzt, welches bei einer grossen Zahl von Knaben - und Mädchengeburten ya Tage tritt. ${ }^{1}$ ) Durch diese Hypothese wird nicht nur die ungefähre Constanz des Geschlechtsverhältnisses, sondern auch die weit merkwürdigere Vertheilung der Abweichungen vom Normalwerth erklärt. Wie die Verkleinerung des Normalverhältnisses bei den unehelichen Geburten unter dieser Voraussetzung wenigstens denkbarer Weise zu crklären wäre, habe ich am angeführten Orte angedeutet.

Hier dürfte nun auch die Frage von Interesse sein, ob die Bcobachtungen über die Zwillingsgeburten mit dieser Hyputhese vereinbar sind. Zunächst ist leicht zu zeigen, dass dies nicht der Fall sein könnte, wonn man eine Zwillingsgeburt wie zwei getrennte, ganz unabhängig von einander folgende Geburten behandeln wollte. Wenn in ciner Urne schwarze und weisse Kugeln im constant bleibenden Verhältniss von $515: 485$ vorhanden sind, so hat man für die möglichen Ergebnisse \%weier unabhängiger Züge folgende Wahrscbeinlichkeiten:

schwarz-schwarz: $(0.515)^{2}$; schwarz-weiss: $0.515 \times 0.485$, weiss-schwarz: $0.485 \times 0.515$; weiss-weiss: $0.485 \times 0.485$, oder: schwarz-schwary: 0.265 , weiss-weiss: 0.235 , und für das Herauskommen zweier' verschiedener Farben ohne Rücksicht auf die Reihenfolge: $0.250+0.250$ oder 0.500 .

Nun ist 0.515 die Wahrscheinlichkeit einer Knabengeburt, die wir in den letzten Jahren in Preussen herrschend gefunden haben; und wenn man den Zug einer schwarzen oder weissen Kugel mit einer Knaben- resp. Mädchengeburt parallelisirt, so sind die eben angeführten Verhältnisszahlen diejenigen, welche bei einer grossen Anzahl Gruppen von je zwci unabhängig auf einander folgenden Geburten für die drei verschiedenen Combinationen der Geschlechter zu Tage treten werden.

Nun zeigt sich aber bei Zwillingsgeburten in Wirklichkeit eine

1) Dass die Physiologen von ihrem Standpunkte nichts gegen diese Hypothese einzuwenden haben, iat aus dor schon von W. Stiedn (Sexualverhältniss, S. 5) angeführten Stelle aus Wagner's Physiol. Handwörterbuch za schliessen. Uehrigens bleibt bei meiner Annahme die Frage ganz offen, ob die Keime an sich gescblechtlich bestimmt sind, oder ob die grössere oder geringere Reife des ausgetretenen Eies das Geschlecht bedingt, was der Thury'schen Hypothese entsprechen würde. 
fanz andere Frequenz der drei Combinationen. Fassen wir dic Zwillingsgeburten (Fälle, nicht Geborene) in den 8 alten Provinzen Preussens vom Jahre 1862 bis 1873 incl. zusammien, so finden wir:

2 Knaben: 38119 mal; 2 Mädchen: 35919 mal; 1 Knn. u. 1 M. $44169 \mathrm{mal}$, woraus sich empirisch die Wahrscheinlichkeiten dieser drei zusammengesetzten Ereignisse ergeben zu resp. 0.322; - $0.304 ;-0.37 .4$, also Zahlen, die mit den oben angetíuhten nichts gemein haben. Nach den letzteren wäre z. B. bei der Hälfte aller Zwillingsgeburten, im vorliegenden Beispicle also in 59103.5 Fällen Geschlechtsverschiedenheit zu erwarten, während diesclbe thatsächlich nur in 44169 Fällen beobachtet worden ist.

48. Durch diesen Widerspruch, anf den bereits L. Moser gestossen ist, wird indess nur bewiesen, was von vornherein wahrscheinlich ist, dass Zwillingsgeburten nicht wic unabhängige Paare von Geburten anzusehen sind. Es scheint ohne Frage sehr natürlich, dass eine zweite Befruchtung, die sich unmittelhar an eine andere unter der denkbar grössten Gleichheit der Linstände anschliesst, mit einer gesteigerten Wahrscheinlichkeit d asselbe Geschlecht ergeben müsse, wie die erste. Wir betrachten hier die Zwillingsbefruchtung als bestehend aus einer crsten und einer zweiten Befruchtung, die durch eine beliebig klein anzunehmende Zeit getrennt sind, und wir bezeichnen mit $x$ die Wahrscheinlichkeit, dass die zweite Befruclitung dasselbe Geschlecht ergibt, wic die erste ; $1-x$ ist dann also die Wahrscheinlichkeit der Geschlechtsverschiedenheit. Am einfachsten ist es jedenfalls, dieses $x$ als gleich anzunehmen, mag die crste Befruchtung männlich oder weiblich ausgefallen sein. Die Walırscheinlichkeit des einen oder des anderen dieser beiden letzteren Fälle aber müssen wir, wenn wir unsere Iypothese äber die Keime festhalten wollen, der iuberhaupt herrschenden Wahrscheinlichkeit einer Knaben- oder Mädcluengeburt gleicbsctzen. Folglich haben wir in unserem Beispiele folgende Wahrscheinlichkeiten:

2 Kuaben $0.515 x ; 2$ Mädchen $0.485 x$

1. Knabe , 2. Mädchen $0.515(1-x)$; 1. Mädchen, 2. Knabe $0.485(1-x)$.

Durch Vergleichung dieser hypothesischen Wahrscheinlichkeiten mit den oben angeführten empirischen aber erhält man: 


$$
\begin{aligned}
- & 76 & - \\
0.515 x=0.322 ; & \text { also } & x=0.625 \\
0.485 x=0.304 ; & & x=0.627 \\
(1-x)=0.374 ; & & x=0.626 .
\end{aligned}
$$

Denunach ergeben dic drei Glcichungen in ies That fast genau denselben Werth von $x$, und wir haben daher einige Berechtigung zu sagen: Bci der ersten Befruchtung in eines Zwillingsconception bestimmt sich das Geschlecht nach dersclben Wahrseheinlichkeit, die in dem betreffenden Lande auch bei einfachen Geburten massgebend ist; wie diese Bestimmung aber anch ausfält, es besteht cine gesteigerte Wahrscheinlichkeit, und zwar in Preussen in der behandelten Periode die Wahrscheinlichkeit 0.626 dafür, dass die zweite Befruchtung dasselbe Geschlecht ergibt. ")

Die obige Hypothese läuft ülrigens einfach darauf hinaus, dass (las Verhältniss der Zahl der Zwillingsgeburten von zwei Knaben zu der Zahl der Mädchen-Zwillingsgeburten dasselbe sein müssc, wie das Vcrhältniss der einfachen Knaben- und Mädchengeburten. ${ }^{2}$ ) Denn die Knabenzwillingsgeburten sollen proportional sein $0.515 x$,

1) Fin Bild dieser Wahrscheinlichkeitsverhältnisse erhält man, wenn man amnimmt, dass gewisse von den schwarzen und weissen Kugeln in der Urne (und zwar jo ein gleicher Bruchtheil von jeder Classe) eine zweite Kugcl in sich einschliessen, nnd zwar so, dass die eingeschlossenen Kugeln auf 1000 Dopyelk tigoln 626 mal diesclbe Farbe hahrn, wie die umschliessenden. Fine andere Vorstellung scheint sich beszer mit den wirklichen phrsiolugiselien Vorgängen vergleichen zu lassen: nämlich die einer sehr Inngen Reihe von gleieh grossen, neben einander liegenden kugeln, in der aher imner mehrere gleichfarbige aufeinander folgen. Hat man nun zufällig eine von diesen Kigeln ergriffen, so wird es wahrscheinlicher sein, dass die nächstfolgende dieselbe Farbe habe, als dass sie ungleichfarbig sei. Aber dieses Bild lässt sich doch in solcher Einfachhoit nicht l'esthaiten, wenn man verlangt, dass die Wahrschcinliclikciten der beiden Farben bei dem ersten Griffe verschieden, dic Wahrscheinlichkeit der Gleichfarbigkeit der Nachbarkugel abcr in beilen Füllen gleich sein soll. Jedenfalls kann das obige Resultat wieder mit der Vorstellung vertinbart werden, dass dio Reife des Eies im Augenblick der Befruehtung irgendwie mit der Geschlechtshestimmung zusammenhänge.

2) Man pllegte bisher hauptsïchlich das Geschlechtsverhültniss der aus Zwilling*geburten stammenden Individ u en zn berücksichtigen, das, wie unsere 'l'heorie snfort erkenven lässt, etwas kleiner wird, als dlas normale Verhältniss. So auch in der jüngst in Hildebrand's und Conral's Jahrbfichern erschiencnen Arbeit von M. Neeffe. Aus unserer Dariggung ist ersichtlich, weiche Wichtigkeit der statistischen Frhebung der $Z$ willingsgeburten naeh ihren drei möglichen Arten zukommt. 
die Mädchenzwilligsgeburten proportional $0.485 x$; das Verhältniss beider Zahłen wäre also $=\frac{0.515}{0.45,5}$, was dem normalen Geschlechtsverhältniss der Geborenen gleich ist.

49. Nun finden wir in der hier behandelter Periode in den alten Provinzen Preussens als Zahlen der Zwillingsgeburten mit Geschlechtsgleichheit und als Verhältnisszahl auf 1000 weibliche '/willingsgeburten:

\begin{tabular}{|c|c|c|c|c|c|c|c|}
\hline $\begin{array}{l}\text { Jilir. } \\
1862\end{array}$ & $\begin{array}{l}2 \mathrm{Kn} . \\
2823\end{array}$ & $\begin{array}{l}2 \text { Mädeh. } \\
2549\end{array}$ & $\begin{array}{l}\text { Verls. } \\
1107\end{array}$ & $\begin{array}{l}\text { Jahr. } \\
1868\end{array}$ & $\begin{array}{l}2 \mathrm{Kn} . \\
3082\end{array}$ & $\begin{array}{c}2 \text { Mädch. } \\
2959\end{array}$ & $\begin{array}{l}\text { Verh. } \\
10.12\end{array}$ \\
\hline$(63)$ & 30993 & 2890 & 1070 & 69 & $3: 02$ & 2926 & 1095 \\
\hline 64 & 327.4 & 3097 & 1057 & 70 & 3134 & 3173 & 1082 \\
\hline 65 & 3199 & $30 ! 7$ & $10: 33$ & 71 & 2794 & 2499 & 1118 \\
\hline iti & 3101 & 3045 & 1019 & 72 & 3522 & 3201 & 1080 \\
\hline 67 & 31.49 & 3057 & 1022 & 73 & 3.142 & $3360 ;$ & 1021 \\
\hline
\end{tabular}

Das Verhältniss aus der Gesammtzahl der Zwillingsgeburten beider Geschlechter ergibt sich "n 1061, was in der That den normalen Wahrscheinlichkeiten 0.515 und 0.485 (auf 3 Stellen abgerundet) entspricht.

Nimmt man einfach das Mittel aus den zwölf Einzelverlältnissen, indem man von der nur unbedeutenden Verschiedenheit der Präcisionen der Finzelbestimmungen absieht, so erhält man 1063. Von diesem Werthe ausgeliend, findet man nach der Methode der kleinsten Quadrate die P'räcision 0.0208, während die combinatorische Methode, bei Anwendung ciner Durchschnitts\%ahl von 6170 jährlichen glcich greschlechtlichen Zwillingsgeburten, die Präcision 0.0261 liefert. Diese beiden P'räcisionsbestimmungen weichen nun allerdings einigermassen von einander ab, so dass es fraglich erscheinen kann, ob die obigen Verhältnisszahlen als typische Wahrscheinlichkeitsgrössen mit normaler und nicht vielmehr mit iibernormaler Dispersion anzusehen sind. Indess ist die erste Bestimmung auf Grund einer einzigen Reihe von nur 12 Einzelwerthen eine ziemlich unsichere, und die Differenz beider Werthe wird noch xiemlich mässig erscheinen, wenn man die Grösse der Unterschiede berücksichtigt, die sich in anderen Füllen bei ähnlichen Rechnungen herausstellen. Die Annahme einer normalen Dispersion ist also noch keineswegs ausgeschlossen.

Was die Zwillingsgeburten mit verschiedenen Geschlechtern betrifft, so würden dieselben nach dieser 'Theorie immer anuähernd 
0.374 der jährlichen Gesammtzahl der Zwillingsgeburten ausmachen müssen. Zur Vergleichung von Beobachtung mit Berechnung diente die folgende 7iusammenstellung der Geburten dieser Art:

\begin{tabular}{rcc|rcc} 
Jahr & beohachtet & berechnet & Jahr & beobachtet & berechnct. \\
1862 & 3285 & 3238 & 1868 & 3462 & 3554 \\
63 & 3590 & 3580 & 69 & 3595 & 3637 \\
64 & 3797 & 3803 & 70 & 3804 & 3894 \\
65 & 3828 & 3786 & 71 & 3258 & 3198 \\
66 & 3678 & 3675 & 72 & 4179 & 4100 \\
67 & 3642 & 3683 & 73 & 4051 & 4061
\end{tabular}

Die Abweichungen zwischen Beobachtung und Rechnung sind also sehr mässig und mit der Annahme jener festen Wabrscheinlichkeit wohl vereinbar.

50. Mit welchem Grade von relativer Genauigkeit bei dem Geschlechtsverhältnisse der Geborenen das durch die doppelte Präcisionsbestimmung gewonnene Kriterium zutrifft, lässt sich am besten durch die vergleichende Untersuchung anderer Verbältnisszablen taxiren, die man gewissermassen stillschweigend als Wahrscheinlichkeitsgrö̈sen anzunehmen pflegt. Die Zahl der Gestorbenen im Alter von 0-1 Jahr dividirt durch die Kahl der Geborenen, aus denen diese Verstorbenen hervorgegangen sind, bezeichnet man ohne Weiteres als empirische Darstellung der Sterbenswahrscheinlichkeit im ersten Altersjahre. Aber verhalten sich die Schwankungen dieses Verluältnisses von einer Jabresgeneration zur andern wirklich so, als wenn eine feste mathematische Wahrscheinlichkeit zu Grunde läge? Wir wollen diese Frage an einem Beispiele ans der belgischen Statistik näher erörtern. In der folgenden Tabelle findet man unter $G$ die Zahl der in den angegebenen Jahren lebend geborenen linaben odex Mädchen; unter $A$ die von diesen Jahresgenerationen gelieferten Gestorbenen im Alter von 0-1 Jahr (erste Hauptgesammtheiten); ${ }^{3}$ ) unter $B$ zur Vergleichung dic (aus zwei Generationen stammenden) Gestorbenen der crsten Altersclasse aus

1) Die belgischen statistischen Documente zerlegen (bis zum Jałıre 186i) die Verstorbenen der ersten Altersclasse nach den Sterbemonaten, combinirt mit den Altergmonaten. Aus diesen kleinen Gruppen kann man mit hinreichender Genauigkeit (unter Halbirung der zweifelhaft geateliten) die Elenentargesammtheiten und snmit die ersten Hauptgesammtheiten zusammensetzen. Die obige Berechnung derselben ist von einigen meiner Jorpater /uhörer auggefuhrt worden. 
dem angeführten Kalenderjahre, also "dritte" Hauptgesammtheiten, welche nach der Hermann'schen Methode an die Stelle der bisher meistens noch nicht bestimmbaren ersten Hauptgesanuntheiten gesetzt werden; unter $\alpha$ die Quotienten aus den Zahlen unter $A$ und der entsprechenden Geburtenzahl, also die möglichst correct bestimmten empirischen Sterbenswahrscheinlichkeiten im ersten Altersjahre; unter $\beta$ die Quotienten aus den Zalilen unter $B$ und den Geburtenzahlen, also die Näherungswerthe der Sterbenswahrscheinlichkeiten nach der Hermann'schen Methode.

\section{$\mathrm{K}$ n a b e $\mathrm{n}$.}

\begin{tabular}{rcrrrc} 
Jahr & $\boldsymbol{G}$ & \multicolumn{1}{c}{$\boldsymbol{A}$} & \multicolumn{1}{c}{$\boldsymbol{B}$} & $\boldsymbol{\alpha}$ & $\boldsymbol{\beta}$ \\
1847 & 60539 & 10217 & 10254 & 0.1688 & 0.1694 \\
48 & 61952 & 9517 & 9501 & 0.1536 & 0.1534 \\
49 & 68093 & 10941 & 10949 & 0.1607 & 0.1608 \\
50 & 67240 & 10632 & 10184 & 0.1580 & 0.1515 \\
51 & 68739 & 10866 & 11219 & 0.1581 & 0.1632 \\
52 & 69234 & 11160 & 11062 & 0.1612 & 0.1598 \\
53 & 65570 & 10313 & 10419 & 0.1573 & 0.1589 \\
54 & 67408 & 11723 & 11062 & 0.1739 & 0.1641 \\
55 & 64630 & 11073 & 11809 & 0.1713 & 0.1827 \\
56 & 68848 & 11530 & 11010 & 0.1675 & 0.1599 \\
57 & 73369 & 14020 & 13332 & 0.1911 & 0.1817 \\
58 & 74292 & 13369 & 13390 & 0.1800 & 0.1802 \\
59 & 76525 & 13460 & 14285 & 0.1759 & 0.1867 \\
60 & 74368 & 11851 & 11361 & 0.1594 & 0.1528 \\
61 & 75674 & 13356 & 13399 & 0.1765 & 0.1771 \\
62 & 74868 & 12354 & 12191 & 0.1650 & 0.1628 \\
63 & 79825 & 14143 & 13664 & 0.1772 & 0.1710 \\
64 & 80022 & 14739 & 14278 & 0.1843 & 0.1784 \\
65 & 79942 & 15862 & 16271 & 0.1984 & 0.2035
\end{tabular}

M ä d c h e n.

$\begin{array}{rlllll}1847 & 57567 & 8142 & 8234 & 0.1411 & 0.1430 \\ \mathbf{4 8} & 58431 & 7528 & 7521 & 0.1288 & 0.1287 \\ 49 & 65012 & 8701 & 8661 & 0.1338 & 0.1332 \\ 50 & 64176 & 8430 & 8320 & 0.1314 & 0.1296 \\ 51 & 65509 & 8515 & 8591 & 0.1300 & 0.1311\end{array}$




\begin{tabular}{rrrrrc} 
& \multicolumn{7}{c}{-80} & & & \\
Jahr & $\boldsymbol{G}$ & $\boldsymbol{A}$ & \multicolumn{1}{c}{$\boldsymbol{B}$} & $\alpha$ & $\beta$ \\
1852 & 65163 & 8824 & 8888 & 0.1354 & 0.1364 \\
53 & 62158 & 8143 & 8144 & 0.1310 & 0.1310 \\
54 & 64429 & 9271 & 8736 & 0.1439 & 0.1356 \\
55 & 61325 & 8863 & 9393 & 0.1445 & 0.1532 \\
56 & 65339 & 9379 & 8888 & 0.1435 & 0.1360 \\
57 & 69922 & 11145 & 10792 & 0.1594 & 0.1543 \\
58 & 70782 & 10458 & 10403 & 0.1478 & 0.1470 \\
59 & 73287 & 10701 & 11459 & 0.1460 & 0.1564 \\
60 & 70300 & 9264 & 8702 & 0.1319 & 0.1558 \\
61 & 71579 & 10679 & 10696 & 0.1492 & 0.1498 \\
62 & 70700 & 9758 & 9708 & 0.1380 & 0.1373 \\
63 & 75739 & 11210 & 10788 & 0.1480 & 0.1424 \\
64 & 75850 & 11962 & 11457 & 0.1577 & 0.1511 \\
65 & 76381 & 12871 & 13297 & 0.1685 & 0.1741
\end{tabular}

Die Ergebnisse der correcteren Berechnung weichen in den einzelnen Jahren von denen der Hermann'schen Näherungsmethode ziemlich beträchtlich ab; fasst man indess die ganze neunzehnjailrige Strecke zusammen, so findet man unter $A$ 231,126 Knaben und 183,854 Mädchen, unter $\boldsymbol{B}$ aber 229,610 Knaben und 182,678 Mädchen. Die Gesammt\%ahl der Geburten beläuft sich auf 1,351,138 Knaben und 1,283,649 Mädehen, so dass wir als Mittelwerth des Sterblichkeitsverhältnisses $\alpha$ erhalten 0.1711 beim männlichen und 0.1432 beim weiblichen Geschlecht, wäbrend der Näherungswerth $\beta$ sich auf resp. 0.1700 und 0.1423 stellt.

51. Wir halten uns hier selbstverständlich an die genaueren Werthe $\alpha$. Die oben angeführten Mittelwerthe 0.1711 und 0.1432 wären als die theoretisch strengen wahrscheinlichsten Werthe der Sterbenswahrscheinlichkeit der Knaben und Mädchen im ersten Altersjahre anzusehen, wenn diese Sterbenswahrscheinlichkeit eine Constante von typischen Charakter mit normaler Dispersion wäre. Denn dann würden die Gewichte der einzelnen Jahreswerthe der Quadratwurzel aus der zugehörigen Geburtenzahl proportional sein. Wenn aber die abstracte Sterbenswahrscheinlichkeit selbst von Jahr zu Jahr zufälligen Schwankungen ausgesetzt ist, d. h. wenn die Dispersion der Abweichungen eine übernormale ist, so ist jene Annahme über das Gewicht der Einzelwerthe theoretisch nicht mehr begründet. Da sich nun schon aus einem vorläufigen Ueberschlage 
ergibt, dass wir im vorliegenden Falle mit einer übernormalen Dispersion zu thun haben, und da überdies die Quadratwurzeln ans der grössten und kleinsten Geburtenzahl nicht allzu sehr verschicden von einander sind, so genügt es für unsere Zwecke, wenn wir der Einfachheit wegen die Methode der kleinsten Quadrate so anwenden, als wenn alle Einzelwerthe gleiche Präcision hätten. Wir gehen daher auch von dem arithmetischen Mittel der Werthe $a$ aus, das bei den Knaben 0.1704 beträgt. Verwandelt man die obigen Werthe $\alpha$ durch Multiplication mit 10000 in ganze Zahlen, so ergibt die Methode der kleinsten Quadrate bei den Knaben den wahrscheinlichen Fehler 83.15 und die Präcision 0.0057. - Durch die eine oder die andere dieser beiden Grössen wird die wirk liche Dispersion der $\Lambda$ bweichungen charakterisirt, unter der einzigen Voraussetzung, dass die Einzelwerthe zufällige Modificationen eines Mittelwerthes seien.

Wenn aber die untersuchten Werthe typische Wahrscheinlichkeitsgrössen mit normaler Dispersion wären, so würde sich der wahrscheinliche Fehler auf 9.5 und die Präcision auf 0.0501 berechnen $!^{1}$ ) Mit andern Worten, die wirkliche Dispersion ist neun Mal so gross, als die normale! Hiernach wird man die Uebereinstimmung würdigen, die zwischen den beiden Arten von Präcisionsbestimmungen bei dem Geschlechtsverhältniss der Geborenen besteht.

Selbst wenn man die am meisten abweichenden Einzelbestimmungen der Sterbenswahrscheinlichkeit, nämlich die den Geburtsjahren 1857 und 1865 entsprechenden, ganz von der Rechnung ausschliesst, so würde sich die nach der Methode der kleinsten Quadrate bestimmte Präcision doch nur auf ungefähr 0.0076 erhöhen, während auch die combinatorische Methode ein von dem vorher gefundenen nur wenig verschiedenes Resultat ergäbe, so dass die gänzliche Unzulässigkeit der Annahme einer normalen Dispersion noch eben so grell hervorträte. Jene Ausschliessung zweier Werthe aber wäre überdies eine durch Nichts gerechtfertigte Willkür.

Man darf übrigens sogar fragen, ob die hier untersuchten Sterblichkeitsverbältnisse auch nur als typische Wahrscheinlichkeitsgrössen mit übernormaler Dispersion angesehen werden dürfen, ob

1) Es ist bei dieser Näherungsrechnung die mittlere jährliche Geburtenzahl 71113 und die Sterbenswahrscheinlichkeit 0.1111 zu Grunde gelegt. 
sie nicht einfach symptomatische Verhältnisszahlen sind, die sich gar nicht in die Wahrscheinlichkeitstheorie einfügen, also trotz ibrer nicht grossen Verschiedenheiten nicht einmal nach der Methode der kleinsten Quadrate behandelt werden können. Es zeigt sich in der That im Ganzen in ibrer Reihe eine Tendenz zum Anwachsen mit der Zeit, die mit der Voraussetzung bloss zufälliger Störungen nicht wohl vereinbar ist. Indess lässt sich aus 19 Einzelwerthen noch keine bestimmte Entscheidung dieser Frage geben. Die Zahl der positiven Abweichungen von dem Mittel 1704 ist 9, die der negativen 10 ; innerhalb der Grenzen des wahrscheinlichen Fehlers \pm 83 liegen 8, ausserhalb desselben 11 Fälle; der Ausdruck $\frac{38\left[\delta^{2}\right]}{[d]^{2}}$ gibt 2.9 statt $\pi$ : alle diese Indicien lassen wenigstens die Möglichkeit des Vorhandenseins eines typischen Mittels offen; jedenfalls aber ist die Zerstreuung der Einzelwerthe eine weit grössere, als wenn sie durch ein Glücksspiel mit constanten Chancen lestimmt worden wäre.

Um dieselbe Entscheidung in Betreff der Sterblichleitsverhältnisse der Mädchen zu geben, bedürfen wir nur eines summarischen Ueberschlags: aus dem Mittelverhältniss 0.1432 und der durchschnittlichen Geburtenzahl 67560 findet man nach der combinatorischen Methode den wahrscheinlichen Fehler der (mit 10000 multiplicirten) Einzelwerthe gleich \pm 9.1; die Beobachtung aber ergibt zwischen den Grenzen 1422.9 und 1441.1 nur 2, ausserhalb verselben aber 17 Fälle. Ferner hat man auf Grund jener Daten nach derselben Methode die der Gewissheit fast gleiche Wahrscheinlichkeit 0.999978 dafür, dass die Abweichungen vom wahren Werthe nach beiden Seiten nicht über 57.26 hinausgehen; wir finden aber zwischen den Grenzen 1374.74 und 1489.26 nur 7 , ausserhalb derselben aber 12 Einzelwerthe, und wenn wir auch bei diesen Grenzbestimmungen den wahrscheinlichsten statt des wahren Werthes substituirt baben, so genügt das Resultat doch vollkommen zur Rechtfertigung der Behauptung, dass auch hier die Dispersion der Abweichungen eine weit grössere ist, als die normale, wie sie bei einem Glücksspiel mit constanten einfachen Chancen vorkommt. Auch sind wieder Zweifel an der Zulässigkeit der Methode der kleinsten Quadrate gestattet, da hier ebenfalls im Ganzen eine Tendenz zum Wachsen bei den Sterblichkeitsverhältnissen obzuwalten scheint. 
52. Behandeln wir nun nach denselben Principien ein Beispiel aus der eigentlichen Moralstatistik.

Die absoluten Jahresziffern der Selbstmorde in den Culturländern bilden entschieden nur eine symptomatische, descriptive Reihe, die nit gewissen gesellschaftlichen Evolutionen parallel läuft. Dividirt man diese Zahlen durch die der geichzeitigen Bevölkerung, so könnte man diese Verhältnisse allenfalls in dem oben dargelegten Sinne als empirische Werthe von zusammengesetzten 'Totalwahrscheinlichkeiten betrachten; da man aber die abstracten Wahrscheinlichkeiten in Grossen und Ganzen von Jahr zu Jahr um eine veränderliche Grösse wachsend annehmen müsste, so wäre eine nutzbringende theoretische Behandlung jener Verhältnisse nach den Regeln der Wahrscheinlichlkeitsrechnung doch nicht möglich, weil man weder mit zufälligen Aenderungen eines typischen Werthes, noch mit einer Grösse zu thun hat, die nach einer bekannten Norm mit der Zeit fortschreitet. 1)

Eher aber könnte man vermuthen, dass die relative Frequenz einer bestimmten Selbstmordart sich als typische Wahrscheinlichkeitsgrösse nachweisen lasse. Die absolute und relative Gesammtzahl der Selbstmorde mag sich synptomatisch vermehren, aber die ausserordentlich zahlreichen und mannigfaltigen Ursachen, welche die zum Selbstmorde Entschlossenen zu der Wahl eines bestimmten Mittels führen, könnten gerade wegen ihrer Mannigfaltigkeit und grossen Zahl einen relativ constanten Bedingungscomplex bilden, der in seinen Wirkungen das Chancenspiel bei ciner constanten Wahrscheinlichkeit nachahmt. Zur Prüfung dieser Vermuthung sind im Folgenden nach den französischen Comptes géuéraux de l'administration de la just. crim. zusammengestellt: unter $S$ die jährliche Gesammtzahl der männlichen Selbstmörder und unter $\boldsymbol{E}$ der Bruchtheil derselben, der sich ertränkt hat.

M ä n n er.

\begin{tabular}{rcc|rcc} 
Jahr & $\boldsymbol{S}$ & $\boldsymbol{E}$ & Jahr & $\boldsymbol{S}$ & $\boldsymbol{E}$ \\
1835 & $\mathbf{1 7 8 4}$ & $\mathbf{0 . 2 5 7}$ & 1838 & 1886 & 0.283 \\
36 & 1775 & 0.293 & 39 & 2049 & 0.290 \\
37 & $\mathbf{1 8 1 1}$ & 0.277 & 40 & 2040 & 0.287
\end{tabular}

1) Eine hypothetische Annahme uber das Fortschreiten der Wabrscheinlichkeit wäre zwecklos, weil vỏllig willkürlich. 


\begin{tabular}{|c|c|c|c|c|c|}
\hline $\mathrm{Jahr}_{\mathrm{r}}$ & $\boldsymbol{S}$ & $E$ & Jahr & $\boldsymbol{s}$ & $E$ \\
\hline 1841 & 2139 & 0.298 & 1855 & 2836 & 0.269 \\
\hline 42 & 2129 & 0.286 & 56 & 3161 & 0.258 \\
\hline 43 & 2291 & 0.314 & 57 & 2970 & 0.276 \\
\hline 44 & 2197 & 0.289 & 58 & 3050 & 0.236 \\
\hline 45 & 2332 & 0.285 & 59 & 3057 & 0.262 \\
\hline 46 & 2329 & 0.295 & 60 & 3076 & 0.251 \\
\hline 47 & 2781 & 0.296 & 61 & 3399 & 0.264 \\
\hline 48 & 2567 & 0.264 & 62 & 3767 & 0.271 \\
\hline 49 & 2736 & 0.290 & 63 & 3637 & 0.248 \\
\hline 50 & 2723 & 0,250 & 64 & 3599 & 0.248 \\
\hline 51 & 2737 & 0.280 & 65 & 4009 & 0.236 \\
\hline 52 & 2780 & 0.292 & 66 & 4169 & 0.247 \\
\hline 53 & 2536 & 0.276 & 67 & 4008 & 0.240 \\
\hline 54 & 2707 & 0.257 & 68 & 4736 & 0.218 \\
\hline
\end{tabular}

53. Im Ganzen zeigen die Verhältnisszablen unter $E$ eine Tendenz zum Sinken; besonders in der letzten Periode des Kaiserreiches scheinen volkspsychologische Einflüsse dem Selbstmorde durch Ertränkung entgegenzuwirken. Schon dieser äusserlich hervortretenden Evolution wegen können die Zahlen unter $E$ nicht als empirische Werthe einer constanten typischen Wahrscheinlichkeit angesehen werden.

Aber es wäre möglich, dass diese Zahlen auf kleineren Zeitstrecken sich wie zufällige Modificationen einer festen Wahrscheinlichkeit verhielten.

Betrachten wir die $15 j a ̈ h r i g e$ Strecke $1835-49$, so finden wir sowohl als arithmetisches Mittel der Einzelverhältnisse, wie auch als Verhältniss der Gesammtzahl der Ertränkungen zur Gesammtzahl der Selbstmorde den Worth 0.287 .

Nach der Metbode der kleinsten Quadrate ergibt sich dann aus jenen 15 Einzelwerthen, wenn wir von ihrer Gewichtsverschiedenheit absehen und sie durch Multiplication mit 1000 zu ganzen Zahlen machen, der wahrscheinliche Fehler $= \pm 9.19$, und die Präcision der Einzelbestimmung $=0.0519$.

Die combinatorische Methode aber führt bei Anwendung der durchschnittlichen Selbstmordziffer 2190 zu dem wahrscheinlichen Fehler \pm 6.52 und der Präcision 0.0731 .

Die beiden Arten der Präcisionsbestimmung liefern also zwar nicht so enorm verschicdene Resultate, wie sie in dem Beispiele 
aus der Sterblichkeitsstatistik zu Tage treten, aber die Differenz ist doch beträchtlich grösser, als die, welche sich durchschnittlich bei der Untersuchung des Geschlechtsverhältnisses der Geborenen herausstellt.

Besonders aber ist $2 u$ beachten, dass diese 15jährige Reihe von vornherein mit Rücksicht daranf ausgewählt ist, dass die $A \dot{b}$ weichungen vom Mittel nicht $z u$ gross würden. Nähme man nur noch das Resultat des Jahres 1850 hinzu, so würde sich der Unterschied zwischen den beiden Präcisionsbestimmungen noch weiter vergrössern.

In der 15jährigen Serie 1850-64 finden wir das arithmetische Mittel der Einzelverhältnisse $=0.263$ und das Summenverhältniss $=0.262$. Die Methode der kleinsten Quadrate ergibt unter denselben Bedingungen wie oben: wahrsch. Abw. \pm 10.07 ; Präcision 0.0474 .

Nach der combinatorischen Methode dagegen findet man mit der mittleren Selbstmordziffer 3069 als wahrscheinliche Abweichung \pm 5.35, als Präcision 0.0891. Mithin meigt sich abermals eine recht beträchtliche Differenz beider Präcisionsbestimmungen, die noch bedeutend grösser werden würde, wenn man der Beobachtungsreihe auch die Verhältnisszahlen der Jahre 1865-68 hinzufügen wollte.

54. Wir lassen hier noch folgen die entsprechenden Ziffern für die

\section{Frauc n.}

\begin{tabular}{rcc|rrc} 
Jahr & $\boldsymbol{E}$ & $\boldsymbol{S}$ & Jahr & $\boldsymbol{S}$ & $\boldsymbol{E}$ \\
1835 & 521 & 0.472 & 1848 & 734 & 0.437 \\
36 & 565 & 0.476 & 49 & 847 & 0.484 \\
37 & 632 & 0.486 & 50 & 873 & 0.435 \\
38 & 700 & 0.453 & 51 & 861 & 0.473 \\
39 & 698 & 0.520 & 52 & 894 & 0.454 \\
40 & 712 & 0.426 & 53 & 879 & 0.438 \\
41 & 675 & 0.490 & 54 & 993 & 0.456 \\
42 & 737 & 0.459 & 55 & 974 & 0.448 \\
43 & 729 & 0.519 & 56 & 1028 & 0.472 \\
44 & 776 & 0.470 & 57 & 997 & 0.467 \\
45 & 752 & 0.440 & 58 & 853 & 0.402 \\
46 & 773 & 0.451 & 59 & 842 & 0.462 \\
47 & 866 & 0.440 & 60 & 974 & 0.418
\end{tabular}




\begin{tabular}{rrr|rrc}
\multicolumn{7}{c}{-86} & - \\
Jahr & $\boldsymbol{S}$ & $\boldsymbol{E}$ & $\mathrm{Jahr}$ & $\boldsymbol{S}$ & $\boldsymbol{E}$ \\
1861 & 1055 & 0.445 & 1865 & 937 & 0.418 \\
62 & 1003 & 0.429 & 66 & 950 & 0.443 \\
63 & 976 & 0.445 & 67 & 1003 & 0.406 \\
64 & 922 & 0.396 & 68 & 1171 & 0.371
\end{tabular}

Es zeigt sich hier noch deutlicher als in der vorhergehenden Tabelle eine langsam sich entwickelnde Abnahme der relativen Häufigkeit des Selbstmordes durch Ertränken. Das Mittel der Verhältnisszahlen beträgt in der 11jährigen Periode 1835-45: 0.474 ; in der 12jährigen Periode 1846-57: 0.455 und in der 11jährigen Periode 1858-68 nur noch 0.421. Von einer in der ganzen Reihe constanten oder nur zufällig veränderlichen relativen Wahrscheinlichkeit dieser Selbstmordart kann also keine Rede sein. Wenn wir aber die oben angeführten Zeitstrecken für sich betrachten, so finden wir, das Tausendstel wieder als Einheit genommen, nach der Methode der kleinsten Quadrate (a) und der combinatorischen Methode (b) folgende Präcisionen:

$$
\begin{array}{lll}
1835-45: & \text { (a) } 0.024 ; & \text { (b) } 0.037 ; \\
1846-57: & 0.0435 ; & 0.0423 \\
1858-68: & 0.032 ; & 0.045
\end{array}
$$

In der mittleren Periode stimmen also die beiden Werthe nicht nur sehr nahe zusammen, sondern die erste Methode gibt sogar eine etwas grössere Präcision als die zweite. Indess darf man desswegen nicht auf eine unternormale Dispersion und eine "verbundene" concrete Massenerscheinung schliessen. Denn erstens sind die Präcisionsbestimmungen (a) unsicher wegen der geringen Zahl der Einzelwerthe, und zweitens sind die Perioden absichtlich so abgegrenzt worden, dass sie möglichst wenig divergirende Einzelwerthe einschliessen. In Wirklichkeit dauert in jeder die Entwicklung in abnehmender Richtung fort, aber dieselbe ist so langsam, dass sich auf kürzere Strecken nur ein solcher Grad von Divergenz der Einzelwerthe zeigt, wie er bei einer typischen Wahrscheinlichkeitsgrösse mit mässig übernormaler oder annähernd normaler Dispersion zu erwarten wäre. Damit ist übrigens noch nicht einmal bestimmt erwiesen, dass die Verhältnisszahlen in jeder Periode wirklich den Charakter von typischen Wahrscheinlichkeitsgrössen besitzen. Um dies erkennen zu lassen, ist ihre Zahl zu klein, und doch kann man auch der fortschreitenden Entwicklung wegen die Theilstrecken nicht grösser machen. 
Kur\%, auch die relative Häufigkeit einer Selbstmordart lässt sich, trotz der auf den ersten Blick oft auffallend gross erscheinenden Stabilität der empirischen Verhältnisszahlen nicht in befriedigender Weise auf das Schema der Wahrscheinlichkeitsrechnung zurückfüren; es zeigt sich eine symptomatische Entwicklung in bestimmter Richtung, und nur in kïrzeren Zeitstrecken, während welcher diese Entwicklung nicht merklich ist, bleiben die Chancen in einem solchen Schwebezustand, dass die Divergenz der Einzelverbältnisse nicht allzu weit ïber die normale hinausgeht.

55. Schliesslich wollen wir auch noch ein Beispiel untersuchen, bei dem es auf die Sicherheit einer verstandesmässigen Entscheidung ankommt. Ich meine das Vcrhältniss der Zahl der Freigesprochenen zu der Zahl der vor die Geschworenen gestellten A ngeklagten (nicht der Anklagen) in Frankreich. 1) Die Daten für dic drei ersten Jahre sind Poisson, die übrigen den bereits erwähnten Comptes génćraux de la just. crim. entnommen.

\begin{tabular}{rcc|rcc} 
Jahr & Angekl. & Freigespr. & Jahr & Angekl. & Freigespr. \\
1825 & 6652 & 0.393 & 1840 & 8226 & 0.334 \\
26 & 6988 & 0.378 & 41 & 7462 & 0.328 \\
27 & 6929 & 0.389 & 42 & 6953 & 0.324 \\
28 & 7396 & 0.385 & 43 & 7226 & 0.324 \\
29 & 7373 & 0.393 & 44 & 7195 & 0.319 \\
30 & 6962 & 0.407 & 45 & 6685 & 0.334 \\
31 & 7606 & 0.461 & 46 & 6908 & 0.329 \\
32 & 8237 & 0.435 & 47 & 8704 & 0.338 \\
33 & 7315 & 0.423 & 48 & 7352 & 0.415 \\
34 & 6952 & 0.401 & 49 & 6983 & 0.397 \\
35 & 7223 & 0.390 & 50 & 7202 & 0.374 \\
36 & 7232 & 0.361 & 51 & 7071 & 0.333 \\
37 & 8094 & 0.368 & 52 & 7096 & 0.312 \\
38 & 8014 & 0.322 & 53 & 7317 & 0.277 \\
39 & 7858 & 0.356 & 54 & 7556 & 0.249
\end{tabular}

1) Die "Verurtheilungs - Wahrscheinlichkeit" setzt sich zusammen aus den Wahrscheinlichkeiten, dass sowohl die Voruntersuchung als die Geschworenen hinsichtlich der Schuld des Angeklagien sich irren oder nicht irsen; die Ergänzung derselben $z \mathrm{u} 1$ ist the "Freisprechungs - Wahrscheinlichkeit", die sich zusammensetzt aus der Wahrscheinlichkeit, dass die Voruntersuchung sich irrt und die Geschworenen sich nicht irren, und der Wahrscheinlichkeit, dass die Voruntersuchung sich nicht irrt und die Geschworencn sich irten. 


\begin{tabular}{rcc|rcc}
\multicolumn{7}{c}{$-\mathbf{8 8}-$} \\
Jahr & Angekl. & Freigespr. & Jahr & Angekl. & Freigespr. \\
1855 & 6480 & 0.250 & $\mathbf{1 8 6 2}$ & $\mathbf{4 9 9 0}$ & 0.256 \\
56 & 6124 & 0.254 & 63 & 4543 & 0.251 \\
57 & 5773 & 0.243 & 64 & 4252 & 0.240 \\
58 & 5375 & 0.225 & 65 & 4154 & 0.221 \\
59 & 4902 & 0.250 & 66 & 4551 & 0.232 \\
60 & 4651 & 0.245 & 67 & 4607 & 0.228 \\
61 & 4813 & 0.252 & 68 & 4528 & 0.234
\end{tabular}

Die ganze Reihe der Verhältnisszahlen der Freigesprochenen ist offenbar als eine symptomatische und descriptive aufzufassen. Sie zeigt deutlich Reactionen, die durch Veränderungen in der Gesetzgebung, theilweise auch durch die politischen Erschütterungen hervorgerufen sind. Die Verhältnisszahlen der Jahre 1825-30 zeigen geringe Schwankungen, nur das Revolutionsjabr 1830 zeichnet sich durch eine grössere Quote von Freigesprochenen aus. Unter den Angeklagten dieses Jahres befanden sich auch einige (16), die auf Grund des Gesetzes vom 8. October 1830 wegen politischer Verbrechen vor die Geschworenen gestellt wurden; 8 von diesen wurden freigesprochen.

Diese erste Periode ist zu kurz, als dass sie die Anwendung der Wahrscheinlichkeitsrechnung nach unserem Verfahren zuliesse. Poisson hat sich mit den Ergebnissen derselben aus einem anderen Gesichtspunkte beschäftigt. Einen scharfen Abschnitt bildet das Jahr 1831, mit dem man eine bis 1836 reichende Uebergangsperiode beginnen kann. Das Gesetz vom 4. Mai 1831 verlangte mindestens 8 Stimmen für die Verurtheilung, was sofort eine Steigerung der Quote der Freisprechungen hervorrief. In entgegengesetzter Richtung jedoch wirkte das Gesetz vom 28. April 1832, das den Geschworenen das Recht übertrugr, mildernde Umstände anzunehmen. Durch die beiden Gesetze vom 9. September 1835 wurden die Pressvergehen den Geschworenen-Gerichten entzogen und wieder die Verurtheilung durch einfache Majorität ermöglicht, daher in den nächstfolgenden Jahren eine weitere erhebliche Abnabme der Freisprechungen.

Uebrigens ist zu bemerken, dass im Jahre 1832 nicht weniger als 672 und 1833 noch 351 Angeklagte wegen politischer Verbrechen vor den Geschworenen standen, von denen resp. 462 und 234 freigesprochen wurden. Schliesst man diese aus, so erhält man als Verhältnisszahl der Freigesprochenen nur resp. 0.412 und 0.411 . 
In den übrigen Jahren ist dic Zahl der politischen Angeklagten so gering, dass sie bier nicht besonders unterschieden zu werden brauchen.

Eine Periode verhältnissmässiger Stabilität bilden die 12 Jahre 1836-47. Die Verlältnisszahlen der Freisprechungen scheinen oberflächlich betrachtet sehr nahe constant, und dennoch ergibt die genauere Untersuchùng, dass die Dispersion der Abweichungen entschieden eine übernormale ist. $\mathrm{Zu}$ demselben Resultat gelangt man sogar noch, wenn man die Ergebnisse der Jahre 1836 und 1837 von der Rechnung ausschliesst.

Die Jahre 1848-53 bilden wieder ein Intermezzo mit ganz concretem Charakter. Das Decret vom 6. März 1848 forderte neun Stimmen zur Verurtheilung und überwies den Geschworenen auch wieder die Pressvergehen. Nach dem Decret vom 18. October 1848 aber waren wieder 8 Stimmen zur Verurtheilung ausreichend. Nach Erlass des Gesetzes vom 9. Juni 1853, das wieder die einfache Majorität entscheidend machte (vorbehaltlich des Rechtes des Gerichtshofs, die Sache eventuell an eine neue Jury zu verweisen) geht die Quote der Freisprechungen noch weiter zurück, zeigt aber nun bis zum Schluss der Reihe wieder eine anscheinend sehr grosse Gleichmässigkeit. Nach der Methode der kleinsten Quadrate berechnet sich indess (die Tausendstel als Einheit genommen) dic Präcision auf nur 0.0623 , während die combinatorisehe Methode auf Grund einer durchschnittlichen jährlichen Zahl von 5153 Angeklagten eine fast doppelt so grosse Präcision, nämlich 0.1184 ergibt. Selbst wenn man die etwas stärker abweichenden vier letzten Jalire ausschliesst, gelangt man nach der ersten Methode mit Hülfe der Jahresergebnisse von $1854-64$ nur zu der Präcision 0.0712. Die Werthe des Freisprechungsverhältnisses divergiren folglich auch in kürzeren Zeiträumen, in denen wir keinen tief eingreifenden äusseren Einfluss nachweisen können, stärker untereinander, als es bei der Annahme einer constanten „Freisprechungs-Wahrscheinlichkeit" zu erwarten wäre.

Es sei hier noch im Allgemeinen bemerkt, dass die Präcisionsbestimmung aus dem mittleren Fehlerquadrat selbst bei nur zehn oder sogar noch weniger Einzelwerthen eine zweckmässige Charakteristik der thatsächlich vorliegenden Dispersion dieser Werthe bildet, die durch Vergleichung mit der combinatorischen Präcisionsbestimmung ein noch bestimmteres Urtheil gestattet. Dagegen ist 


$$
-90-
$$

der Schluss auf den allgemeinen Charakter der untersuchten Wahrscheinlichkeitsgrössen, d. h. auf die Normalität oder Abnormität ihrer Dispersion überhaupt, bei so geringer Zahl der Einzelwerthe natürlich sehr unsicher.

56. Nach meinen bisherigen Untersuchungen, die freilich noch zu vervollständigen sind, glaube ich nun folgende Sütze aufstellen zu dürfen:

Wirklich typische Reihen, sei es von absoluten oder von Wahrscheinlichkeitsgrössen, sind in den menschlichen Massenerscheinungen verbältnissmässig nur selten nachzuweisen. Die Lebenslänge der Normalgruppe und das Geschlechtsverhältniss der Geborenen bieten gut charakterisirte Beispiele der einen und der anderen Art dar, die freilich beide überwiegend die physische Seite des Menschenlebens betreffen.

Es scheint, dass typische Reihen nur bei solchen Massencrscheinungen auftreten, bei denen entweder in jedem Einzelfalle eine annähernd gleiche Tendenz zur Erreichung eines bestimmten Zieles vorhanden ist, oder in denen in jedem Einzelfalle ein gleichartiger Bedingungscomplex zu Grunde liegt, der so wirkt, als wenn eine gemeinschaftliche, constante, oder nur zufällig um ein Mittel oscillirende Wahrscheinlichkeit für das Vorkommen des Ereignisses massgebend wäre. Von den eigentlich generischen unterscheiden sich diese letztern Massenerscheinungen dadurch, dass wir die gleichartigen Bedingungscomplexe der Einzelfälle nicht weiter aufJösen können.

Sind die Bedingungscomplexe der Einzelfälle selbst sehr verschiedenartig und mannigfaltig, so $\mathrm{kann}$ allerdings dennoch das Totalsystem aller Bedingungen in einem Beharrungszustande ') bleiben, in weichem wieder die Analogie eines Glïcksspiels mit gegebenen Chancen zutrifft.

Dieser Fall liegt aber unzweifelhaft nicht vor, wenn die Einzelwerthe des Verhältnisses nachweislich durch nicht zufällige Einwirkungen beeinflusst sind, oder wenn sich auch nur thatsäcblich eine weiter nicht zu erklärende Periodicität oder eine längere Zeit

1) Beharrungszustand ist, im Gegensatz zu dem bewegungalosen Gleichgewichtgzustande, der dauernd gleichbleibende innere Bewegungszustand eines Systems bei ebenfalls gleichbleibenden ausseren Beziehungen. 
hindurch dauernde Zunahme oder Abnahme der Einzelwerthe bemerklich macht.

Unter diesen letzteren Voraussetzungen aber ist die untersuchte statistische Reihe keine typische, sondern eine symptomatische, und man kann schon jetzt mit Bestimmtheit behaupten, dass die menschlichen Massenerscheinungen ganz überwiegend zu Reihen dieser Art führen. Die Verkettung der menschlichen Dinge wirkt ihrer Natur nach meistens auf Veränderungen in einem bestimmten Sinne hin; der Zustand des vorhergehenden Jahres ist mitbedingend und mitbestimmend fiir den neuen Zustand des folgenden, und daher sind auch die Zahlenverhältnisse, welche die zeitlich aufeinanderfolgenden Zustände einer gewissen Art mehr oder weniger charakterisiren, nicht unabhängig von einander, wie zufällige Modificationen einer festen Wahrscheinlichkeitsgrösse, sondern jedes vorhergehende bildet im Allgemeinen den Ausgang für die Veränderung des folgenden.

Formell freilich kann man jeden Einzelwerth einer symptomatischen Reihe ebenfalls als Näherungswerth einer abstracten Wahrscheinlichkeitsgrösse betrachten; aber da man dann weiter annehmen muss, dass sich die zu Grunde liegende Wahrscheinlichkeit selbst von Jabr zu Jahr oder von irgend einer Zeitmassstrecke zur andern in einer uns unbekannten Weise ändert, so ist mit solcher Einführung des Wahrscheinlichkeitsbegriffes wenig gewonnen. Mögen dann auch die Einzelwerthe streckenweise nur geringe Schwankungen aufweisen, sie fügen sich doch nicht in das Schema der Wahrscheinlichkeitsrechnung, es sei denn, dass auf der ganzen betrachteten Strecke die Annahme einer nur wenig, wenn auch in bestimmter Richtung veränderlichen abstracten Wabrscheinlichkeit des Ereignisses gestattet wäre.

In diesen letzteren Falle wäre die Dispersion der Einzelwerthe eine annähernd normale, aber sie könnte möglicher Weise grösser sein, als sie sich bei stärkerer Veränderlichkeit der abstracten Walirscheinlichkeit in derselben Zeitstrecke vielleicht herausgestellt hätte. Denn gerade durch die Veränderlichkeit der zu Grunde liegenden Wahrscheinlichkeit kann in kleineren Bruchstücken der Reihen eine unternormale Dispersion auftreten; aber solche Erscheinungen sind dann als $Z$ u fälle anzusehen, und sie beweisen noch keineswegs das Vorhandensein von verbundenen concreten Massenerscheinungen, in denen die Einzelwerthe vermöge einer 
inneren Beziehung unter sich in abnorm engen Grenzen gehalten würden. $Z ı$ dieser letzteren Annahme wäre man nur genöthigt, wenn bei einer grösseren Anzahl aufeinanderfolgender Einzelwerthe durch das Kriterium $c$ ) des $\S 20$ mit voller Sicherheit eine unternormale Dispersion nachgewiesen würde. Nach allen bisherigen Erfahrungen aber darf man die Möglichkeit eines solchen Nachweises kühn in Abrede stellen. Die straffste Formel, in welche sich menschliche Massenerscheinungen - und zwar nur wenige Arten derselben - erfahrungsmässig einfïgen lassen, ist die der normalen Dispersion; und in diesem Falle ist die Unabhängigkeit des Einzelereignisses gegenüber den durch eine mathematische Wahrscheinlichkeit ausgedrückten Möglichkeitsbedingungen desselben noch ebenso gross, wie die Unabhängigkeit des einzelnen Wurfes eines Würfels in einer grossen Reihe von Versuchen, in der näherungswcise jede der sechs Nummern gleich häufig herauskommt. Befände sich selbst die Menschheit in einem Beharrungszustande, so würde für alle Seiten dieses Zustandes, die sich durch statistische Zahlenverbältnisse charakterisiren liessen, höchstens jene Formel gelten, und so würde sich noch in befriedigender Weise die Freiheit der Einzelbandlung mit den Existenzbedingungen des Ganzen vereinbaren. Aber Beharrung ist im Leben der Menschheit nur die Ausnahme, die Regel ist Evolution in aufsteigender oder absteigender Richtung; die menschliche Gesellschaft ist fortwährend in Thätigkeit, um aus eigener Kraft und mit eigener Verantwortlichkeit die Grundlagen des Zustandes zu ändern, der übrigens, auch wenn er bestehen bliebe, für das Individuum nicht ein zwingendes Gesetz, sondern nur Bedingungen seines Handelns aufstellen würde. 


\section{An $\mathrm{ang}$.}

Zur Ausführung der theoretischen Berechnungen, wie sie beispielsweise S. 48 vorkommen, genügt schon die folgende abgekürzte Tabelle des im Texte als $F_{*}$ bezeichneten Integrals $\frac{2}{\sqrt{\pi}} \int_{0}^{u} e^{-2} d t$

\begin{tabular}{|c|c|c|c|c|c|}
\hline $\boldsymbol{u}$ & $F_{n}$ & $\boldsymbol{u}$ & $F_{u}$ & $\boldsymbol{u}$ & $F_{u}$ \\
\hline 0.00 & 0.000 & 0.25 & 0.276 & 0.50 & 0.521 \\
\hline 0.01 & 0.011 & 0.26 & 0.287 & 0.51 & 0.529 \\
\hline 0.02 & 0.023 & 0.27 & 0.297 & 0.52 & 0.538 \\
\hline 0.03 & 0.034 & 0.28 & 0.308 & 0.53 & 0.540 \\
\hline 0.04 & 0.045 & 0.29 & 0.318 & 0.54 & 0.555 \\
\hline 0.05 & 0.056 & 0.30 & 0.329 & 0.55 & 0.563 \\
\hline 0.06 & 0.068 & 0.31 & 0.339 & 0,56 & 0.572 \\
\hline 0.07 & 0.079 & 0.32 & 0.349 & 0.57 & 0.580 \\
\hline 0.08 & 0.090 & 0.33 & 0.359 & 0.58 & 0.588 \\
\hline 0.09 & 0.101 & 0.34 & 0.369 & 0.59 & 0.596 \\
\hline 0.10 & 0.112 & 0,35 & 0.374 & 0.60 & 0.604 \\
\hline 0.11 & 0.124 & 0.36 & 0.389 & 0.61 & 0.612 \\
\hline 0.12 & 0.135 & 0.37 & 0.399 & 0,62 & 0.619 \\
\hline 0.13 & 0.146 & 0.38 & 0.409 & 0.63 & 0.627 \\
\hline 0.14 & 0.157 & 0.39 & 0.419 & $0 \cdot 64$ & 0.635 \\
\hline 0.15 & 0.168 & 0.40 & 0.428 & 0.65 & 0.612 \\
\hline 0.16 & 0.179 & 0.41 & 0.438 & 0.66 & 0.649 \\
\hline 0.17 & 0.190 & 0.42 & 0.447 & 0.67 & 0.657 \\
\hline 0.18 & 0.201 & 0.43 & 0.457 & 0.68 & 0.664 \\
\hline 0.19 & 0.212 & 0.44 & 0.466 & 0.69 & 0.671 \\
\hline 0.20 & 0.223 & 0.45 & 0.475 & 0.70 & 0.678 \\
\hline 0.21 & 0.234 & 0.46 & 0.485 & 0.71 & 0.685 \\
\hline 0.22 & 0.244 & 0.47 & 0.494 & 0.72 & 0.691 \\
\hline 0.23 & 0.255 & 0.48 & 0.50 .3 & 0.73 & 0.698 \\
\hline 0.24 & 0.266 & 0.49 & 0.512 & 0.74 & 0.705 \\
\hline
\end{tabular}


$-94-$

\begin{tabular}{|c|c|c|c|c|c|}
\hline$u$ & $F_{n}$ & $\boldsymbol{u}$ & $F_{n}$ & $u$ & $F_{\text {t }}$ \\
\hline 0.75 & 0.711 & 1.10 & (1).880 & 1.45 & 0.960 \\
\hline 0.76 & 0.718 & 1.11 & $0.8 \times 4$ & 1.46 & 0.961 \\
\hline 0.77 & 0.724 & 1.12 & 0.887 & 1.47 & 0.962 \\
\hline 0.78 & 0.730 & 1.13 & 0.890 & 1.48 & 0.964 \\
\hline 0.79 & 0.736 & 1.14 & 0.893 & 1.49 & 0.965 \\
\hline 0.80 & 0.741 & 1.15 & 0.896 & 1.50 & 0.966 \\
\hline 0.81 & 0.748 & 1.16 & 0.899 & 1.51 & 0.967 \\
\hline 0.82 & 0.754 & 1.17 & 0.902 & 1.52 & 0.968 \\
\hline 0.83 & 0.760 & 1.18 & 0.905 & 1.53 & 0.970 \\
\hline 0.84 & 0.765 & 1.19 & 0.908 & 1.54 & 0.971 \\
\hline 0.85 & 0.761 & 1.20 & 0.910 & 1.55 & 0.972 \\
\hline 0.86 & 0.776 & 1.21 & 0.913 & 1.56 & 0.973 \\
\hline 0.87 & 0.781 & 1.22 & 0.916 & 1.57 & 0.974 \\
\hline 0.88 & $0.7 \times 7$ & 1.23 & 0.918 & 1.58 & 0.975 \\
\hline 0.89 & 0.792 & 1.24 & 0.921 & 1.59 & 0.925 \\
\hline 0.90 & ย.ส97 & 1.25 & 0.923 & 1.60 & 0.976 \\
\hline 0.91 & 0.802 & 1.26 & 0.925 & 1.62 & 0.978 \\
\hline 0.92 & 0.807 & 1.27 & 0.928 & 1.64 & 0.980 \\
\hline 0.93 & 0.812 & 1.28 & 0.930 & 1.66 & 0.981 \\
\hline 0.9 .1 & 0.816 & 1.29 & 0.932 & 1.68 & 0.982 \\
\hline 0.95 & 0.821 & 1.30 & 0.934 & 1.70 & 0.984 \\
\hline 0.96 & 0.825 & 1.31 & 0.936 & 1.72 & 0.985 \\
\hline 0.97 & 0.830 & 1.32 & 0.938 & 1,74 & 0.986 \\
\hline 0.98 & 0.834 & 1.33 & 0.940 & 1.76 & 0.987 \\
\hline 0.99 & 0.839 & 1.34 & 0.942 & 1.78 & 0.988 \\
\hline 1.00 & 0.843 & 1.35 & 0.944 & 1.80 & 0.989 \\
\hline 1.01 & 0.847 & 1.36 & 0.946 & 1.82 & 0.990 \\
\hline 1.02 & 0.851 & 1.37 & 0.947 & 1.81 & 0.991 \\
\hline 1.03 & 0.855 & 1.38 & 0.919 & 1.86 & 0.991 \\
\hline 1.0 .8 & 0.859 & 1.39 & 0.951 & 1.88 & 0.992 \\
\hline 1.05 & 0.862 & 1.40 & 0.952 & 1.90 & 0.993 \\
\hline 1.06 & 0.860 & 1.41 & 0.954 & 1,95 & 0.994 \\
\hline 1.07 & 0.870 & 1.42 & 0.955 & 2.00 & 0.995 \\
\hline 1.08 & 0.873 & 1.43 & 0.957 & 2.05 & 0.996 \\
\hline 1.09 & 0,877 & 1.44 & 1.958 & 2.10 & 0.997 \\
\hline
\end{tabular}




\section{Inhalt.}

I. Allgemeinste Eintheilung der Massenerscheinungen - . (Die Statistik als Hulfswissenschaft und als selbständige Wissenschaft S. 1. Generische und concrete Massenerscheinungen S. 4. Naturgesetz und Massenerscheinungen S. 7. Verbundene und unverbundene Massenerscheinungen S. 12.)

II. Die Theorie der Massenerscheinungen und die Wahrscheinlichkeitsrechnung . . . . . . . . (Objective Bedeutung der mathematischen Wahrscheinlichkeit S. 14. Empirischer Nachweis derselben S. 23. Kriterien des Grades der Dispersion S. 28. Symptomatische und typische Reihen S. 33.)

III. Absolute typische Grössen . . . . . . . . . (Dic verschiedenen Mittelwerthe S. 34. Galton's Staffelungsmethod: S. 39. Theorie des Normalalters S. 42. Beweis derselben durch Beispiele S. 46.)

IV. Typische Wahrscheinlichkeitsgrössen . . . . . (Das Gesehlechtsverhältniss der Geborenen als relativ vollkommensteg Beispiel derselben S.64. Hypothetische Erklärung dieser 'Thatsache S. 72. Die Verhältnisse der Zwillingggeburten S. 74. Kindersterblichkeit in Belgien S. 78. Selbstmord durch Ertranken in Frankreich S. 33. Freisprechungen vor den französischen Geschworenengerichten S. 87. Schlussbemerkungen S. 90.)

Anhang 


$$
-1
$$




\section{\$nftem}

\section{ber \\ Bettelbanfpolitif}

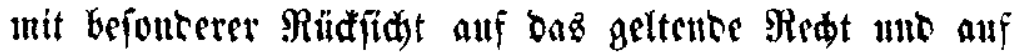
Deutid Berhältniffe.

(Ein Eandbud bez Bettelbanfwejeng.

Bon

\section{Dr. Roolph 10aguer,}

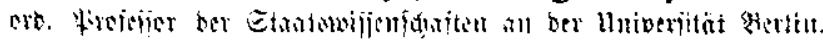

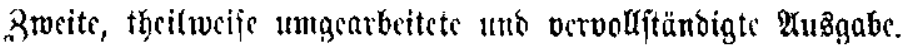

Breis: 16 gxt. 60 f. 
